\begin{tabular}{l|l|l}
$\begin{array}{l}\text { Università } \\
\text { della } \\
\text { Svizzera } \\
\text { italiana }\end{array}$ & $\begin{array}{l}\text { Faculty } \\
\text { of Economics }\end{array}$ & IdEP Economic Papers \\
& & \\
\hline & & $2021 / 02$
\end{tabular}

B. Lerch

From blve to steel-collar jobs: the decline in employment gaps? 


\title{
From Blue to Steel-Collar Jobs: The Decline in Employment Gaps?*
}

\author{
Benjamin Lerch \\ Università della Svizzera italiana
}

July 2021

\begin{abstract}
The adoption of labor-replacing technologies has already displaced thousands of workers in the US. In this paper, I analyze how the adverse effects of the implementation of robots in firms' production processes are spreading among the population and how they are shaping the composition of labor markets. Exploiting exogenous variation in robot exposure across local labor markets and over time, I find that the introduction of industrial robots between the mid-1990s and 2014 contributes to the decline in the gender employment gap but increases the race and ethnicity employment gap. This finding follows from men and racial and ethnic minorities being more exposed to robots because of their over-representation in blue-collar jobs. Despite their predominance in the manufacturing sector, the labor market impacts of robots are not confined to these industries, but spill over also to the service sector.
\end{abstract}

Keywords: industrial robots, employment, gender, race and ethnicity.

JEL Codes: J15, J16, J23.

${ }^{*}$ I am extremely grateful to Giovanni Pica for his guidance in this project. I thank Lorenz Kueng, Fabrizio Mazzonna and the participants of the USI Brown Bag Seminars for valuable feedback. I thank Pascual Restrepo and Yu Zhou for sharing their data. All remaining errors are my own.

Email: benjamin.lerch@usi.ch 


\section{Introduction}

Advances in labor-replacing technologies such as robotics and artificial intelligence are poised to shape the future of labor markets. The implementation of robots in firms' production processes has increased rapidly over the last decades due to astonishing progress in robotics' productivity and the concomitant decline in quality-adjusted prices (Graetz and Michaels, 2018). Economists have recently started to examine their labor market impacts and found that the adoption of industrial robots has reduced aggregate employment in the United States (Acemoglu and Restrepo, 2020) and has displaced thousands of workers from the labor force (Lerch, 2020), fueling the concerns that automation is going to take over the jobs of millions of workers in the years to come (Brynjolfsson and McAfee, 2014, Frey and Osborne, 2017). Despite the growing importance of these technologies, little is known about how their effects are spreading among the population and how they are going to shape the composition of labor markets.

This paper addresses these questions by investigating the impact of robot adoption on employment of different demographic groups in the US between 1993 and 2014. Using data from the Census and the American Community Survey matched with industry-level data about the adoption of industrial robots from the International Federation of Robotics (IFR), I find that the labor market effects of robots are distributed unevenly among the population. The adverse effects of robots mainly affect the employment outlook of men and of racial and ethnic minorities, in particular Black and Hispanic workers. But why are these demographic groups more exposed to the negative effects of robot adoption than women and whites?

To guide the analysis, I build a simple production model with heterogeneous individuals and endogenous job sorting in which workers compete with robots in the execution of various tasks. Firms produce goods combining brawn labor, brain labor and robot capital, where robots are relative substitutes of brawn labor and relative complements to brain labor. The labor force consists of individuals who differ in their gender and race/ethnicity. Individuals are endowed heterogeneously with brawn and brain skills and sort endogenously in jobs according to their comparative skill advantage (Borghans et al., 2014). On one hand, men are better endowed with brawn skills and are, therefore, more likely to be employed in brawn-task intensive occupations, while women tend to 
work in jobs with a more intensive use of communication and interpersonal skills (Ngai and Petrongolo, 2017, Rendall, 2017). On the other hand, racial and ethnic minorities are more likely to include groups of low-skill immigrants with imperfect knowledge of English and therefore posses, on average, lower communication skills than white workers (Antecol et al., 2003, Peri and Sparber, 2009, Llull, 2018). These workers tend to work in brawn-task intensive occupations. The comparative (dis-)advantages in certain skills imply that the gender employment gap and the race and ethnicity employment gap are both positive. As firms accumulate robot capital, they decrease their demand for brawn labor (displacement effect) and increase their demand for brain labor (productivity effect). The impact of robots on aggregate employment is ambiguous, depending on which effect prevails. However, the model predicts that the adoption of robots clearly decreases the gender employment gap, since women benefit more from the productivity effect than men, and increases the race and ethnicity employment gap, since racial and ethnic minorities suffer from a larger displacement effect than whites.

The bulk of the paper investigates these predictions empirically using a local labor market analysis. Using data from the Dictionary of Occupation Titles, I impute task measures associated with the physical intensity (brawn tasks) and the required intellectual ability (brain tasks) of jobs to build occupational segregation measures in the labor market (Ge and Zhou, 2020). In line with the predictions of the model, I find that both employment gaps are positive, although on a declining trend, and that men and racial and ethnic minorities are over-represented in blue-collar occupations with a high workload of brawn tasks, such as precision production, craft, and repair occupations, machine operators, and transportation and moving occupations. These occupations are more likely to be exposed to the adoption of industrial robots, since robots can be programmed to perform autonomously several manual tasks, including material handling, assembling, welding and processing (IFR, 2018). On the other hand, I find that women and whites are employed more often in occupations that require more brain and less brawn skills such as white-collar occupations. ${ }^{1}$ These occupations are usually less susceptible to automation through the adoption of robots. Moreover, workers employed in brain task-intensive occupations may potentially benefit from the implementa-

\footnotetext{
${ }^{1}$ These findings are in line with existing evidence which shows that women are over-represented in white-collar occupations, especially in low- and middle-skill jobs (Blau, 1998, Bacolod and Blum, 2010, Black and Spitz-Oener, 2010, Olivetti and Petrongolo, 2016, Petrongolo and Ronchi, 2020) and Blacks and Hispanics are over-represented in blue-collar jobs at the lower end of the skill distribution (King, 1992, Couch and Daly, 2002).
} 
tion of robots, since new technologies are often complementing labor in non-automatable tasks and they contribute to the creation of new jobs and activities (Autor and Dorn, 2013, Autor, 2015).

To estimate the labor market effects of the adoption of robots, I follow Acemoglu and Restrepo (2020) and build a shift-share measure constructed from the interaction of baseline industry employment shares within local labor markets, proxied by Commuting Zones (Tolbert and Sizer, 1996), with the adoption of industrial robots in the US. Identification builds on the assumption that advances in robotics vary by industry and expose local labor markets differently depending on their industrial composition of employment. The adoption of robots, however, could be fueled by domestic shocks that influence also firms' demand of labor. I account for endogeneity and identify changes in the adoption of robots that are driven by the technological advances in robotics (supply shock) using an instrumental variable strategy. The shift component is instrumented using the simultaneous adoption of robots in Europe and the share component uses plausibly exogenous industry employment shares that precede the introduction of industrial robots.

From the results emerges that the adoption of robots alters significantly the composition of labor markets. I find that robot exposure has reduced local employment both among men and women, but has decreased it relatively more for male workers, contributing to the decline in the gender employment gap. According to my estimates, one additional robot displaces, on average, twice as many male as female workers, where displaced workers are individuals who do not find a job or who lost their job directly or indirectly due to the adoption of robots. ${ }^{2}$ Although a narrowing in the gender employment gap seems to be beneficial for the achievement of gender equality, it is important to consider that this effect is driven by an aggregate employment loss that is relatively larger for men than for women, a result which is far from desirable. Furthermore, I find that robots have increased the race and ethnicity employment gap, curbing its secular decline. This result follows from an employment reduction among racial and ethnic minorities that, accounting for the relative population size of demographic groups, is three times as large as for whites. These effects are particularly pronounced in labor markets with a substantial share of blue-collar jobs, since they

\footnotetext{
${ }^{2}$ The repeated cross-sectional nature of the data does not allow me to disentangle direct from indirect displacement effects of robots, since I am tracing local labor markets rather than the career progression of individual workers. Industrial robots are known to replace blue-collar manufacturing workers by taking over tasks previously performed by labor. As a response, these workers may leave the labor force or move to other non-automated jobs (e.g. low-skill services), displacing also workers who are not directly competing with robots
} 
are more susceptible to the adoption of robots.

Industrial robots are mainly implemented to perform blue-collar work in industries of the manufacturing sector. Their labor market impacts are, however, not confined to these industries, since the reduction in manufacturing employment could contract aggregate demand in the local economy, decreasing also the demand for labor in industries that are not directly affected by the shock (Faber et al., 2019, Acemoglu and Restrepo, 2020, Helm, 2020). I find such an effect in case of the race and ethnicity employment gap, which is driven by increasing employment rate differentials between whites and non-whites in the service sector. This result does not imply that robots do not have an impact on employment in manufacturing industries, but that they are decreasing it without significant differences by race and ethnicity. The differences emerge once the effect spills over to local service-sector industries, where mostly racial and ethnic minority workers are losing their jobs and do not find re-employment opportunities. This finding could suggest that robots are triggering employment effects that go beyond broad composition effects, such as discrimination against racial and ethnic minorities in the service sector, which cannot be explained using observables.

The rest of the paper is organized as follows. Section 2 presents the related literature. Section 3 introduces a model to illustrate the mechanism through which robot capital affects the demand for human skills and the employment gaps. Section 4 describes the data. Section 5 presents the empirical strategy and potential threats to identification. Section 6 reports the results and performs a set of robustness checks. Section 7 concludes.

\section{$2 \quad$ Literature}

This paper mainly contributes to two strands of the literature. First, there is a growing number of studies on the disruptive labor market impacts of technological progress and the demand for human skills. The debate over the influence of the use of new technologies on the occupational structure has long been dominated by the assumption that technological change favors highly skilled occupations (Katz and Murphy, 1992, Goldin and Katz, 2009). However, recent evidence argues that labor markets are instead undergoing an increasing job polarization, suggesting that automation technologies are mostly displacing workers employed in middle-skill jobs, causing a reallocation of 
labor towards high-skill and low-skill occupations that are difficult to automate (Acemoglu, 1999, Goos and Manning, 2007, Goos et al., 2009, Autor and Dorn, 2013). This finding stems from the fact that automation is increasingly taking over jobs with a large routine task content, but it is not yet able to perform jobs that require creative, problem-solving and coordination skills (Autor et al., 2003, Acemoglu and Autor, 2011, Autor and Dorn, 2013). In spite of this observation, the rapid advances in robotics and artificial intelligence (AI) are likely to widen massively the range of tasks that are going to be automated in the near future, including non-routine tasks. Recent evidence finds that AI is currently substituting humans in a subset of tasks, but it is not having detectable aggregate labor market consequences, since the displacement of workers from non-AI occupation is compensated by the creation of AI-related jobs (Acemoglu et al., 2020b). In contrast, the adoption of industrial robots shows substantial negative effects on aggregate employment and wages (Acemoglu and Restrepo, 2020), having already displaced almost half a million workers from the US labor market (Lerch, 2020). This paper focuses on the latter shock and explores how the adverse effects of robots are spreading among the population, a crucial but neglected policy-relevant outcome.

Second, I complement the literature that studies the determinants of labor market inequalities by gender, race and ethnicity. Employment and wage gaps are declining since the implementation of the Civil Right Act in 1964, but are still highly persistent. A vast body of the literature argues that inequalities persist because of discriminatory reasons (see Guryan and Charles (2013) for a review) and labor supply factors (Altonji and Blank, 1999, Marianne, 2011, Blau and Kahn, 2017). However, evidence suggests that also demand-side factors are increasingly important determinants of the existence and development of pay differences and employment gaps (Ngai and Petrongolo, 2017, Petrongolo and Ronchi, 2020). A striking example is the rise of white-collar jobs in the service sector through the diffusion of information and communication technologies (ICT). The transition towards these occupations has favored the employment opportunities of women, reducing substantially the gender employment gap (Weinberg, 2000, Black and Spitz-Oener, 2010, Beaudry and Lewis, 2014, Olivetti and Petrongolo, 2016). This trend, however, is unlikely to hold in the future, since these jobs are also increasingly threatened by the risks of automation (Brussevich et al., 2019, Ge and Zhou, 2020, Chuan and Zhang, 2021). I contribute to this literature by providing evidence on 
the impact of industrial robots, an increasingly important demand-side factor (as outlined in the previous paragraph) on the secular decline in the employment gaps in the US.

To my knowledge, the effect of robots on race and ethnicity gaps has not been subject of study so far. ${ }^{3}$ Conversely, there has been growing interest on the differential labor market impact of robots by gender. Recent work by Ge and Zhou (2020) studies the heterogeneity in the effect of robots on pay differences between men and women in the US. They find that the adoption of robots is decreasing average wages and that the reduction is stronger for men than for women, narrowing the gender wage gap. This trend is fairly different among European countries, where robots have a positive effect on wages of medium- and high-skill jobs in which women are usually under-represented (Aksoy et al., 2021). ${ }^{4}$ These findings are in line with Bacolod and Blum (2010) and Yamaguchi (2018) who argue that the gender gap is strongly influenced by the relative price of the skills in which men and women have a comparative advantage. Despite this insightful result, the heterogeneous impact of robots on the extensive margin of employment of men and women remains unclear. Anelli et al. (2019) address this question without finding significant differences in the effect of robots on employment by gender in the short-term. This result is likely to follow from the fact that labor markets need some time to adjust to the shock. This paper departs from their work as it explores the (existing) long-term impacts of automation on the gender employment gap and, based on the occupational segregation observed in the data, investigates the mechanism through which the adoption of industrial robots affects employment opportunities for men and women, as well as by race and ethnicity.

\section{$3 \quad$ Robots and employment gaps: A task-based model}

This section presents a simple Roy model with heterogeneous workers and endogenous job sorting to exposit the mechanism through which the adoption of robots affects the demand for human skills and the employment gaps, based on the occupational segregation in the labor market (Roy, 1951). The model builds on Autor et al. (2003) and Ge and Zhou (2020), but extends their framework

\footnotetext{
${ }^{3}$ There is suggestive evidence from Cook et al. (2019) and Muro et al. (2019) though, showing that Blacks and Hispanics are employed more often in jobs that are more susceptible to automation in the next decades.

${ }^{4}$ This result is not surprising given that, except for France (Acemoglu et al., 2020a, Bonfiglioli et al., 2020), the adoption of robots in European countries is mainly causing a reallocation of human labor across industries with negligible effects on aggregate employment (Graetz and Michaels, 2018, Dauth et al., 2019, Dottori, 2020).
} 
by allowing workers to choose whether to supply labor or not, a necessary condition to study the effects of automation on the employment gaps.

I consider a production model with two task inputs, manual and non-manual tasks, that are used to produce an output good $Y$ in a competitive labor supply-demand framework in a closed economy. Tasks can be carried out by three factor inputs. Manual tasks $(A)$ can be carried out by brawn labor, $L_{A}$, or they can be automated through the adoption of robot capital, $R$. Non-manual tasks $(B)$ can be carried out only by brain labor, $L_{B}$ (they cannot be automated). The production of goods combines both types of labor and robot capital, measured in efficiency units, using the following technology:

$$
Y_{t}=\left(R_{t}^{\rho}+L_{A, t}^{\rho}\right)^{\frac{\beta}{\rho}} L_{B, t}^{1-\beta}
$$

with $\beta, \rho \in(0,1)$ and $\beta<\rho$. In this simple setting, robot capital is an imperfect substitute of $L_{A}$ and a relative complement to $L_{B}$. The elasticity of substitution between manual and non-manual tasks is equal to 1 , while the elasticity of substitution between robot capital and brawn labor is $\frac{1}{1-\rho}$ and, by assumption, it is greater than 1 . Perfect competition in the economy implies that in equilibrium labor is paid its marginal productivity. The first order conditions of the production function with respect to labor inputs provide the following endogenous labor demand functions:

$$
\begin{gathered}
\omega_{A, t}=\beta\left(R_{t}^{\rho}+L_{A, t}^{\rho}\right)^{\frac{\beta}{\rho}-1} L_{A, t}^{\rho-1} L_{B, t}^{1-\beta} \\
\omega_{B, t}=(1-\beta)\left(R_{t}^{\rho}+L_{A, t}^{\rho}\right)^{\frac{\beta}{\rho}} L_{B, t}^{-\beta}
\end{gathered}
$$

where $\omega_{A}$ and $\omega_{B}$ are the respective labor wages per efficiency unit.

Robots are produced and competitively supplied each period using the following technology $R_{t}=$ $Y_{R, t} \frac{e^{\delta t}}{\theta}$, where $Y_{R, t}$ is the amount of the final output allocated to produce robots and $\theta=e^{\delta}$ is an efficiency parameter, with productivity rising at rate $\delta>0$ due to technological progress (Autor and Dorn, 2013). ${ }^{5}$ In the first period $(t=1)$, one unit of $Y_{R}$ can be used to produce one efficiency unit of $R\left(1=\frac{e^{\delta}}{\theta}\right)$. Competition guarantees that the real price of robot capital (per efficiency unit) is equal to marginal (and average) cost: $p_{t}=\theta e^{-\delta t}$. The price is falling exogenously over time due

\footnotetext{
${ }^{5}$ This assumption implies that robot capital fully depreciates in each period or, in other words, that the flow of services provided by robots is continuously paid its rental price as these services are consumed (Autor and Dorn, 2013).
} 
to technical advances and is the causal force of the model. From here on, I omit time subscripts.

Labor is supplied by a unit continuum of individuals $i \in[0,1]$ who are endowed with skills in both tasks, $\xi_{i}=\left[x_{A, i}, x_{B, i}\right] .{ }^{6}$ Skills are distributed independently and identically over all individuals according to a density function $f\left(x_{A, i}, x_{B, i}\right)$ with support over $x_{j, i} \in\left[\varepsilon_{j}, 1+\varepsilon_{j}\right]$, where $\varepsilon_{j} \geq 0$ and $j=\{A, B\}$. I assume that $\varepsilon_{B}=0 .{ }^{7}$ Price-taking workers are equipped with one unit of labor supply and, given their skill endowment and labor wages, choose the employment allocation that maximizes their income: $\max \left\{\omega_{A} x_{A, i}, \omega_{B} x_{B, i}, \omega_{N}\right\}$. They may supply labor by choosing between $L_{A}, L_{B}$ or any convex combination of the two, or, alternatively, they may choose not to supply any labor and consume one unit of leisure, earning exogenous non-labor income $\omega_{N}$. Hence, workers supply:

$$
\left\{\begin{array}{l}
\text { brawn labor if } x_{A, i}>\frac{\omega_{N}}{\omega_{A}} \text { and } x_{B, i}<\frac{\omega_{A}}{\omega_{B}} x_{A, i} \\
\text { brain labor if } x_{A, i}>\frac{\omega_{N}}{\omega_{A}} \text { and } x_{B, i}>\frac{\omega_{A}}{\omega_{B}} x_{A, i} \text { or if } x_{A, i}<\frac{\omega_{N}}{\omega_{A}} \text { and } x_{B, i}>\frac{\omega_{N}}{\omega_{B}} \\
\text { no labor } \quad \text { if } x_{A, i}<\frac{\omega_{N}}{\omega_{A}} \text { and } x_{B, i}<\frac{\omega_{N}}{\omega_{B}}
\end{array}\right.
$$

The model abstracts from involuntarily unemployment so that labor markets clear. Workers choose brawn labor over non-employment and over brain labor if they are sufficiently skilled in the execution of brawn tasks. Analogously, they supply brain labor if they have enough brain skills and do not supply any labor if they are not sufficiently skilled in either task. The shares of individuals who are employed in brawn and brain labor and those who are not employed are given by:

$$
\begin{gathered}
N_{A}=\int_{\bar{x}_{A}}^{1+\varepsilon_{A}} \int_{0}^{x_{B, i}^{*}} f\left(x_{A, i}, x_{B, i}\right) d x_{B, i} d x_{A, i} \\
N_{B}=\int_{\varepsilon_{A}}^{\bar{x}_{A}} \int_{\bar{x}_{B}}^{1} f\left(x_{A, i}, x_{B, i}\right) d x_{B, i} d x_{A, i}+\int_{\bar{x}_{A}}^{1+\varepsilon_{A}} \int_{x_{B, i}^{*}}^{1} f\left(x_{A, i}, x_{B, i}\right) d x_{B, i} d x_{A, i} \\
N_{N}=\int_{\varepsilon_{A}}^{\bar{x}_{A}} \int_{0}^{\bar{x}_{B}} f\left(x_{A, i}, x_{B, i}\right) d x_{B, i} d x_{A, i}
\end{gathered}
$$

\footnotetext{
${ }^{6}$ It is important to draw a distinction between skills and tasks. Tasks are units of work activity that produce output, while skills are a worker's stock of capabilities for performing tasks in exchange for wages (Autor, 2013).

7 This normalization keeps the model simple without affecting the generality of my results.
} 
where $\bar{x}_{A}=\frac{\omega_{N}}{\omega_{A}}, \bar{x}_{B}=\frac{\omega_{N}}{\omega_{B}}, x_{B, i}^{*}=\frac{\omega_{A}}{\omega_{B}} x_{A, i}$ and $N_{N}=1-N_{A}-N_{B} .{ }^{8}$ Figure 5 illustrates the distribution of individuals in $N_{A}, N_{B}$ and $N_{N}$ graphically in a two-dimensional space in which every point designates the endowment of brawn and brain skills, $\left(x_{A, i}, x_{B, i}\right)$, of an individual $i$. According to the skill thresholds described previously, the yellow area denotes the share of individuals who are employed in brawn labor, the green area denotes the share of individuals employed in brain labor and the blue area denotes the share of individuals who are not employed. Based on the choice of individuals, I quantify aggregate labor supplies by summing over workers' skill endowments in efficiency units:

$$
\begin{gathered}
L_{A}=\int_{\bar{x}_{A}}^{1+\varepsilon_{A}} \int_{0}^{x_{B, i}^{*}} x_{A, i} f\left(x_{A, i}, x_{B, i}\right) d x_{B, i} d x_{A, i} \\
L_{B}=\int_{\varepsilon_{A}}^{\bar{x}_{A}} \int_{\bar{x}_{B}}^{1} x_{B, i} f\left(x_{A, i}, x_{B, i}\right) d x_{B, i} d x_{A, i}+\int_{\bar{x}_{A}}^{1+\varepsilon_{A}} \int_{x_{B, i}^{*}}^{1} x_{B, i} f\left(x_{A, i}, x_{B, i}\right) d x_{B, i} d x_{A, i}
\end{gathered}
$$

In equilibrium, wages adjust such that labor supply (Equations 3.8 and 3.9) equals labor demand (Equations 3.2 and 3.3).

Suppose that there are two types of individuals in equal proportions, let's say men, $M$, and women, $W$, and that men have a comparative advantage in brawn skills. The comparative advantage is given by a shift of the support over the distribution of brawn skills, $x_{A, i} \in\left[\varepsilon_{A}, 1+\varepsilon_{A}\right]$, to the right, i.e. $\varepsilon_{A}^{M}>0$ and $\varepsilon_{A}^{W}=0$ (Pitt et al., 2012, Rendall, 2017).

Proposition 1 The comparative advantage of men in brawn skills implies that they are employed more often in brawn labor, while women opt more often for non-employment. In equilibrium, the employment rate of men is higher than the employment rate of women.

Panel A of Figure 5 shows that this proposition must hold since men have the same support over the distribution of brain skills as women $\left(\varepsilon_{B}=0\right)$, but, on average, they have more brawn skills $\left(\varepsilon_{A}^{M}>\varepsilon_{A}^{W}\right) .{ }^{9}$ Using a gender-specific form of Equation 3.7 and by computing the difference in the

\footnotetext{
${ }^{8}$ To ensure that $N_{A} \geq 0, N_{B} \geq 0$ and $N_{N} \geq 0$, it must hold that $\varepsilon_{A} \leq \bar{x}_{A}$. Moreover, $\omega_{N}$ must be sufficiently small, i.e. $\omega_{N}<\min \left\{\omega_{A}, \omega_{B}\right\}$ is always true, such that not all workers with $\varepsilon_{j}=0$ choose non-employment over labor $\left(L_{A}=0\right.$ or $\left.L_{B}=0\right)$. Finally, starting from $t=1$ the wage per efficiency unit of brain labor has to be larger than the wage of brawn labor, $\omega_{B}=\omega_{A}+\mu$ with $\mu>0$. This assumption ensures a well-defined solution of the model and is based on patterns observed in the data which show that, on average, white-collar labor is paid more than blue-collar labor (see Figure A1).

${ }^{9}$ The claim that fewer men opt for non-employment works with any skill distribution function which assumes that men have a comparative advantage in brawn skills, conditional on men and women having the same skill density between $\left[\varepsilon_{A}, 1\right]$.
} 
employment rates, it is straightforward to show that the gender employment gap is positive:

$$
E G^{(M, W)}=\left(1-N_{N}^{M}\right)-\left(1-N_{N}^{W}\right)=\int_{0}^{\varepsilon_{A}^{M}} \int_{0}^{\bar{x}_{B}} f\left(x_{A, i}, x_{B, i}\right) d x_{B, i} d x_{A, i}>0
$$

where Equation 3.10 denotes the density of the population in the bottom left rectangle (light blue area) of Figure 5. Supposing that skills are distributed uniformly between $\varepsilon_{j}$ and $1+\varepsilon_{j}$, the expression of the gender employment gap would simplify to $\varepsilon_{A}^{M} \bar{x}_{B}$.

Analogously, it is possible to compute the race and ethnicity employment gap by changing the assumption on the skill distribution from a comparative advantage of men in brawn skills because of $\varepsilon_{A}^{M}>0$ to a comparative advantage of racial and ethnic minorities (non-whites, $N W$ ) in brawn skills because of $\varepsilon_{B}^{N W}<0$ (see Figure A2). This assumption follows from the fact that racial and ethnic minorities are more likely to include low-skill immigrants with imperfect knowledge of English and therefore possess, on average, lower communication skills than white workers (Antecol et al., 2003, Peri and Sparber, 2009, Llull, 2018). That is, whites have a comparative advantage in the skills required to perform brain labor, while racial and ethnic minorities have a comparative advantage in brawn skills.

Proposition 2 The comparative advantage of whites in brain skills implies that they are employed more often in brain labor, while racial and ethnic minorities opt more often for non-employment. In equilibrium, the employment rate of whites is higher than the employment rate of racial and ethnic minorities.

The proof of this proposition is provided in Appendix A1. Next, I show that an increase in robot capital has employment effects which differ by gender, and analogously by race and ethnicity.

As outlined previously, the driving force of the model is an exogenous decrease in the price of robot capital over time. As robots become cheaper, firms demand less brawn labor, which is reflected in a decrease in brawn wages, $\omega_{A}$. Panel $\mathrm{B}$ of Figure 5 shows that the decrease in brawn wages makes brain labor and non-labor income relatively more attractive to workers, who respond by moving away from brawn task-intensive jobs. This is often referred to as 'displacement effect'. As a consequence, workers with sufficiently high brain skills move to brain labor, while less skilled workers leave the labor force. Moreover, the inflow of robot capital more than offsets the decrease 
in brawn labor, yielding a net increase in the intensity of the manual task input in firms' production (it becomes cheaper to produce with capital) which boosts the productivity of brain labor and, therefore, raises brain wages, $\omega_{B}$. This, in turn, induces even more workers to reallocate their labor supply from brawn labor towards brain labor and also some previously non-employed individuals to join the labor force and supply brain labor. I refer to this effect as 'productivity effect'. The overall effect of robots on aggregate employment is ambiguous and depends on the relative size of the displacement and the productivity effect (see Appendix A1). Which of the two effects dominates is an empirical question, and crucially depends on the elasticity of substitution between capital and labor (see Figures A3, A4 and A5). Nevertheless, the adoption of robots alters significantly the composition of labor markets, with the employment effects differing by gender and by race and ethnicity.

Proposition 3 The comparative advantage of men in brawn skills implies that the adoption of robot capital reduces the gender employment gap.

This proposition follows from the fact that women benefit more from the productivity effect than men because of their comparative advantage in brain skills. This claim is also visible in Panel B of Figure 5 which shows that the productivity effect is larger for women than for men, decreasing employment rate differentials by gender. Furthermore, the figure shows that robots cause a sharp decline in the employment gap in brawn labor, since men are leaving these jobs more often than women. The partial derivative of Equation 3.10 with respect to the price of robots yields:

$$
\frac{\partial E G^{(M, W)}}{\partial p}=-\int_{0}^{\varepsilon_{A}^{M}} f\left(x_{A, i}, \bar{x}_{B}\right) \frac{\bar{x}_{B}}{\omega_{B}} \frac{\partial \omega_{B}}{\partial p} d x_{A, i}>0
$$

This result holds also when I relax the assumption that $\beta<\rho$, allowing robot capital to be a relative complement of brawn labor (see Equation A1.17), and follows from one of three different scenarios. First, robots reduce male employment more than female employment. Second, robots increase male employment less than female employment. Third, robots reduce male employment and increase female employment. I investigate which scenario occurs in the empirical analysis.

Analogously, it is possible to compute the effect of robots on changes in the race and ethnicity employment gap (see Panel B of Figure A2). 
Proposition 4 The comparative advantage of whites in brain skills implies that the adoption of robot capital increases the race and ethnicity employment gap.

This proposition follows from racial and ethnic minorities suffering from a larger displacement effect than whites. Again, I provide the proof in Appendix A1. In the remaining part of the paper, I test Propositions 1 to 4 empirically in the US labor market. The setting of the empirical strategy is described in the next sections.

\section{$4 \quad$ Data}

This section describes the main data sources along with a set of summary statistics.

\subsection{Industrial robots}

I obtain data about the adoption of robots from the International Federation of Robotics (IFR). The IFR is a survey that collects data on the shipment and operational stock of industrial robots by country, industry and year ranging back to 1993 for 50 countries. ${ }^{10}$ Industrial robots are machines that can be programmed to autonomously perform several manual tasks (e.g. assembly, material handling, packing and welding) without the intervention of a human worker. ${ }^{11}$ The IFR breaks down the stock of operational robots according to the International Standard Industrial Classification (ISIC) Rev. 2-4 and provides consistent data for six broad industries outside the manufacturing sector and 13 industries within the manufacturing sector.

These data are praised for their reliability, but they include also some limitations that I briefly address in the following. First, a fraction of the stock of industrial robots is not attributed to any industry and is referred to as 'unclassified'. I attribute unclassified robots proportionally to an industry's share of total classified robots for each year (Graetz and Michaels, 2018). Second, up to 2011, the IFR provides data on the operational stock of robots only for North America as a whole, which includes the United States, Canada and Mexico. This aggregation introduces noise,

\footnotetext{
${ }_{10}$ The operational stock is calculated as the sum of robot installations in the previous 12 years.

11 The IFR defines industrial robots as 'automatically controlled, reprogrammable, multipurpose manipulator(s), programmable in three or more axes, which can be either fixed in place or mobile for use in industrial automation applications' (IFR, 2018, p.29). They do not include conveyor belts, cranes or elevators, since these machines do not meet the above requirements.
} 
but is not a major concern for the identification of US robot adoption, since the Unites States account for more than 90 percent of the North American market and the instrumental variable (IV) strategy presented in Section 5 purges this type of measurement error (Acemoglu and Restrepo, 2020). Third, the stock of robots by industry going back to the 1990s is only available for a subset of European countries: Denmark, Finland, France, Germany, Italy, Norway, Spain, Sweden, and the United Kingdom. The IFR provides data on the total stock of robots in North America from 1993, but it does not provide industry breakdowns until 2004. For these years, I attribute the aggregate number of robots to industries proportionally to their shares of the total stock in $2004 .^{12}$

Between the mid-1990s and 2014, the stock of robots in the US has increased by about 1.5 robots per thousand workers (a fivefold or roughly 180'000 units compared to its 1993 level, see Figure 1) and, according to the International Federation of Robotics, it is expected to grow even more in the future (IFR, 2018, pp.535-540). Following Acemoglu and Restrepo (2020), I use these data to build a measure of robot adoption at the industry level:

$$
\Delta M_{j,\left(t_{0}, t_{1}\right)}^{U S}=\frac{R_{j, t_{1}}^{U S}-R_{j, t_{0}}^{U S}}{L_{j, 1990}^{U S}}-g_{j,\left(t_{0}, t_{1}\right)}^{U S} \frac{R_{j, t_{0}}^{U S}}{L_{j, 1990}^{U S}}
$$

where $R_{j, t}^{U S}$ is the US stock of robots in industry $j$ at time $t$ and $L_{j, 1990}^{U S}$ is the industry employment level in 1990. The second term adjusts the measure of robot adoption for industry growth, where $g_{j,\left(t_{0}, t_{1}\right)}^{U S}=\Delta \ln \left(Y_{j, t}^{U S}\right)$ is the growth rate of output in industry $j$ between $t_{0}$ and $t_{1}$. I obtain data on employment and output at the industry level from the Integrated Industry-Level Production Account (KLEMS) of the Bureau of Economic Affairs (BEA). ${ }^{13}$

Table 1 reports summary statistics of Equation 4.1 for the US and Europe. The statistics show that robots are mainly adopted in a subset of industries of the manufacturing sector, including the automotive, basic metals, electronics, food and beverages, metal products, and the plastics and chemicals industry. These industries are concentrated in US states of the Rust Belt, as illustrated in Figure 2. In the following, I refer to them as 'high robot-intensive manufacturing' industries. I refer to the remaining industries of the manufacturing sector as 'low robot-intensive manufacturing'

\footnotetext{
${ }^{12}$ I use the same procedure to impute the stock of robots for Denmark, for which the industry breakdown starts in 1996.

${ }^{13}$ I use comparable data for several European countries from the EU KLEMS database (Jägger, 2017) to construct the instrument of my IV strategy (see Section 5).
} 
industries and to industries outside of the manufacturing sector as 'non-manufacturing' industries.

\subsection{Employment gaps}

I obtain data on employment and relevant demographic characteristics from the decennial Census samples for 1970, 1980, 1990 and 2000, and the American Community Survey (ACS) for the years 2007 and 2014. ${ }^{14}$ Both datasets are publicly provided by the Integrated Public Use Microdata Series (IPUMS) and are repeated cross-sectional surveys that include between 1 and 5 percent of the US population (Ruggles et al., 2019). They provide a rich set of information on each sampled individual, such as sex, race, ethnicity, age, education, employment, industry, occupation, and the county group of residence. I restrict my sample to the non-institutionalized civilian population between 25 and 64 years of age and aggregate the counts to 722 Commuting Zones (CZs) that cover all metropolitan and rural areas of the US mainland and act as proxies of US local labor markers (Tolbert and Sizer, 1996). ${ }^{15,16}$

I use these data to compute measures of the employment gaps by race and ethnicity and by gender at the local labor market level:

$$
E G_{c, t}^{(M, W)}=E_{c, t}^{M}-E_{c, t}^{W}
$$

where $E_{c, t}^{g}$ is the employment rate (employment count divided by the working-age population) of demographic group $g \in\{M, W\}$ in $\mathrm{CZ} c$ at time $t$. In case of the gender employment gap, $M$ and $W$ represent men and women, while they represent whites and non-whites (or racial and ethnic minorities) for the race and ethnicity employment gap. Racial and ethnic minorities include Blacks, Hispanics, Asians, American Indian, Alaska natives and other, not elsewhere classified, races. ${ }^{17}$

Table 2 reports summary statistics on employment by demographic characteristics in 1990 and its changes between 1990 and 2014. In line with Propositions 1 and 2, I find that the employment gaps

\footnotetext{
${ }^{14} \mathrm{I}$ follow the literature and increase the sample size of the ACS samples using data from the 3-year sample of 2006-2008 and the 5-year sample of 2012-2016.

${ }^{15} \mathrm{CZs}$ represent economically relevant regions for labor markets and are formed by clusters of counties with strong commuting ties within CZs and weak commuting ties across CZs (Autor and Dorn, 2013).

16 The IPUMS provide county groups or Public Use Microdata Areas as lowest geographic units. I follow Autor and Dorn (2013) and aggregate data at the CZ level using a crosswalk that provides a probabilistic matching of sub-state geographic units in US Census Public Use Files to CZs from David Dorn.

${ }^{17}$ Figure A6 shows that the distribution of these minorities is heterogeneous across CZs, with the largest concentration in states of the Sun Belt (Arizona, Florida, New Mexico, Mississippi, South Carolina, Texas).
} 
are positive -7.89 percentage points by race and ethnicity and 18.3 percentage points by gender. Interestingly, both gaps are on a declining trend with the average decline in the race and ethnicity employment gap being smaller and the average decline in the gender employment gap being larger in CZs that are more exposed to the adoption of robots. ${ }^{18}$

Figure A7 in the Appendix provides further information on the distribution of the employment gaps across US local labor markets. Specifically, the race and ethnicity gap is largest in states of the northern part of the Wheat Belt (Minnesota, North Dakota and South Dakota), while the gender gap is particularly large in Texas and in CZs of the northern part of the Jell-O Belt (especially in Idaho and Utah).

\subsection{Brawn and brain tasks}

Besides the existence of employment gaps, Propositions 1 and 2 predict that US labor markets are characterized by a persistent occupational segregation that exposes workers heterogeneously to the adoption of robots. I analyze the relative exposure of workers to robots by imputing task measures associated with their occupations according to the brawn and brain task intensity of labor.

Following Autor et al. (2003) and Ge and Zhou (2020), I measure the task intensity of labor using information on the skill requirements of jobs at detailed occupation level from the Dictionary of Occupational Titles (DOT) (US Department of Labor, 1977). Although occupations combine elements from each task category and task intensity varies among occupations within these broad groups, they capture the central tendencies of the data (Acemoglu and Autor, 2011). Brawn task-intensive occupations are jobs with a large workload of manual tasks. In the DOT, they include eye, hand and foot coordination (EYEHAND); motor coordination (MOTOR); finger and manual dexterity (FINGDEX and MANDEX); and physical strength (STRENGTH). Conversely, brain task-intensive jobs need less physical skills, but require the following temperaments: quantitative reasoning, language, and verbal and numerical aptitude (GEDs); direction, control and planning for activity (DCP); interpreting feeling, ideas, facts in terms of personal viewpoint (FIF); influencing people in their opinions, attitudes or judgment about ideas or things (INFLU); making generalizations, evaluations, or decisions based on sensory or judgmental criteria (SJC); making generalization, judgments, or

\footnotetext{
${ }_{18}$ The values of Columns 4 and 6 in Panel B are statistically different at the 1 percent level.
} 
decisions based on measurable or verifiable criteria (MVC); and dealing with people beyond giving and receiving instructions (DEPL).

Brawn and brain task measures are computed from the averages of the relevant DOT variables and are standardized using the percentile values of their ranks in the 1970 employment distribution, a decade before the introduction of industrial robots in the US (Ge and Zhou, 2020). I match these measures with 315 occupations from the 1990 Census and, using a double median split, I construct four broad occupation groups. The first group includes occupations that are both brawn and brain task intensive (e.g. mechanical engineers). I refer to them as 'skill-intensive' occupations. The second group includes 'white-collar' occupations that are intensive in brain tasks, but require only few brawn skills (e.g. secretaries and teachers). The third group includes 'blue-collar' occupations that are intensive in brawn tasks and need only few brain skills (e.g. material movers and operators). Finally, I refer to occupations that do not require particular brawn or brain skills as 'low-skill' occupations (e.g. household cleaners and servants).

The breakdown of workers in brawn and brain task-intensive jobs by race and ethnicity and by gender is illustrated in Figure 3. I find that workers from racial and ethnic minorities are employed more often in blue-collar occupations and that women are employed more often in white-collar occupations. Moreover, non-white and female workers are also over-represented in jobs that do not require particular brawn or brain skills. A list of occupations with the highest and lowest shares of non-white and female workers by task specialization is illustrated in Table A2.

Figure 4 further shows that robots are mostly employed in industries with a larger brawn task content, while they are adopted least in brain task-intensive industries. This empirical evidence suggests that robot capital is more substitutable for brawn skills than for brain skills and, therefore, that male and non-white workers are more likely to be exposed to the adverse effects of robots than women and whites. ${ }^{19}$

${ }^{19}$ The assumption that $\rho$ in the production of good $Y$ is sufficiently high is justified, i.e. robot capital $R$ is a relative substitute of $L_{A}$ (see Equation 3.1). 


\section{$5 \quad$ Empirical strategy}

This section presents the empirical strategy and the construction of a measure of robot exposure. I estimate the labor market impact of robots on the employment gaps in first differences over three time periods (1993-2000, 2000-07, 2007-14). ${ }^{20}$ The key estimating equation is given by:

$$
\Delta \mathrm{EG}_{c,\left(t_{0}, t_{1}\right)}^{(M, W)}=\beta^{(M, W)} \mathrm{US} \text { robot exposure }{ }_{c,\left(t_{0}, t_{1}\right)}+\mathbf{X}_{c,\left(t_{0}, t_{1}\right)}^{\prime} \boldsymbol{\Gamma}^{(M, W)}+\varepsilon_{c,\left(t_{0}, t_{1}\right)}^{(M, W)}
$$

where $\Delta \mathrm{EG}_{c,\left(t_{0}, t_{1}\right)}^{(M, W)}$ is the change in the employment gap among working-age individuals in CZ $c$ between year $t_{0}$ and $t_{1}$.

Following Acemoglu and Restrepo (2020), I measure a local labor market's exposure to industrial robots using a shift-share approach:

$$
\text { US robot exposure }{ }_{c,\left(t_{0}, t_{1}\right)}=\sum_{j \in J} \ell_{c, j}^{1990} \Delta M_{j,\left(t_{0}, t_{1}\right)}^{U S}
$$

where $\Delta M_{j,\left(t_{0}, t_{1}\right)}^{U S}$ is a measure of the growth of robot capital between year $t_{0}$ and $t_{1}$ at the industry level (see Equation 4.1) which is apportioned across local labor markets using CZs' industry employment shares, $\ell_{c, j}^{1990}=\frac{L_{c, j}^{1990}}{L_{c}^{1990}}$. The baseline employment shares are kept constant to avoid endogeneity and serial correlation across periods of my stacked first-difference specification.

Identification builds on the assumption that advances in robotics vary by industry and expose local labor markets differently depending on the industrial composition of employment. However, US firms could adopt robots in response to domestic shocks which influence also the demand for labor. For instance, positive demand shocks might induce US firms to raise both capital and employment, biasing the estimates of the effect of robots upwards. To address the endogeneity concern and identify robot adoption that is driven by the supply shock, I apply an IV strategy and instrument the shift component of Equation 5.2 using contemporaneous changes in the stock of robots in seven

\footnotetext{
${ }^{20}$ Note that in the 1990s the IPUMS includes only data from the 1990 Census. For comparability across periods, I rescale the 1990-2000 period to a 7-year equivalent change.
} 
European countries with a comparable adoption of robots as the US:

$$
\text { EU7 robot exposure } e_{c,\left(t_{0}, t_{1}\right)}=\sum_{j \in J} \frac{1}{7} \sum_{i \in E U 7} \ell_{c, j}^{1970} \Delta M_{j,\left(t_{0}, t_{1}\right)}^{i}
$$

where $\Delta M_{j,\left(t_{0}, t_{1}\right)}^{i}$ measures the growth of robot capital at the industry level in country $i \in E U 7$. EU7 countries include Denmark, Finland, France, Italy, Spain, Sweden and the United Kingdom. Furthermore, I instrument the share component with plausibly exogenous employment shares (Goldsmith-Pinkham et al., 2020). I use industry employment shares from 1970 to focus on the industrial composition of employment that precedes the introduction of industrial robots, which started in the 1980s (Acemoglu and Restrepo, 2020).

The IV strategy aims at identifying the labor market effects of exogenous improvements in robotics available to US firms. It relies on the assumptions that the adoption of robots in European countries is positively related to the adoption of robots in the US, but it is unrelated to domestic labor market conditions. The first condition can be easily verified (see Figure A8 and Table A3 for firststage estimates). However, the exclusion restriction may not be necessarily fulfilled, since the rapid adoption of robots in Europe could have made European firms more competitive than their US peers, unveiling a possible causal link with US labor market conditions via product market competition. Although I cannot fully rule out this possibility, I address this potential threat to identification through the construction of the instrument and a set of robustness checks. First, the instrument purposely does not include the countries with the heaviest adoption of industrial robots, namely South Korea, Germany, and Japan. These countries are also among the main trading partners of the US and could directly impact US employment through the national adoption of robots. Second, I construct an instrument which includes only countries that are least engaged in trade with the US and whose adoption of robots is unlikely to affect US employment. Third, I account for international competition in the product market between the US and Europe by including a shift-share measure of US import exposure à la Autor et al. (2013) from the seven European countries that are included in the instrument. In Section 6.3, I show that my results are unlikely to be driven by an increase in product market competition through the heavier utilization of robots in Europe.

Returning to Equation 5.1, it is important to note that the effect of robot adoption on the employ- 
ment gaps may be consistent with different employment paths. As has been mentioned in Section 3 , in case of a reduction of the (positive) gender employment gap, robots could be reducing male employment more than female employment, they could be increasing male employment less than female employment or they could be reducing male employment and be increasing female employment. I investigate which scenario occurs by estimating the effect of robots on demographic-specific employment rates:

$$
\Delta \mathrm{E}_{c,\left(t_{0}, t_{1}\right)}^{g}=\beta^{g} \mathrm{US} \text { robot exposure } c_{c,\left(t_{0}, t_{1}\right)}+\mathbf{X}_{c,\left(t_{0}, t_{1}\right)}^{\prime} \Gamma^{g}+\varepsilon_{c,\left(t_{0}, t_{1}\right)}^{g}
$$

where $\Delta \mathrm{E}_{c,\left(t_{0}, t_{1}\right)}^{g}$ is the change in the employment rate among working-age individuals of demographic group $g \in\{M, W\}$ in $\mathrm{CZ} c$ between year $t_{0}$ and $t_{1}$. The measure of robot exposure is the same as in Equation 5.1, with $\beta^{g}$ being the effect of robots on the employment rate of group $g$. Let's consider again the case in which robots reduce the (positive) employment gap between $M$ and $W$, that is $\beta^{(M, W)}=\beta^{M}-\beta^{W}<0 .{ }^{21}$ Estimating $\beta^{M}$ and $\beta^{W}$ individually allows me to identify which of the above mentioned employment paths occurs.

The estimating equations include also a vector of time-invariant regional characteristics and economic variables, $\mathbf{X}^{\prime}$, to control for factors that could confound the estimated effect of robots on labor market outcomes. These variables include a measure of Chinese import competition (Autor et al., 2013) and Bartik-style measures of personal computer adoption and IT capital intensity. Furthermore, they include information on the demographic characteristics of labor markets, the industrial and occupational composition of employment, and the local composition of industries and occupations by gender, race and ethnicity. Details about the construction of the variables are provided in Appendix A2. Finally, I control for state fixed effects and year dummies interacted with nine census-division fixed effects to account for division-specific business cycles. ${ }^{22}$

\footnotetext{
${ }^{21}$ Equality $\beta^{(M, W)}=\beta^{M}-\beta^{W}$ follows from the fact that $\Delta \mathrm{EG}_{c,\left(t_{0}, t_{1}\right)}^{(M, W)}=\Delta \mathrm{E}_{c,\left(t_{0}, t_{1}\right)}^{M}-\Delta \mathrm{E}_{c,\left(t_{0}, t_{1}\right)}^{W}$ such that the three scenarios can be written as (i) $\beta^{M}<\beta^{W}<0$, (ii) $0<\beta^{M}<\beta^{W}$ and (iii) $\beta^{M}<0<\beta^{W}$.

${ }^{22}$ Census divisions are administrative divisions of the US territory in nine broad groups of states: New England, Middle Atlantic, South Atlantic, East North Central, East South Central, West North Central, West South Central, Mountain and Pacific.
} 


\section{$6 \quad$ Empirical results}

This section presents the empirical results on the labor market effect of robots on the employment gaps and explores the influence of industries, occupations and other socio-demographic characteristics in the determination of the effects.

\subsection{Robots and employment gaps}

I start by estimating the labor market effect of robots on the race and ethnicity and the gender employment gap using Equation 5.1. The IV estimates are reported in Table 3. The coefficients are standardized and represent the estimated effect of a one standard deviation increase in US robot exposure on the change in the respective employment gap in percentage points. Regressions are weighted by the CZ population in 1990 and standard errors allow for arbitrary clustering at the state level. ${ }^{23}$ Importantly, the results include only partial equilibrium effects of robot adoption and do not account for aggregate effects resulting from cross-CZ spillovers that could influence the gender-specific demand for labor in other areas. ${ }^{24}$

Column 1 reports the estimates of a parsimonious specification that includes only state fixed effects and division-specific time fixed effects. The estimates show that robots have a positive effect on the race and ethnicity employment gap and a negative effect on the gender employment gap, i.e. the adoption of robots decreases the relative employment rate of racial and ethnic minorities (in particular for Black and Hispanic workers, see Table A4) and increases the relative employment rate of women. Since both employment gaps are positive during my sample period, these results suggest that robots are widening the race and ethnicity employment gap and that they are narrowing the gender employment gap. However, these estimates have to be interpreted carefully, since they could be capturing the effect of omitted variables. I include additional controls in the following columns

\footnotetext{
${ }^{23}$ As outlined in Cadena and Kovak (2016), when examining outcomes across labor markets of different sizes, efficient weights must consider individuals' sampling weights to account for inherent heteroskedasticity. They also show that optimal weights are strongly correlated with initial population sizes of the unit of reference. At this point, it is important to note that there are two sources of heteroskedasticity in the distribution of the population of different demographic groups. First, CZs strongly differ in their population size. Second, CZs differ in the shares of racial and ethnic minorities in the local population (see Figure A6). I examine the role of weights in Section 6.3.

${ }^{24}$ A parametric model to quantify the general equilibrium effects of robots on employment is presented in Acemoglu and Restrepo (2020), although is does not allow to differentiate for gender-specific cross-CZ effects.
} 
to account for potential confounders.

Column 2 includes changes in the employment gaps between 1970 and 1990 to account for pretrends that could have influenced both labor market outcomes and the adoption of robots from the 1990s. Column 3 includes also a set of variables that control for other (non-robot) technologies which could have influenced labor market outcomes simultaneously to the introduction of industrial robots. Column 4 controls for the China trade shock, which has been shown to have significant effects on US local labor market outcomes in recent decades (Autor et al., 2013, Acemoglu et al., 2016). ${ }^{25}$ Column 5 adds a set of covariates that account for systematic differences in demographic characteristics and the employment composition of CZs. Finally, Column 6 includes a set of covariates that control for the initial composition of employment within occupations and industries by gender, race and ethnicity.

The inclusion of these covariates does not alter my estimates of the labor market effect of robots on the employment gaps, which remain economically and statistically significant at conventional levels. I find that a one standard deviation increase in the adoption of robots decreases the gender employment gap by 0.619 percentage points and increases the race and ethnicity employment gap by 0.817 percentage points. This finding suggests that one additional robot per thousand workers reduces the local gender employment gap by 1.3 percentage points, contributing to its secular decline, but increases the race and ethnicity employment gap by 1.7 percentage points. ${ }^{26,27}$

To uncover the employment path that is driving these results, I estimate the labor market effect of robots on demographic-specific employment rates using Equation 5.4. Figure 6 illustrates the results using my preferred specification. I find that robots decrease employment across all demo-

${ }^{25}$ Although the China trade shock had a deep impact on US manufacturing employment, Table A5 in the Appendix shows that it did not significantly affect the employment gaps. The result on the gender employment gap is in line with Autor et al. (2013), who show that the shock has a similar impact on male and female employment (in percentage points of the population of reference).

${ }^{26}$ In robot units, each additional robots per thousand workers reduces the gender employment gap by 1.261 percentage points $(0.619 / 0.491$ where the denominator is the standard deviation of US robot exposure, see Table A6). I compute the magnitude of the race and ethnicity employment gap analogously.

${ }^{27}$ Note that employment estimates are larger than those reported in Acemoglu and Restrepo (2020), since they are not exploiting variation within states, but only within broad census divisions. However, as demographic-specific labor market outcomes are highly heterogeneous across US states, it is important account for systematic differences across them. As a comparison, Table A7 reports estimates of the effect of robots on employment rates and employment gaps, controlling only for time-varying division fixed effects. Compared to the estimates of Figure 6 below, the results show that the relative effects by gender and race and ethnicity are unaffected by the exclusion of these controls, despite the differences in the absolute size. 
graphic groups, but reduce it more for racial and ethnic minorities and for men. According to my estimates, the introduction of robots has displaced twice as many male workers as female workers and, accounting for the relative population size of demographic groups, almost three times as many non-white workers as white workers. These findings are consistent with the notion that men and racial and ethnic minorities are employed more often in blue-collar jobs that are more susceptible to automation through the adoption of robots, leading to a decrease in the gender employment gap but to an increase in the race and ethnicity employment gap. ${ }^{28}$ In line with this prediction, I find that CZs that are more intensive in blue-collar work in 1970, a proxy for a labor market's specialization in brawn-task intensive jobs before the introduction of industrial robots, are using more robots (see Figure A9) and experience larger changes in the employment gaps because of their adoption (see Figure A10). ${ }^{29}$

Finally, I analyze the impact of robots on the employment gaps in more detail by breaking down employment by additional demographic characteristics. The results are reported in Table 4. I find that the labor market effects of robots are almost entirely driven by workers with less than a college degree. This finding follows from the fact that these individuals are more likely to be employed in blue-collar jobs (see Figure A11). However, it does not imply that the employment of collegeeducated workers has not been influenced by the adoption of robots (the effect is smaller though, see Figure A12), but that it has not been influenced differently by race and ethnicity and by gender. The effect of robots on the race and ethnicity employment gap is relatively stable and persistent across prime-age workers, with a peak between 45 and 54 years, but it is not significantly different between men and women and it does not depend on whether individuals are natives or immigrants (see Table A8). The effect on the gender employment gap is largest among young workers (25 and 34 years) and halves in size from 35 years. Also in this case, I find no significant difference in the effect of robots on the gender employment gap by race and ethnicity.

28 Table A9 further shows that robots affect labor force participation gaps in the same direction as they do with the employment gaps, suggesting that a significant share of displaced workers is leaving the labor force (Lerch, 2020).

${ }^{29}$ Using the notation of the model in Section 3, a firm's production intensity in manual tasks is increasing in $\beta$. In line with the empirical results, Figure A5 shows that an increase in robot capital has a stronger effect on the gender employment gap for large values of $\beta$. 


\subsection{Employment gaps by industry and occupation}

From the model in Section 3, we know that robots are not only decreasing the overall gender employment gap, but that they are also reducing the gender employment gap among brawn taskintensive occupations. Analogously, they are increasing the race and ethnicity employment gap in these occupations. To test these predictions empirically, I break down employment by the task content of occupations (skill-intensive, white-collar, blue-collar and low-skill jobs, see Section 4 for details) and estimate Equation 5.1 within each occupation group. I repeat this exercise by industry group (high robot-intensive manufacturing, low robot-intensive manufacturing and nonmanufacturing industries) to analyze the effect of robots on the employment gaps also from an industrial perspective. The results are presented in Table 5.

I find that industrial robots are indeed narrowing the gender employment gap among brawn taskintensive jobs, in particular in blue-collar occupations. This effect is almost entirely driven by the set of industries of the manufacturing sector with the heaviest adoption of robots. In these industries, robots are displacing more male than female workers by taking over the tasks they used to perform. However, the effect of robots is not confined to the manufacturing sector and affects also employment in non-manufacturing industries. Although this effect might seem surprising at first, it has to be considered that the employment reduction in the manufacturing sector could contract aggregate demand in the local economy, decreasing also the demand for labor in industries that are not directly affected by the shock (Faber et al., 2019, Acemoglu and Restrepo, 2020, Helm, 2020). This finding is visible in case of the race and ethnicity employment gap, which is driven by increasing employment rate differentials in blue-collar jobs of non-manufacturing industries, especially in the service sector. ${ }^{30}$ This result does not imply that robots are not decreasing manufacturing employment, but that they are decreasing it without significant differences by race and ethnicity (see Figure A13). The differences emerge once the effect spills over to local service-sector industries, where mostly non-white workers are losing their jobs (0.9 percentage points). ${ }^{31}$ This effect appears

\footnotetext{
30 Table A10 breaks down the effect of robots from Column 7 in Table 5 and reports estimates of the effect of robots on the race and ethnicity employment gap within non-manufacturing industries (agriculture, construction, education and research, mining, services, and utilities). From the results emerges that the increase in employment rate differentials in non-manufacturing industries is driven by the service sector.

31 Table A11 shows that the labor market effect of robots on the race and ethnicity employment gap is indeed mostly caused by the adoption of robots in manufacturing industries.
} 
strong at first glance. However, it has to be considered that these results are expressed in percentage points of the population of reference. While the proportional loss of jobs among non-whites is large, the magnitude of the loss in absolute terms is similar across racial and ethnic groups. This result follows from the fact that the population of reference of non-whites is much smaller than the population of whites. $^{32}$

These results show that robots are shifting the employment gaps towards zero among blue-collar occupations and, in case of the gender employment gap, among highly exposed manufacturing industries (see Table A13). However, the adoption of robots is also widening the (already positive) race and ethnicity employment gap in the service sector, with mostly non-white workers losing their job and not finding re-employment opportunities because of robots. This result could follow from labor market effects of robots that go beyond broad composition effects and which cannot be explained using observables. For example, the spillover effect of robots on the employment of racial and ethnic minorities in the service sector could be fueled by non-observable factors such as discrimination against Black and Hispanic workers in these industries, an interesting question that should be addressed by future research.

\subsection{Robustness checks}

This section performs a set of robustness checks in support of the identification strategy and of my preferred specification. It shows that my results are not driven by an increase in product market competition from Europe, pre-existing trends or the construction of the measure of a local labor market's robot adoption.

Product market competition A concern that I need to address is that the adoption of robots in Europe is influencing US labor market conditions through increased product market competition, violating the exclusion restriction of my IV strategy. Although I cannot rule out this possibility, I can show that it is rather unlikely that my results are driven by this causal link. In Table A14, I estimate the labor market impact of robots on the employment gaps by controlling for international

\footnotetext{
${ }^{32}$ In 1990, the average proportion of racial and ethnic minorities was about 15 percent. This value increased up to 23 percent in 2014. Table A12 shows that the size of the (indirect) effect of robot adoption on the employment of whites and non-whites in non-manufacturing industries is not statistically different, if expressed in terms of the total population.
} 
competition on the product market using a shift-share measure of US imports from Europe à la Autor et al. (2013). Between the mid-1990s and 2014, trade flows from Europe to the US have increased substantially. This increase is mainly driven by a rise in imports of manufacturing goods that is positively related to the introduction of robots in Europe (see Figure A14). As US imports could be subject to domestic shocks that affect also local labor demand (demand shocks), I account for endogeneity of imports by using trade flows from Europe to Canada, a country with a comparable trade engagement with European countries (see Figure A15). Reassuringly, my estimates are not significantly affected by the inclusion of these additional controls. In a second approach, I omit from the instrument the European countries with the largest trade engagement with the US, namely the UK, Italy and France. By including only countries that are less likely to impact US labor market conditions through product market competition because of their national adoption of robots, the results lose some precision (because of the heavier exposure of the instrument to labor market shocks in Nordic countries and in Spain) but remain statistically significant at conventional levels. These findings suggest that my estimates are unlikely to be driven by an increase in product market competition through the heavier utilization of robots in Europe.

Pre-trends The secular decline in the race and ethnicity and the gender employment gap raises the concern that the decrease in the employment gaps and the adoption of industrial robots are driven by some common factors. For instance, changes in the employment gaps and the adoption of robots could both stem from a labor market's industrial composition of employment. In this case, my estimates could confound the impact of robot exposure with pre-existing local labor market trends. I account for this concern in my preferred specification by controlling for past changes in the employment gaps between 1970 and 1990 and the employment composition of industries and occupations by gender, race and ethnicity. Furthermore, I perform a 'placebo test' in which I test the relationship between past employment gaps and the adoption of robots between the 1990s and 2000s to verify that my results are capturing the period specific effects of robots on the employment gaps. The results are reported in Table A15. I find no evidence of the existence of pre-trends that influence the impact of robots on the employment gaps and that there is no economically or statistically significant association between robot adoption and past employment gaps.

Weights Figure A6 in the Appendix shows that there is substantial variation in the distribution of 
racial and ethnic minorities in the US, with the largest concentration in states of the Sun Belt because of their proximity to Mexico and the Caribbean islands. Table A16 examines the role of population weights and the geographic distribution of non-whites for the determination of the effect of robots on changes in the race and ethnicity employment gap. I start by estimating Equation 4.2 using as regression weights the initial population of non-whites in the CZ. The size of the estimates is larger than in my preferred specification, suggesting that the effect is likely to emerge from labor markets with a larger population of racial and ethnic minorities. Column 2 estimates the effect of robots on the employment gaps without any weights. The results are not economically nor statistically significant, since CZs with a small population of non-whites receive too much weight. Column 3 restricts the sample to CZs with a large population of racial and ethnic minorities and repeats the exercise of the previous column (see Panel B of Figure A6), showing that the results specific to these CZs are very similar to my preferred specification's estimates in Table $3 .{ }^{33}$ This finding suggests that my main results are indeed driven by CZs with a sufficiently large population of racial and ethnic minorities and that this effect is captured by the population weight of my preferred specification. The homogeneous distribution of men and women across labor markets does not expose my results to the above mentioned concerns. As illustrated in Panel B of Table A16, the estimates of the labor market effect of robots on the gender employment gap are economically and statistically significant across all specifications, independently of the regression weights.

Additional robustness checks Tables A17 to A20 in the Appendix report additional robustness checks. Table A17 shows that the exact construction of the shift-share measure is not affecting my results. Panels A and B report estimates with a different mix of European countries used in the construction of the instrument. Panel C reports estimates using an instrument with baseline employment shares from 1990, $\ell_{c, j}^{1990}$, rather than those from 1970. Panel D reports estimates using measures that omit the adjustment for industry growth, $g_{j,\left(t_{0}, t_{1}\right)} \frac{R_{j, t_{0}}}{L_{j, 1990}}$. The estimates are not significantly different from my preferred specification. Table A18 excludes a set of outlying CZs with the heaviest adoption of robots. Panel A reports estimates when excluding the area around Detroit (MI), which is the CZ with the largest exposure to robots, while Panel B excludes CZs in the top 1 percentile of the distribution of robot exposure during my sample period. The results

\footnotetext{
${ }^{33}$ I perform a double median split and select the $275 \mathrm{CZs}$ with a population of non-whites and a share of the non-white population above the US local labor market median.
} 
lose some precision, because most of the identification is coming from CZs in the Rust Belt (see Figure 2), but they are not significantly different from my baseline results, especially for individuals without a college degree. These findings suggest that my results are not solely driven by the subset of CZs with the largest adoption of robots. Table A19 shows that unobserved heterogeneity does not alter my results. Panel A includes covariates of $\mathrm{CZ}$ characteristics at the beginning of each subperiod (1990, 2000 and 2007) instead of covariates from 1990. Panel B uses a more demanding specification and includes CZ fixed effects. Using both specifications, the results are quantitatively and qualitatively significant at conventional levels. Finally, Table A20 shows that the effects are economically and statistically significant already before the Great Recession, which is particularly reassuring with respect to the fact that the alteration of labor market conditions during this period of time is not driving my results.

\section{$7 \quad$ Conclusion}

The rapid rise in the adoption of industrial robots since the 1990s has already displaced thousands of workers in the US. However, it remains unclear how the adverse labor market effects of robots are spreading among the population. This paper addresses this gap by investigating the impact of robot adoption on employment of different demographic groups. I find that the effects of robots are distributed unevenly among the population and that they reduce employment relatively more for men and for racial and ethnic minorities, contributing to the secular decline in the gender employment gap but increasing the race and ethnicity employment gap. Between 1993 and 2014, robots have, on average, displaced twice as many male workers as female workers and, accounting for the relative population size of demographic groups, almost three times as many non-white workers as white workers. This result is driven by the over-representation of these workers in brawn taskintensive occupations that are exposed to the adoption of robots, especially in blue-collar jobs. Although industrial robots are mainly implemented to perform blue-collar work in manufacturing industries, their labor market impacts are not confined to these industries. I find significant spillover effects of robots to service-sector industries, in which mostly non-white workers are losing their jobs and do not find re-employment opportunities. This finding could be fueled by unobservable factors that go beyond composition effects, such as discrimination against racial and ethnic minorities in 
the service sector, an important question that should be addressed by future research.

\section{References}

Acemoglu, Daron, "Changes in unemployment and wage inequality: An alternative theory and some evidence," American economic review, 1999, 89 (5), 1259-1278.

- and David Autor, "Skills, tasks and technologies: Implications for employment and earnings," in "Handbook of labor economics," Vol. 4, Elsevier, 2011, pp. 1043-1171.

_ and Pascual Restrepo, "Robots and jobs: Evidence from US labor markets," Journal of Political Economy, 2020, 128 (6), 2188-2244.

_ , Claire LeLarge, and Pascual Restrepo, "Competing with Robots: Firm-Level Evidence from France," Technical Report, National Bureau of Economic Research 2020.

_ , David Autor, David Dorn, Gordon H Hanson, and Brendan Price, "Import competition and the great US employment sag of the 2000s," Journal of Labor Economics, 2016, 34 (1), 141198.

_ , _ , Jonathon Hazell, and Pascual Restrepo, "AI and Jobs: Evidence from Online Vacancies," Technical Report, National Bureau of Economic Research 2020.

Aksoy, Cevat Giray, Berkay Özcan, and Julia Philipp, "Robots and the gender pay gap in Europe," European Economic Review, 2021, p. 103693.

Altonji, Joseph G and Rebecca M Blank, "Race and gender in the labor market," Handbook of labor economics, 1999, 3, 3143-3259.

Anelli, Massimo, Osea Giuntella, and Luca Stella, "Robots, Labor Markets, and Family Behavior," 2019.

Antecol, Heather, Deborah A Cobb-Clark, and Stephen J Trejo, "Immigration policy and the skills of immigrants to Australia, Canada, and the United States," Journal of Human Resources, 2003, 38 (1), 192-218.

Autor, David, "The" task approach" to labor markets: an overview," Technical Report, National Bureau of Economic Research 2013.

_ , "Why are there still so many jobs? The history and future of workplace automation," Journal 
of economic perspectives, 2015, 29 (3), 3-30.

- and David Dorn, "The growth of low-skill service jobs and the polarization of the US labor market," American Economic Review, 2013, 103 (5), 1553-97.

_ , _, and Gordon Hanson, "The China syndrome: Local labor market effects of import competition in the United States," American Economic Review, 2013, 103 (6), 2121-68.

_, Frank Levy, and Richard J Murnane, "The skill content of recent technological change: An empirical exploration," The Quarterly journal of economics, 2003, 118 (4), 1279-1333.

Bacolod, Marigee P and Bernardo S Blum, "Two sides of the same coin us ?residual? inequality and the gender gap," Journal of Human resources, 2010, 45 (1), 197-242.

Beaudry, Paul and Ethan Lewis, "Do male-female wage differentials reflect differences in the return to skill? Cross-city evidence from 1980-2000," American Economic Journal: Applied Economics, 2014, 6 (2), 178-94.

Black, Sandra E and Alexandra Spitz-Oener, "Explaining women's success: technological change and the skill content of women's work," The Review of Economics and Statistics, 2010, 92 (1), 187-194.

Blau, David M, "Labor force dynamics of older married couples," Journal of Labor Economics, 1998, $16(3), 595-629$.

Blau, Francine D and Lawrence M Kahn, "The gender wage gap: Extent, trends, and explanations," Journal of Economic Literature, 2017, 55 (3), 789-865.

Bonfiglioli, Alessandra, Rosario Crinò, Harald Fadinger, and Gino Gancia, "Robot imports and firm-level outcomes," 2020.

Borghans, Lex, Bas Ter Weel, and Bruce A Weinberg, "People skills and the labor-market outcomes of underrepresented groups," ILR Review, 2014, 67 (2), 287-334.

Brussevich, Mariya, Ms Era Dabla-Norris, and Salma Khalid, Is Technology Widening the Gender Gap? Automation and the Future of Female Employment, International Monetary Fund, 2019.

Brynjolfsson, Erik and Andrew McAfee, The second machine age: Work, progress, and prosperity in a time of brilliant technologies, WW Norton \& Company, 2014.

Cadena, Brian C and Brian K Kovak, "Immigrants equilibrate local labor markets: Evidence 
from the Great Recession," American Economic Journal: Applied Economics, 2016, 8 (1), 257-90.

Chuan, Amanda and Weilong Zhang, "Workplace Automation and the Gender Gap in College Enrollment," 2021.

Cook, Kelemwork, Duwain Pinder, Shelley Stewart III, Amaka Uchegbu, and Jason Wright, "The future of work in black America," McKinsey $\&$ Company, October, 2019.

Couch, Kenneth and Mary C Daly, "Black-white wage inequality in the 1990s: A decade of progress," Economic Inquiry, 2002, 40 (1), 31-41.

Dauth, Wolfgang, Sebastian Findeisen, Jens Suedekum, and Nicole Woessner, "The Adjustment of Labor Markets to Robots," University of Würzburg, 2019.

Dottori, Davide, "Robots and employment: evidence from Italy," Bank of Italy Occasional Paper, 2020, (572).

Faber, Marius, Andres Sarto, and Marco Tabellini, "The Impact of Technology and Trade on Migration: Evidence from the US," Harvard Business School BGIE Unit Working Paper, 2019, $(20-071)$.

Frey, Carl Benedikt and Michael A Osborne, "The future of employment: How susceptible are jobs to computerisation?," Technological forecasting and social change, 2017, 114, 254-280.

Ge, Suqin and Yu Zhou, "Robots, computers, and the gender wage gap," Journal of Economic Behavior \& Organization, 2020, 178, 194-222.

Goldin, Claudia Dale and Lawrence F Katz, The race between education and technology, Harvard University Press, 2009.

Goldsmith-Pinkham, Paul, Isaac Sorkin, and Henry Swift, "Bartik instruments: What, when, why, and how," American Economic Review, 2020, 110 (8), 2586-2624.

Goos, Maarten, Alan Manning, and Anna Salomons, "Job polarization in Europe," American economic review, 2009, 99 (2), 58-63.

_ and _ , "Lousy and lovely jobs: The rising polarization of work in Britain," The review of economics and statistics, 2007, 89 (1), 118-133.

Graetz, Georg and Guy Michaels, "Robots at work," Review of Economics and Statistics, 2018, $100(5), 753-768$.

Guryan, Jonathan and Kerwin Kofi Charles, "Taste-based or statistical discrimination: the 
economics of discrimination returns to its roots," The Economic Journal, 2013, 123 (572), F417F432.

Helm, Ines, "National Industry Trade Shocks, Local Labour Markets, and Agglomeration Spillovers," The Review of Economic Studies, 2020, 87 (3), 1399-1431.

IFR, "World Robotics 2018," Technical Report, International Federation of Robotics 2018.

Jägger, Kirsten, "EU KLEMS Growth and Productivity Accounts 2017 release," Description of Methodology and General Notes 2017.

Katz, Lawrence F and Kevin M Murphy, "Changes in relative wages, 1963-1987: supply and demand factors," The quarterly journal of economics, 1992, 107 (1), 35-78.

King, Mary C, "Occupational segregation by race and sex, 1940-88," Monthly Labor Review, 1992, $115(4), 30-37$.

Lerch, Benjamin, "Robots and Nonparticipation in the US: Where Have All the Workers Gone?," Available at SSRN 3650905, 2020.

Llull, Joan, "Immigration, wages, and education: A labour market equilibrium structural model," The Review of Economic Studies, 2018, 85 (3), 1852-1896.

Marianne, Bertrand, "New perspectives on gender," in "Handbook of labor economics," Vol. 4, Elsevier, 2011, pp. 1543-1590.

Muro, Mark, Robert Maxim, and Jacob Whiton, "Automation and artificial intelligence: How machines are affecting people and places," 2019.

Ngai, L Rachel and Barbara Petrongolo, "Gender gaps and the rise of the service economy," American Economic Journal: Macroeconomics, 2017, 9 (4), 1-44.

Olivetti, Claudia and Barbara Petrongolo, "The evolution of gender gaps in industrialized countries," Annual review of Economics, 2016, 8, 405-434.

Peri, Giovanni and Chad Sparber, "Task specialization, immigration, and wages," American Economic Journal: Applied Economics, 2009, 1 (3), 135-69.

Petrongolo, Barbara and Maddalena Ronchi, "Gender gaps and the structure of local labor markets," Labour Economics, 2020, 64, 101819.

Pitt, Mark M, Mark R Rosenzweig, and Mohammad Nazmul Hassan, "Human capital investment and the gender division of labor in a brawn-based economy," American Economic 
Review, 2012, 102 (7), 3531-60.

Rendall, Michelle, "Brain versus brawn: the realization of women's comparative advantage," University of Zurich, Institute for Empirical Research in Economics, Working Paper, 2017, (491).

Roy, Andrew Donald, "Some thoughts on the distribution of earnings," Oxford economic papers, 1951, 3 (2), 135-146.

Ruggles, Steven, Sarah Flood, Ronald Goeken, Josiah Grover, Erin Meyer, Jose Pacas, and Matthew Sobek, "IPUMS USA: Version 9.0 [dataset]. Minneapolis, MN, https://doi.org/10.18128/D010.V9.0," Technical Report 2019.

Tolbert, Charles M and Molly Sizer, "US commuting zones and labor market areas: A 1990 update," Technical Report 1996.

Weinberg, Bruce A, "Computer use and the demand for female workers," ILR Review, 2000, 53 (2), 290-308.

Yamaguchi, Shintaro, "Changes in returns to task-specific skills and gender wage gap," Journal of Human Resources, 2018, 53 (1), 32-70. 


\section{Figures}

Figure 1: Industrial robots and employment gaps

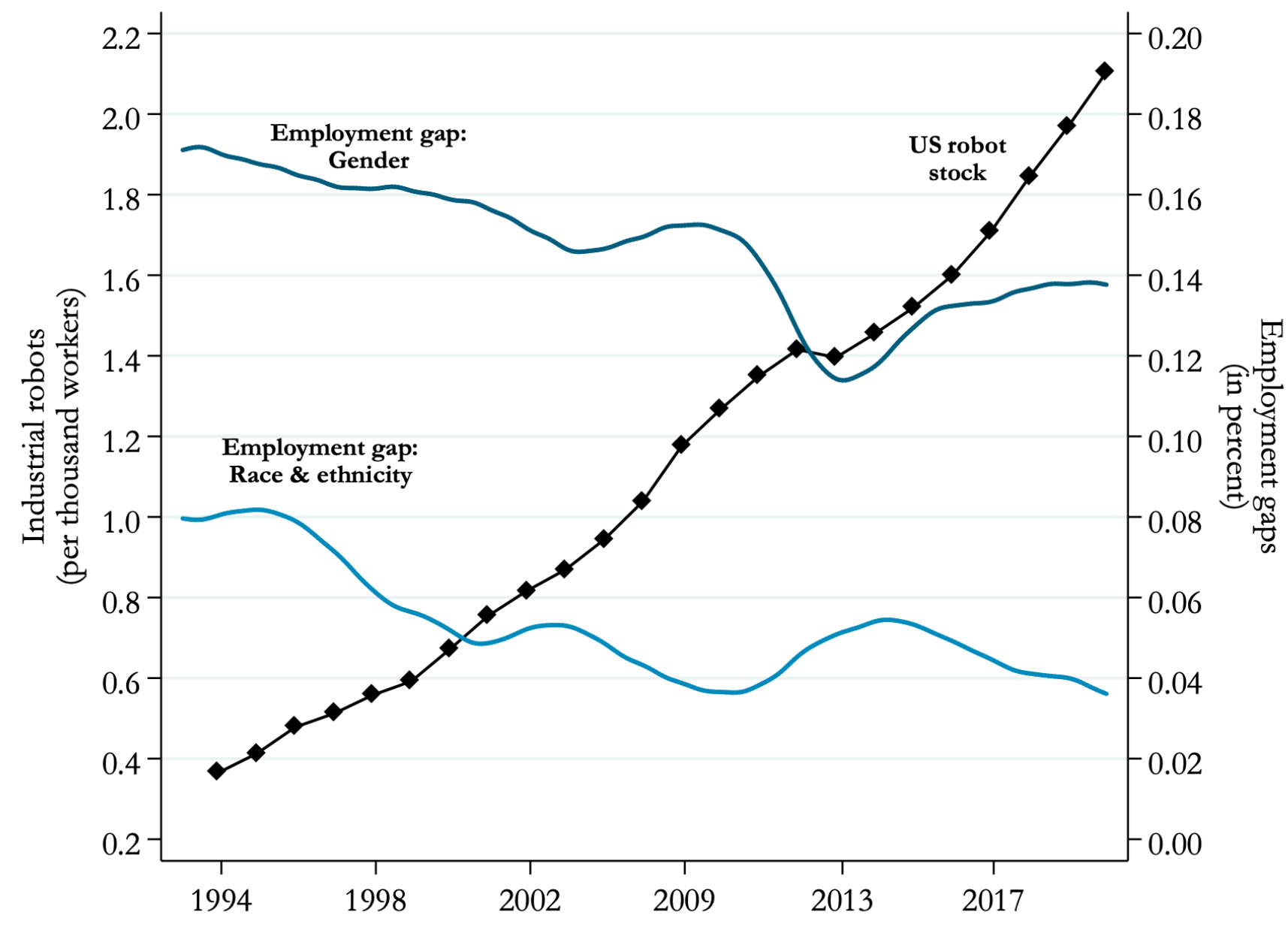

Note: This figure illustrates the race and ethnicity employment gap, the gender employment gap and the stock of industrial robots per thousand workers in the US between 1993 and 2017. The number of workers is kept constant at its 1993 level. I compute the employment gaps using monthly data from the Current Population Survey. 
Figure 2: Robot exposure at the commuting zone level, 1993-2014

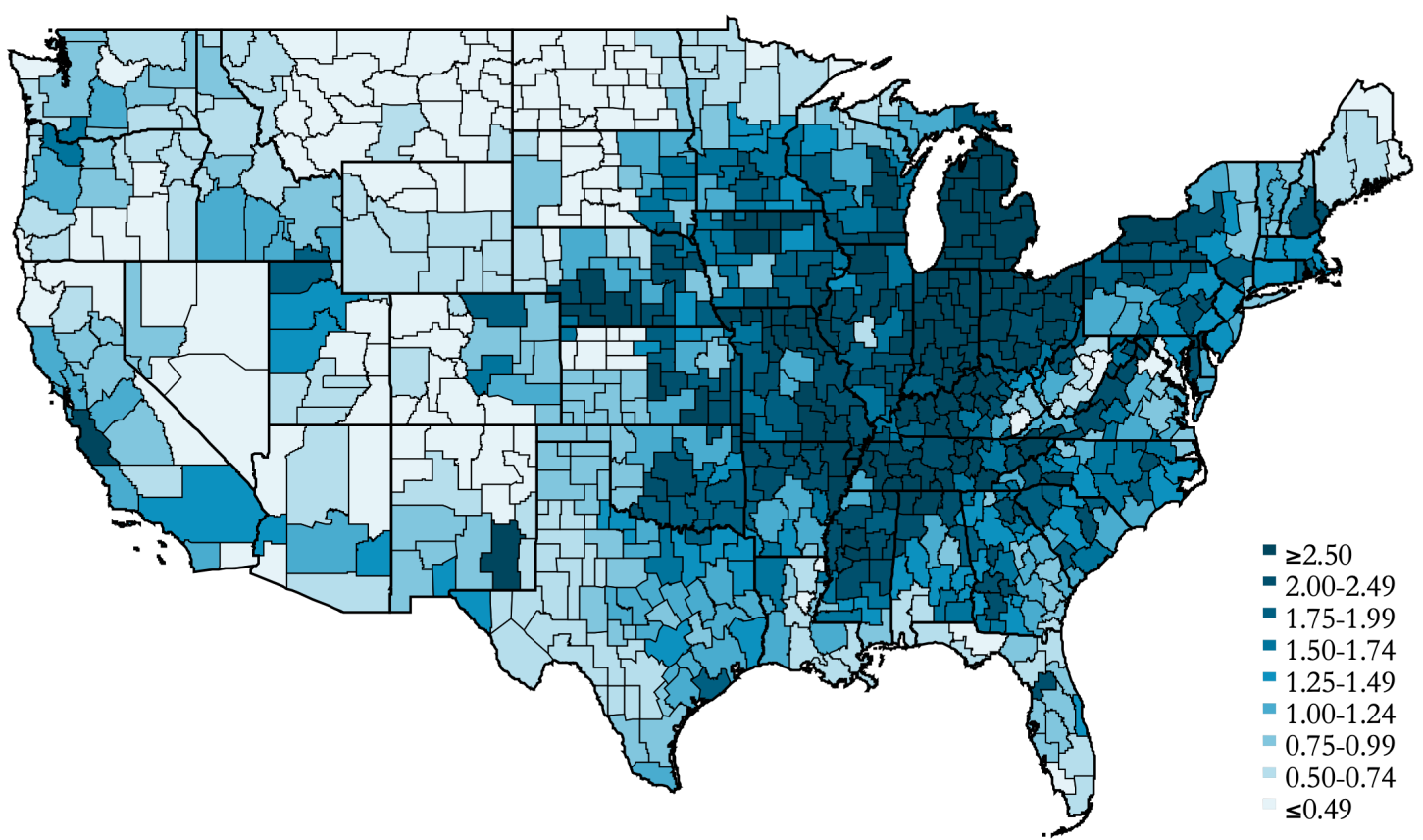

Note: This figure illustrates the geographic distribution of US robot exposure (in robots per thousand workers) at the CZ level between 1993 and 2014. 
Figure 3: Occupations and demographics

Panel A: Race and ethnicity

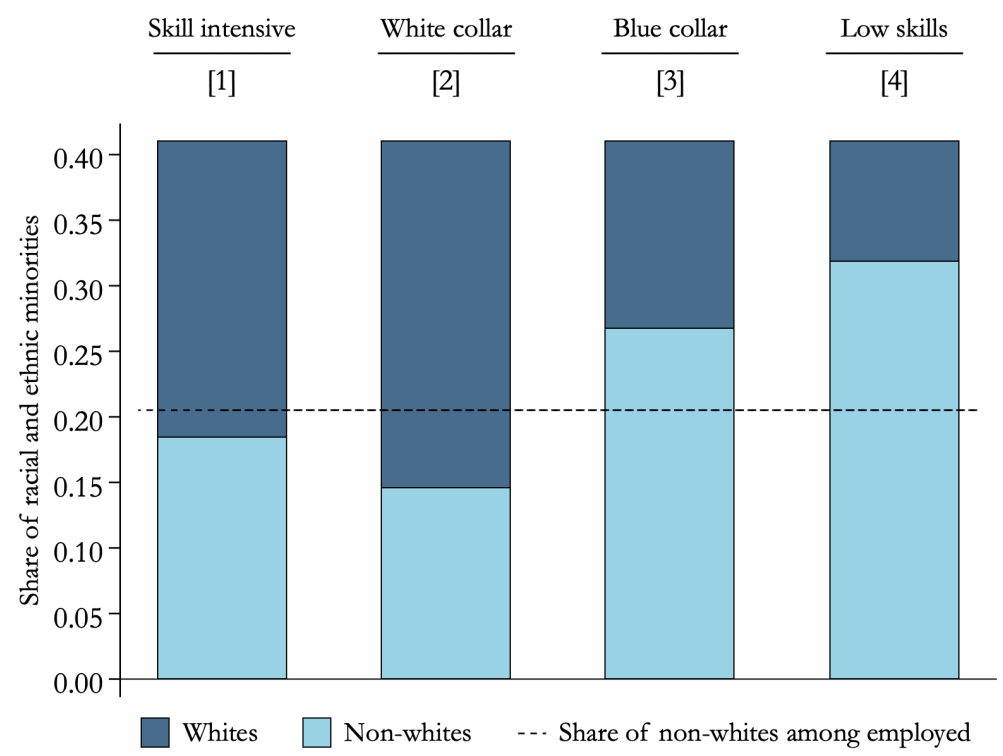

Panel B: Gender

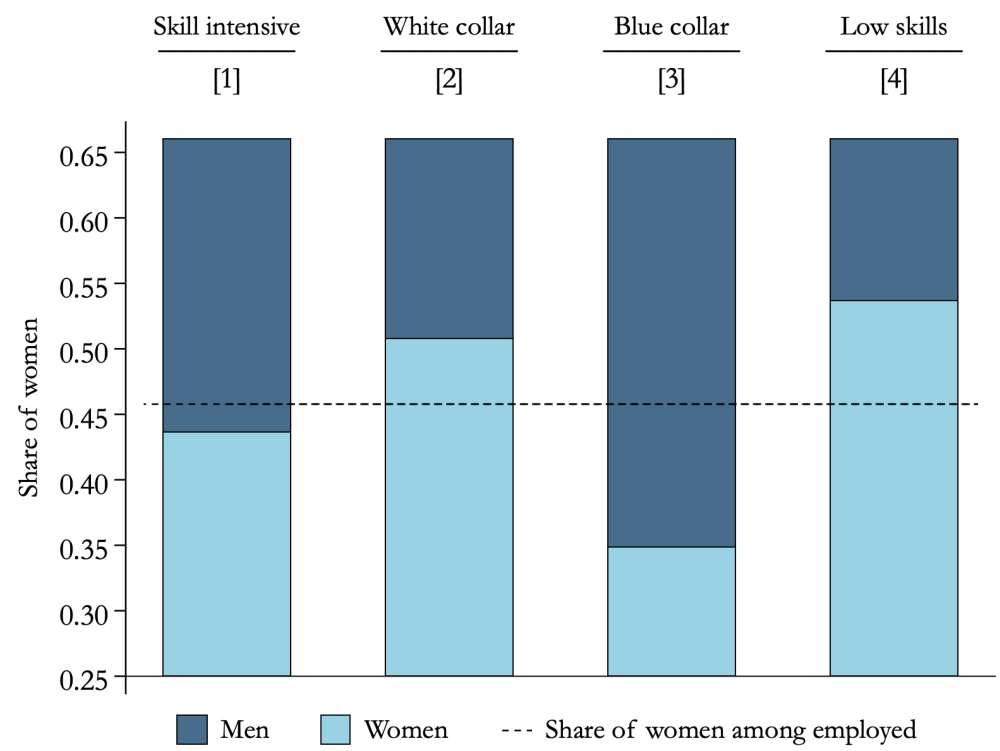

Note: This figure illustrates the shares of women and non-whites across different occupation groups in 1990 . I perform a median split of the standardized measures of brawn and brain task content of jobs and assign them to one of four groups: skill-intensive, white-collar, blue-collar or low-skill jobs. Skill-intensive jobs include occupations that are both brawn and brain task intensive. White-collar jobs include occupations that are brain task intensive and require only few brawn skills. Blue-collar jobs include occupations that are brawn task intensive and require only few brain skills. Low-skill jobs include occupations that do not require particular brawn or brain skills. The share of non-whites among the employed is computed from the number of non-white workers divided by the employed population. Analogously, I compute the share of women among the employed. 
Figure 4: Industries and tasks

\section{Panel A: Brawn tasks}

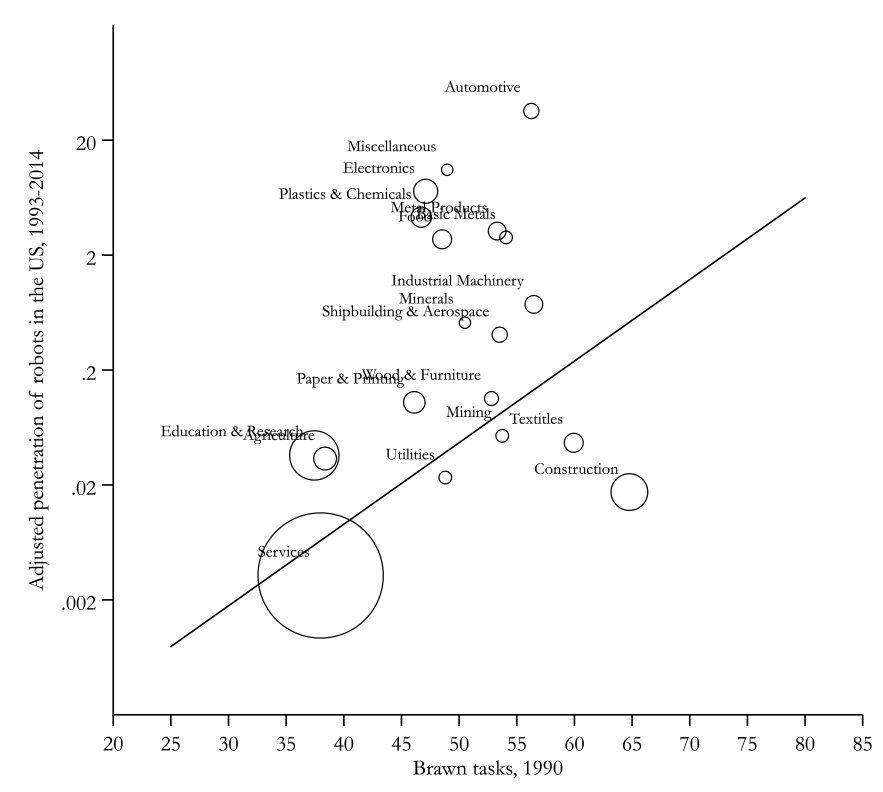

Panel B: Brain tasks

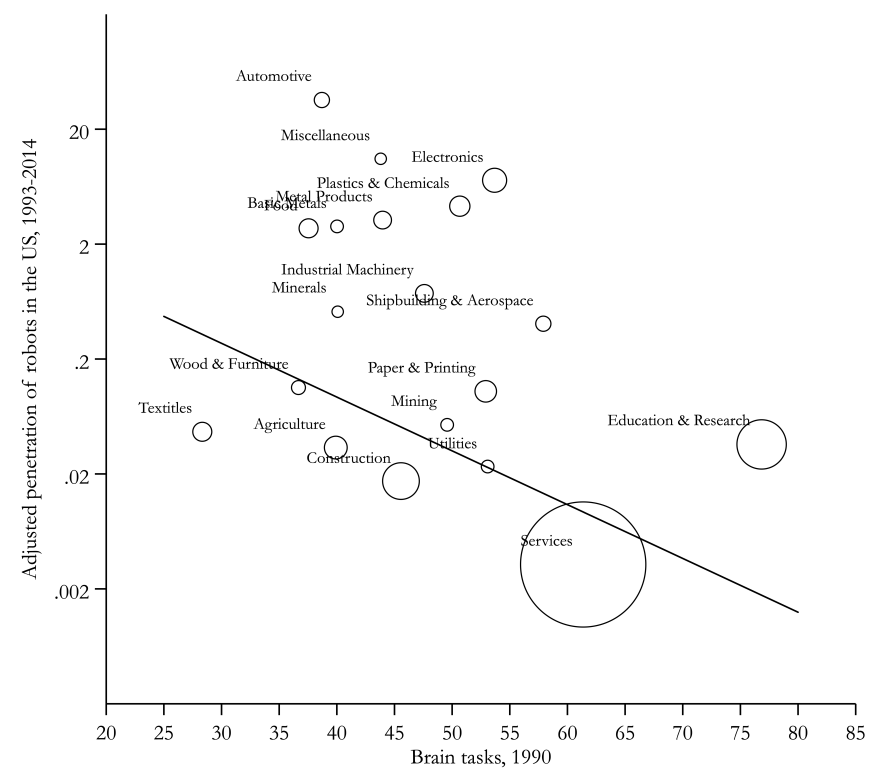

Note: This figure illustrates the relationship between the growth in the (log) stock of robots per thousand workers at the IFR industry level between 1993 and 2014 (see Equation 4.1) and the brawn and brain task content in these industries, expressed as the average standardized task content of workers that are employed in these industries in 1990. 
Figure 5: Robots and employment by gender

Panel A: Employment by gender

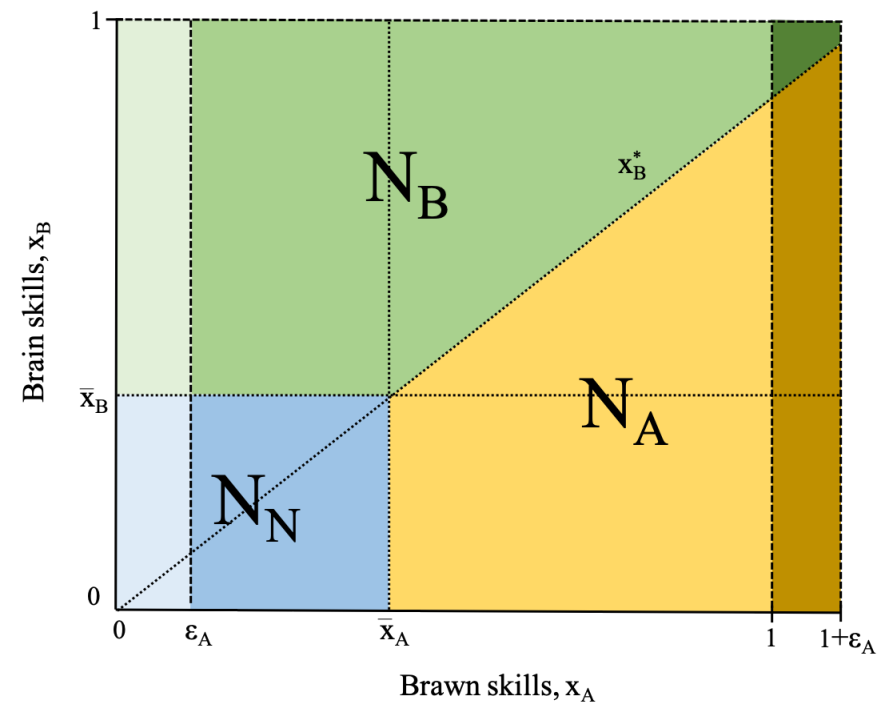

Panel B: Robots and employment by gender

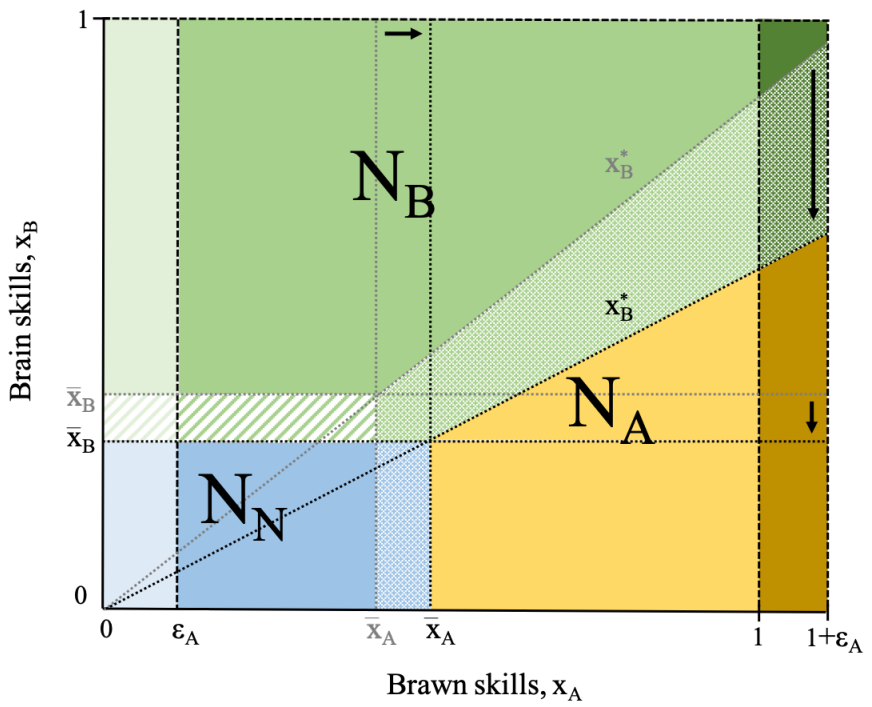

Note: This figure illustrates an economy's population density by employment status and gender in equilibrium, when solving for Equations 3.2, 3.3, 3.8 and 3.9. $N_{A}, N_{B}$ and $N_{N}$ represent the share of individuals that supply brawn labor, brain labor and no labor. $\varepsilon_{A}>0$ is the comparative advantage of men in brawn skills, and $\bar{x}_{A}=\frac{\omega_{N}}{\omega_{A}}, \bar{x}_{B}=\frac{\omega_{N}}{\omega_{B}}$ and $x_{B, i}^{*}=\frac{\omega_{A}}{\omega_{B}} x_{A, i}$. Panel $\mathrm{B}$ illustrates the impact of a decrease in the price of robot capital on relative wages and the equilibrium allocation of labor. 
Figure 6: Robots and employment rates

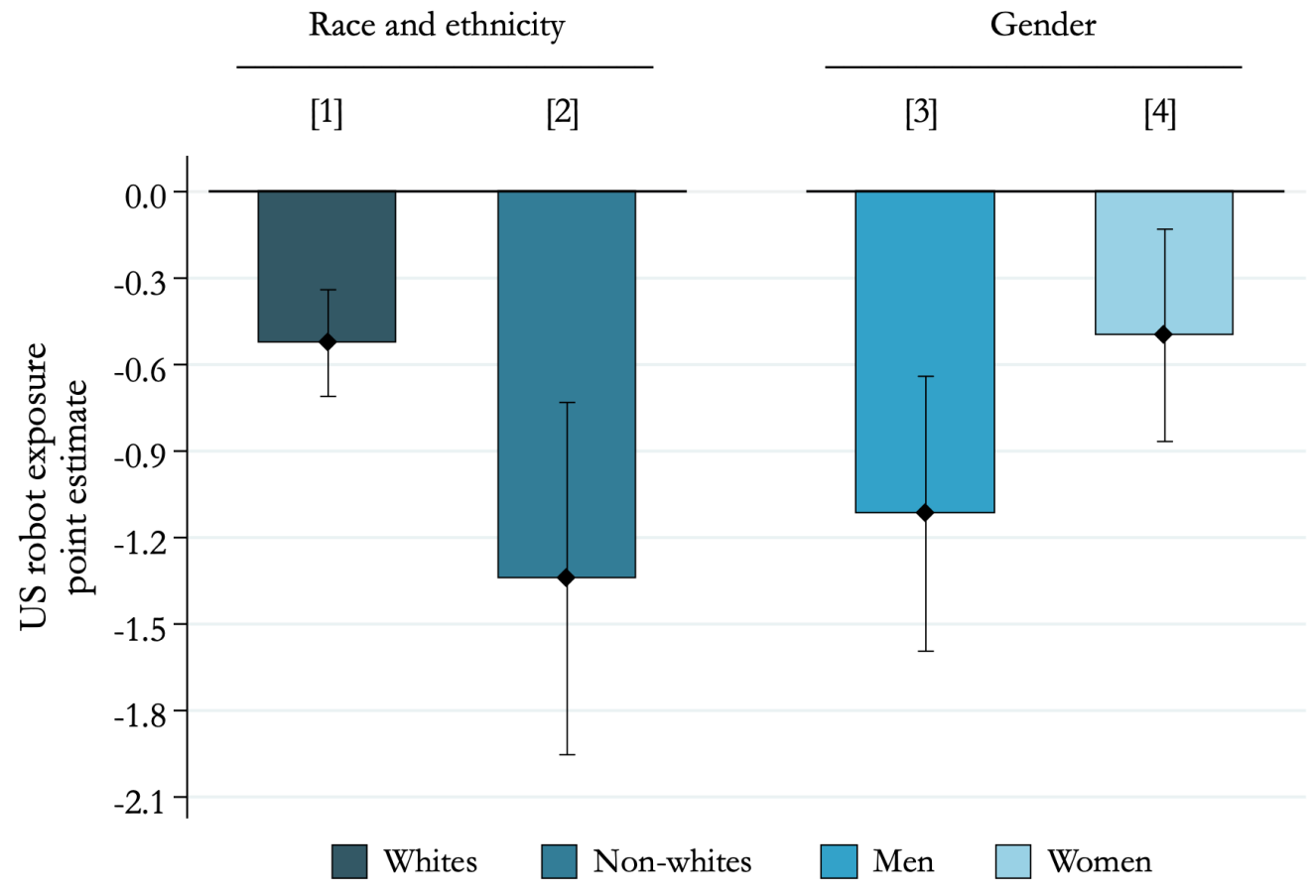

Note: This figure illustrates the IV point estimates of the effect of US robot exposure on the change in employment by race and ethnicity and by gender. Changes are expressed in percentage points of the population subgroup and are multiplied by 100. Independent variables are standardized to have mean zero and standard deviation of one. There are three time periods and 722 CZs. Standard errors are robust against heteroskedasticity and allow for clustering at the state level. Confidence intervals are at the $95 \%$ level. Regressions include covariates of my preferred specification and are weighted by CZ population in 1990. 


\section{Tables}

Table 1: Descriptive statistics: Industrial robots

\begin{tabular}{|c|c|c|c|c|c|}
\hline & \multicolumn{2}{|c|}{$\begin{array}{l}\text { Robots in the US } \\
\text { per thousand } \\
\text { workers }\end{array}$} & \multicolumn{2}{|c|}{$\begin{array}{l}\text { Robots in EU7 } \\
\text { countries per } \\
\text { thousand workers }\end{array}$} & \multirow{2}{*}{ 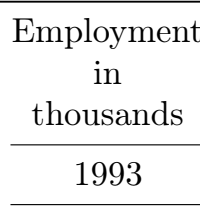 } \\
\hline & 1993 & $\Delta_{14-93}$ & 1993 & $\Delta_{14-93}$ & \\
\hline & {$[1]$} & {$[2]$} & {$[3]$} & {$[4]$} & {$[5]$} \\
\hline \multicolumn{6}{|c|}{ Panel A: High robot-intensive manufacturing } \\
\hline Automotive & 24.25 & 82.69 & 18.2 & 57.12 & 1111 \\
\hline Basic Metals & 1.39 & 5.37 & 0.84 & 7.34 & 712 \\
\hline Electronics & 2.01 & 10.99 & 2.34 & 3.31 & 2868 \\
\hline Food and Beverages & 1.02 & 4.62 & 0.38 & 8.93 & 1862 \\
\hline Metal Products & 1.69 & 6.51 & 6.91 & 11.13 & 1689 \\
\hline Plastics and Chemicals & 1.80 & 7.43 & 2.85 & 16.04 & 2205 \\
\hline \multicolumn{6}{|c|}{ Panel B: Low robot-intensive manufacturing } \\
\hline Industrial Machinery & 0.39 & 1.52 & 3.01 & 6.18 & 1541 \\
\hline Minerals & 0.04 & 0.58 & 0.60 & 3.64 & 558 \\
\hline Miscellaneous & 0.49 & 11.66 & 2.56 & 2.93 & 690 \\
\hline Paper and Printing & 0.00 & 0.10 & 0.19 & 0.83 & 2467 \\
\hline Shipbuilding and Aerospace & 0.02 & 0.44 & 0.73 & 2.18 & 1111 \\
\hline Textiles & 0.00 & 0.05 & 0.24 & 0.88 & 1848 \\
\hline Wood and Furniture & 0.00 & 0.12 & 1.14 & 2.75 & 1048 \\
\hline \multicolumn{6}{|l|}{ Panel C: Non-manufacturing } \\
\hline Agriculture & 0.00 & 0.03 & 0.00 & 0.18 & 2552 \\
\hline Construction & 0.00 & 0.02 & 0.00 & 0.11 & 7108 \\
\hline Education and Research & 0.00 & 0.04 & 0.03 & 0.33 & 12636 \\
\hline Mining & 0.00 & 0.05 & 0.23 & 1.36 & 763 \\
\hline Services & 0.00 & 0.00 & 0.00 & 0.00 & 84776 \\
\hline Utilities & 0.00 & 0.02 & 0.00 & 0.25 & 745 \\
\hline
\end{tabular}

Note: This table presents the number of robots adopted in the United States and seven European countries (Denmark, Finland, France, Italy, Spain, Sweden and the United Kingdom) by year and industry. Panel A reports the number of robots in manufacturing industries with the largest adoption of robots during the sample period. Panel B reports the number of robots in other manufacturing industries. Panel $\mathrm{C}$ reports the number of robots for six sectors outside of manufacturing. Columns 1 and 3 report the stock robots per thousand workers in 1993. Columns 2 and 4 report the change in the stock of robots between 1993 and 2014 per thousand workers in 1993. Column 5 reports the number of workers by industry in 1993. 
Table 2: Descriptive statistics: Employment

\begin{tabular}{|c|c|c|c|c|c|c|}
\hline & \multicolumn{2}{|c|}{ All } & \multicolumn{2}{|c|}{ 1st quartile } & \multicolumn{2}{|c|}{ 4th quartile } \\
\hline & 1990 & $\Delta_{14-90}$ & 1990 & $\Delta_{14-90}$ & 1990 & $\Delta_{14-90}$ \\
\hline & {$[1]$} & {$[2]$} & {$[3]$} & [4] & {$[5]$} & {$[6]$} \\
\hline \multicolumn{7}{|c|}{ Panel A: Employment rates } \\
\hline White & 76.7 & -1.42 & 76.3 & -2.17 & 76.4 & -0.83 \\
\hline Non-white & 68.8 & 0.94 & 70.0 & 1.01 & 67.2 & 0.99 \\
\hline Male & 84.3 & -4.46 & 83.8 & -4.14 & 84.4 & -4.73 \\
\hline Female & 66.0 & 1.64 & 65.4 & 1.23 & 65.8 & 2.32 \\
\hline \multicolumn{7}{|c|}{ Panel B: Employment gaps } \\
\hline Race and ethnicity & 7.89 & -2.37 & 6.22 & -3.18 & 9.13 & -1.82 \\
\hline Gender & 18.3 & -6.10 & 18.3 & -5.37 & 18.6 & -7.06 \\
\hline Observations & 722 & 722 & 181 & 181 & 180 & 180 \\
\hline
\end{tabular}

Note: This table presents the average employment rates for whites, non-whites (or racial and ethnic minorities), men and women and the average employment gaps in 1990 as well as changes between 1990 and 2014 weighted by CZ population in 1990. Columns 1 and 2 reports averages over all $722 \mathrm{CZs}$ in the sample. Columns 2 to 6 split the sample into quartiles according to a labor market's exposure to robots between 1993 and 2014 and report averages of the employment rates and employment gaps for the first and the fourth quartile. 
Table 3: Robots and employment gaps

\begin{tabular}{|c|c|c|c|c|c|c|}
\hline & \multicolumn{6}{|c|}{ Panel A: Race and ethnicity } \\
\hline & {$[1]$} & {$[2]$} & {$[3]$} & {$[4]$} & {$[5]$} & {$[6]$} \\
\hline US robot exposure & $\begin{array}{c}0.640^{* * *} \\
(0.232)\end{array}$ & $\begin{array}{c}0.669^{* * *} \\
(0.231)\end{array}$ & $\begin{array}{c}0.662^{* * *} \\
(0.233)\end{array}$ & $\begin{array}{c}0.663^{* * *} \\
(0.233)\end{array}$ & $\begin{array}{c}0.797^{* * *} \\
(0.267)\end{array}$ & $\begin{array}{c}0.817^{* * *} \\
(0.270)\end{array}$ \\
\hline \multirow[t]{3}{*}{ Observations } & 2166 & 2166 & 2166 & 2166 & 2166 & 2166 \\
\hline & \multicolumn{6}{|c|}{ Panel B: Gender } \\
\hline & {$[1]$} & {$[2]$} & {$[3]$} & {$[4]$} & {$[5]$} & {$[6]$} \\
\hline US robot exposure & $\begin{array}{c}-0.508^{* * *} \\
(0.141)\end{array}$ & $\begin{array}{c}-0.516^{* * *} \\
(0.139)\end{array}$ & $\begin{array}{c}-0.537^{* * *} \\
(0.142)\end{array}$ & $\begin{array}{c}-0.537^{* * *} \\
(0.141)\end{array}$ & $\begin{array}{c}-0.609^{* * *} \\
(0.156)\end{array}$ & $\begin{array}{c}-0.619^{* * *} \\
(0.160)\end{array}$ \\
\hline Observations & 2166 & 2166 & 2166 & 2166 & 2166 & 2166 \\
\hline \multicolumn{7}{|l|}{ Covariates: } \\
\hline Region & $\checkmark$ & $\checkmark$ & $\checkmark$ & $\checkmark$ & $\checkmark$ & $\checkmark$ \\
\hline Year & $\checkmark$ & $\checkmark$ & $\checkmark$ & $\checkmark$ & $\checkmark$ & $\checkmark$ \\
\hline Pre-trends & & $\checkmark$ & $\checkmark$ & $\checkmark$ & $\checkmark$ & $\checkmark$ \\
\hline Computer \& IT & & & $\checkmark$ & $\checkmark$ & $\checkmark$ & $\checkmark$ \\
\hline Chinese imports & & & & $\checkmark$ & $\checkmark$ & $\checkmark$ \\
\hline Demographics & & & & & $\checkmark$ & $\checkmark$ \\
\hline Occupations & & & & & $\checkmark$ & $\checkmark$ \\
\hline Industries & & & & & $\checkmark$ & $\checkmark$ \\
\hline Composition & & & & & & $\checkmark$ \\
\hline
\end{tabular}

Note: This table presents IV estimates of the effect of US robot exposure on the race and ethnicity employment gap and the gender employment at the CZ level. Changes are expressed in percentage points of the working-age population subgroup and are multiplied by 100. Independent variables are standardized to have mean zero and standard deviation of one. There are three time periods and $722 \mathrm{CZs}$. Column 1 includes only state fixed effects and time-varying division fixed effects. Column 2 includes also pre-trends in the change of the employment gaps between 1970 and 1990. Column 3 controls for the adoption of personal computers and IT capital intensity. Column 4 includes the exposure to Chinese imports. Column 5 includes also demographic (share of individuals aged between 25 and 34 years, 35 and 44 years, 45 and 54 years, the share of Blacks, Hispanics, women and individuals with less than a college degree and logarithmic population), industry (share of employment in the contruction, manufacturing, mining, research, service and utilities sector) and occupation (share of employment in routine, offshorable, skill-intensive, white-collar, blue-collar and low-skill occupations) characteristics of CZs in 1990. Column 6 controls also for the initial composition of employment by race, ethnicity and gender within occupation and industry groups. Standard errors are robust against heteroskedasticity and allow for clustering at the state level. Regressions are weighted by CZ population in 1990. Coefficients with ${ }^{* * *},{ }^{* *}$ and ${ }^{*}$ are significant at the $1 \%, 5 \%$ and $10 \%$ confidence level. 
Table 4: Robots and employment gaps: Demographics

\begin{tabular}{|c|c|c|c|c|c|c|c|c|}
\hline & \multicolumn{8}{|c|}{ Panel A: Race and ethnicity } \\
\hline & \multicolumn{2}{|c|}{ Gender } & \multicolumn{2}{|c|}{ Education } & \multicolumn{4}{|c|}{ Age } \\
\hline & Men & Women & $\begin{array}{l}\text { College } \\
\text { degree }\end{array}$ & $\begin{array}{l}\text { Less than } \\
\text { college }\end{array}$ & $\begin{array}{l}25-34 \\
\text { years }\end{array}$ & $\begin{array}{l}35-44 \\
\text { years }\end{array}$ & $\begin{array}{l}45-54 \\
\text { years }\end{array}$ & $\begin{array}{l}55-64 \\
\text { years }\end{array}$ \\
\hline & {$[1]$} & {$[2]$} & {$[3]$} & {$[4]$} & {$[5]$} & {$[6]$} & {$[7]$} & {$[8]$} \\
\hline US robot exposure & $\begin{array}{l}0.891^{* *} \\
(0.344)\end{array}$ & $\begin{array}{l}0.749^{* *} \\
(0.279)\end{array}$ & $\begin{array}{c}0.320 \\
(0.295)\end{array}$ & $\begin{array}{c}0.948^{* * *} \\
(0.294)\end{array}$ & $\begin{array}{l}0.705^{* *} \\
(0.296)\end{array}$ & $\begin{array}{l}0.847^{* *} \\
(0.399)\end{array}$ & $\begin{array}{c}1.189^{* * * *} \\
(0.316)\end{array}$ & $\begin{array}{c}0.472 \\
(0.328)\end{array}$ \\
\hline \multirow[t]{5}{*}{ Observations } & 2166 & 2166 & 2166 & 2166 & 2166 & 2166 & 2166 & 2166 \\
\hline & \multicolumn{8}{|c|}{ Panel B: Gender } \\
\hline & \multicolumn{2}{|c|}{ Race and ethnicity } & \multicolumn{2}{|c|}{ Education } & \multicolumn{4}{|c|}{ Age } \\
\hline & Whites & Non-whites & $\begin{array}{l}\text { College } \\
\text { degree }\end{array}$ & $\begin{array}{l}\text { Less than } \\
\text { college }\end{array}$ & $\begin{array}{l}25-34 \\
\text { years }\end{array}$ & $\begin{array}{l}35-44 \\
\text { years }\end{array}$ & $\begin{array}{l}45-54 \\
\text { years }\end{array}$ & $\begin{array}{l}55-64 \\
\text { years }\end{array}$ \\
\hline & {$[1]$} & {$[2]$} & {$[3]$} & {$[4]$} & {$[5]$} & $\overline{[6]}$ & {$[7]$} & {$[8]$} \\
\hline US robot exposure & $\begin{array}{c}-0.620^{* * *} \\
(0.130)\end{array}$ & $\begin{array}{c}-0.704^{* *} \\
(0.338)\end{array}$ & $\begin{array}{c}0.065 \\
(0.176)\end{array}$ & $\begin{array}{c}-0.877^{* * *} \\
(0.186)\end{array}$ & $\begin{array}{c}-1.036^{* * *} \\
(0.293)\end{array}$ & $\begin{array}{c}-0.448^{* *} \\
(0.201)\end{array}$ & $\begin{array}{c}-0.421^{* *} \\
(0.168)\end{array}$ & $\begin{array}{c}-0.678^{* * *} \\
(0.190)\end{array}$ \\
\hline Observations & 2166 & 2166 & 2166 & 2166 & 2166 & 2166 & 2166 & 2166 \\
\hline Covariates: & $\checkmark$ & $\checkmark$ & $\checkmark$ & $\checkmark$ & $\checkmark$ & $\checkmark$ & $\checkmark$ & $\checkmark$ \\
\hline
\end{tabular}

Note: This table presents IV estimates of the effect of US robot exposure on the change in the race and ethnicity employment gap and the gender employment gap by education level and age at the CZ level. Changes are expressed in percentage points of the working-age population subgroup and are multiplied by 100. Independent variables are standardized to have mean zero and standard deviation of one. There are three time periods and $722 \mathrm{CZs}$. All columns include state fixed effects and time-varying division fixed effects and control for the adoption of personal computers, IT capital intensity, the exposure to Chinese imports, the demographic (share of individuals aged between 25 and 34 years, 35 and 44 years, 45 and 54 years, the share of Blacks, Hispanics, women and individuals with less than a college degree and logarithmic population), industry (share of employment in the contruction, manufacturing, mining, research, service and utilities sector) and occupation (share of employment in routine, offshorable, skill-intensive, white-collar, blue-collar and low-skill occupations) characteristics of CZs, as well as the employment composition by race, ethnicity and gender within occupation and industry groups in 1990. Standard errors are robust against heteroskedasticity and allow for clustering at the state level. Regressions are weighted by CZ population in 1990. Coefficients with ${ }^{* * *},{ }^{* *}$ and ${ }^{*}$ are significant at the $1 \%, 5 \%$ and $10 \%$ confidence level. 
Table 5: Robots and employment gaps: Occupations and industries

\begin{tabular}{|c|c|c|c|c|c|c|c|}
\hline & \multicolumn{7}{|c|}{ Panel A: Race and ethnicity } \\
\hline & \multicolumn{4}{|c|}{ Occupation } & \multicolumn{3}{|c|}{ Industry } \\
\hline & $\begin{array}{c}\text { Skill } \\
\text { intensive }\end{array}$ & $\begin{array}{l}\text { White } \\
\text { collar }\end{array}$ & $\begin{array}{l}\text { Blue } \\
\text { collar }\end{array}$ & $\begin{array}{l}\text { Low } \\
\text { skills }\end{array}$ & $\begin{array}{c}\text { High } \\
\text { robot- } \\
\text { intensive }\end{array}$ & $\begin{array}{c}\text { Low } \\
\text { robot- } \\
\text { intensive }\end{array}$ & $\begin{array}{l}\text { Non- } \\
\text { manufac- } \\
\text { turing }\end{array}$ \\
\hline & {$[1]$} & {$[2]$} & {$[3]$} & {$[4]$} & {$[5]$} & {$[6]$} & {$[7]$} \\
\hline US robot exposure & $\begin{array}{c}0.011 \\
(0.103)\end{array}$ & $\begin{array}{c}0.147 \\
(0.130)\end{array}$ & $\begin{array}{c}0.611^{\text {*** }} \\
(0.177)\end{array}$ & $\begin{array}{c}0.053 \\
(0.110)\end{array}$ & $\begin{array}{c}0.152 \\
(0.176)\end{array}$ & $\begin{array}{c}0.001 \\
(0.076)\end{array}$ & $\begin{array}{c}0.667^{* * *} \\
(0.240)\end{array}$ \\
\hline \multirow[t]{5}{*}{ Observations } & 2166 & 2166 & 2166 & 2166 & 2166 & 2166 & 2166 \\
\hline & \multicolumn{7}{|c|}{ Panel B: Gender } \\
\hline & \multicolumn{4}{|c|}{ Occupation } & \multicolumn{3}{|c|}{ Industry } \\
\hline & $\begin{array}{c}\text { Skill } \\
\text { intensive }\end{array}$ & $\begin{array}{l}\text { White } \\
\text { collar }\end{array}$ & $\begin{array}{l}\text { Blue } \\
\text { collar }\end{array}$ & $\begin{array}{l}\text { Low } \\
\text { skills }\end{array}$ & $\begin{array}{c}\text { High } \\
\text { robot- } \\
\text { intensive }\end{array}$ & $\begin{array}{c}\text { Low } \\
\text { robot- } \\
\text { intensive }\end{array}$ & $\begin{array}{l}\text { Non- } \\
\text { manufac- } \\
\text { turing }\end{array}$ \\
\hline & {$[1]$} & {$[2]$} & {$[3]$} & {$[4]$} & {$[5]$} & {$[6]$} & {$[7]$} \\
\hline US robot exposure & $\begin{array}{c}-0.220^{* * *} \\
(0.047)\end{array}$ & $\begin{array}{c}0.109 \\
(0.078)\end{array}$ & $\begin{array}{c}-0.562^{* * *} \\
(0.094)\end{array}$ & $\begin{array}{c}0.002 \\
(0.062)\end{array}$ & $\begin{array}{c}-0.476^{* * *} \\
(0.096)\end{array}$ & $\begin{array}{l}-0.046 \\
(0.034)\end{array}$ & $\begin{array}{c}-0.099 \\
(0.160)\end{array}$ \\
\hline Observations & 2166 & 2166 & 2166 & 2166 & 2166 & 2166 & 2166 \\
\hline Covariates: & $\checkmark$ & $\checkmark$ & $\checkmark$ & $\checkmark$ & $\checkmark$ & $\checkmark$ & $\checkmark$ \\
\hline
\end{tabular}

Note: This table presents IV estimates of the effect of US robot exposure on the change in the race and ethnicity employment gap and the gender employment gap by industry and occupation group at the CZ level. Occupation groups are computed from a median split of the standardized measures of the brawn and brain task content of jobs. Skill-intensive jobs include occupations that are both brawn and brain task intensive. White-collar jobs include occupations that are brain task intensive and require only few brawn skills. Blue-collar jobs include occupations that are brawn task intensive and require only few brain skills. Lowskill jobs include occupations that do not require particular brawn or brain skills. Industry groups are created according to the relative adoption of industrial robots of industries. High robot-intensive manufacturing industries include the industries with the heaviest adoption of industrial robots. Low robot-intensive manufacturing industries include the remaining manufacturing industries, while non-manufacturing industries include all industries outside of the manufacturing sector. Changes are expressed in percentage points of the working-age population subgroup and are multiplied by 100. Independent variables are standardized to have mean zero and standard deviation of one. There are three time periods and 722 CZs. All columns include state fixed effects and time-varying division fixed effects and control for the adoption of personal computers, IT capital intensity, the exposure to Chinese imports, the demographic (share of individuals aged between 25 and 34 years, 35 and 44 years, 45 and 54 years, the share of Blacks, Hispanics, women and individuals with less than a college degree and logarithmic population), industry (share of employment in the contruction, manufacturing, mining, research, service and utilities sector) and occupation (share of employment in routine, offshorable, skill-intensive, white-collar, blue-collar and low-skill occupations) characteristics of CZs, as well as the employment composition by race, ethnicity and gender within occupation and industry groups in 1990. Standard errors are robust against heteroskedasticity and allow for clustering at the state level. Regressions are weighted by CZ population in 1990. Coefficients with ${ }^{* * *},{ }^{* *}$ and ${ }^{*}$ are significant at the $1 \%, 5 \%$ and $10 \%$ confidence level. 


\section{Online Appendix: \\ From Blue to Steel-Collar Jobs: \\ The Decline in Employment Gaps? \\ Benjamin Lerch}

\section{A1 Proofs of propositions}

In this part of the Appendix, I provide proofs and further results of the equilibrium labor market impact of robots on the demand for human skills and the employment gaps.

The model presents a basic production function which combines labor (brawn labor, $L_{A}$, and brain labor, $L_{B}$ ) and robot capital, $R$, to produce an output good $Y$ (see Equation 3.1). The perfectly competitive environment implies that input factors are paid their marginal productivity (see Equations 3.2 and 3.3). Robot capital is produced and competitively supplied each period using the following technology, $R_{t}=Y_{R, t} \frac{e^{\delta t}}{\theta}$, where $Y_{R, t}$ is the amount of the final output allocated to produce robots and $e^{\delta(t-1)}$ is the total factor productivity (Autor and Dorn, 2013). That is, firms can sell their output good $Y$ at the normalized price of 1 or they can invest a share of their production, $Y_{R, t}$, in the production of robot capital at price $p_{t}$ :

$$
\pi_{t}=Y_{R, t}-p_{t} R_{t}
$$

Taking the first order condition of Equation A1.1 with respect to $Y_{R, t}$ gives:

$$
\frac{\partial \pi_{t}}{\partial Y_{R, t}}=1-p_{t} \frac{e^{\delta t}}{\theta}=0
$$

which solves $p_{t}=\theta e^{-\delta t}$.

Labor is supplied by a unit continuum of individuals who are endowed with independently and identically distributed skills on two input tasks, $f\left(x_{A, i}, x_{B, i}\right)$ with support $x_{j, i} \in\left[\varepsilon_{j}, 1+\varepsilon_{j}\right]$, where $j=\{A, B\}$ and $\varepsilon_{A} \geq 0$ and $\varepsilon_{B}=0$. Workers want to maximize their income and may supply labor by choosing between brawn labor, brain labor or any convex combination of the two, or they may choose not to supply any labor and consume one unit of leisure. These assumptions imply that workers choose tasks according to their comparative advantage, given their skills and equilibrium wages. The share of individuals who supply labor is determined by Equations 3.5 and 3.6, while the share of individuals who is not employed is given by Equation 3.7. Labor supplies are determined by Equations 3.8 and 3.9. In equilibrium, wages adjust such that labor demand and labor supply are equal.

According to Proposition 1, the comparative advantage of men in brawn skills implies that they 
are employed more often in brawn labor and that women opt more often for non-employment. Analogously, Proposition 2 claims that whites are employed more often in brain labor, given their comparative advantage in brain skills, and that racial and ethnic minorities opt more often for nonemployment. Consequently, the gender employment gap and the race and ethnicity employment gap are both positive.

I prove these propositions by supposing that the labor force consists of two types of individuals in equal proportions, let's say men, $M$, and women, $W$, and that men have a comparative advantage in brawn skills, $\varepsilon_{A}^{M}>0$ and $\varepsilon_{A}^{W}=0$. The comparative advantage implies that in equilibrium the employment gap in brawn labor is positive:

$$
E G_{A}^{(M, W)}=N_{A}^{M}-N_{A}^{W}=\int_{0}^{\varepsilon_{A}} \int_{0}^{x_{B, i}^{*}} f\left(x_{A, i}, x_{B, i}\right) d x_{B, i} d x_{A, i}>0
$$

i.e. men are employed more often in brawn task-intensive jobs than women. The gender employment gap, expressed as the difference between the employment rate of men and the employment rate of women, can be computed using gender-specific forms of Equation 3.7:

$$
E G^{(M, W)}=\left(1-N_{N}^{M}\right)-\left(1-N_{N}^{W}\right)=\int_{0}^{\varepsilon_{A}^{M}} \int_{0}^{\bar{x}_{B}} f\left(x_{A, i}, x_{B, i}\right) d x_{B, i} d x_{A, i}>0
$$

The positive sign of this expression suggests that the employment rate of men is higher than the employment rate of women.

To compute the employment gap by race and ethnicity the assumption on the comparative advantage of racial and ethnic minorities in brawn skills has to be changed to $\varepsilon_{B}^{N W}<0$ and $\varepsilon_{A}^{g}=\varepsilon_{B}^{W H}=0$ with $g \in\{W H, N W\}$. The employment rates are given by the following equations:

$$
\begin{gathered}
N_{A}=\int_{\bar{x}_{A}}^{1} \int_{\varepsilon_{B}}^{x_{B, i}^{*}} f\left(x_{A, i}, x_{B, i}\right) d x_{B, i} d x_{A, i} \\
N_{B}=\int_{0}^{\bar{x}_{A}} \int_{\bar{x}_{B}}^{1+\varepsilon_{B}} f\left(x_{A, i}, x_{B, i}\right) d x_{B, i} d x_{A, i}+\int_{\bar{x}_{A}}^{1} \int_{x_{B, i}^{*}}^{1+\varepsilon_{B}} f\left(x_{A, i}, x_{B, i}\right) d x_{B, i} d x_{A, i}
\end{gathered}
$$

The comparative advantage of whites in brain skills implies that a higher proportion of them supplies brain labor in equilibrium:

$$
E G_{B}^{(W H, N W)}=N_{B}^{W H}-N_{B}^{N W}=\int_{0}^{1} \int_{\varepsilon_{B}}^{0} f\left(x_{A, i}, x_{B, i}\right) d x_{B, i} d x_{A, i}>0
$$

The supply of brawn and brain labor is computed analogously to Equations 3.8 and 3.9. The proportion of workers who are not employed is equal to:

$$
N_{N}=\int_{0}^{\bar{x}_{A}} \int_{\varepsilon_{B}}^{\bar{x}_{B}} f\left(x_{A, i}, x_{B, i}\right) d x_{B, i} d x_{A, i}
$$


Using Equation A1.8, the computation of the race and ethnicity employment gap is straightforward:

$$
E G^{(W H, N W)}=\left(1-N_{N}^{W H}\right)-\left(1-N_{N}^{N W}\right)=\int_{0}^{\bar{x}_{A}} \int_{\varepsilon_{B}^{N W}}^{0} f\left(x_{A, i}, x_{B, i}\right) d x_{B, i} d x_{A, i}>0
$$

As stated in Proposition 1, Equations A1.3 and A1.4 show that the comparative advantage of men in brawn skills implies that in equilibrium they are employed more often in brawn labor and that the gender employment gap is positive. Moreover, Equations A1.7 and A1.9 show that the comparative advantage of whites in brain skills implies that they are employed more often in brain labor and that the race and ethnicity employment gap is positive too, confirming the statement of Proposition 2 .

From Equation A1.2, we know that the price of robots decreases over time due to exogenous technological progress, raising the amount of robot capital adopted in the production of output good $Y$. An increase in the adoption of robots has adverse effects on the demand for labor and, through changes in wages, also on the labor supply. In the following, I provide the relevant proofs of Propositions 3 and 4 which state that an increase in robot capital decreases the gender employment gap and increases the race and ethnicity employment gap. To understand the underlying mechanism through which the adoption of robots influences the equilibrium amounts of labor in the economy, I compute the components of the following equations, which show the partial derivatives of brawn and brain labor with respect to the price of robots:

$$
\begin{aligned}
& \frac{\partial L_{A}}{\partial p}=\frac{\partial L_{A}}{\partial \omega_{A}} \frac{\partial \omega_{A}}{\partial p}+\frac{\partial L_{A}}{\partial \omega_{B}} \frac{\partial \omega_{B}}{\partial p} \\
& \frac{\partial L_{B}}{\partial p}=\frac{\partial L_{B}}{\partial \omega_{A}} \frac{\partial \omega_{A}}{\partial p}+\frac{\partial L_{B}}{\partial \omega_{B}} \frac{\partial \omega_{B}}{\partial p}
\end{aligned}
$$

I start with the computation of the partial derivatives of $L_{A}$ and $L_{B}$ with respect to labor wages:

$$
\begin{aligned}
\frac{\partial L_{A}}{\partial \omega_{A}}= & -\left[\frac{\partial}{\partial \bar{x}_{A}} \int_{\bar{x}_{A}}^{1+\varepsilon_{A}}\left(\int_{0}^{x_{B, i}^{*}} x_{A, i} f\left(x_{A, i}, x_{B, i}\right) d x_{B, i}\right) d x_{A, i}\right] \frac{\bar{x}_{A}}{\omega_{A}}+ \\
& +\int_{\bar{x}_{A}}^{1+\varepsilon_{A}}\left(x_{A, i}\right)^{2} f\left(x_{A, i}, \bar{\omega} x_{A, i}\right) \frac{1}{\omega_{B}} d x_{A, i}>0
\end{aligned}
$$

where $\bar{\omega}=\frac{\omega_{A}}{\omega_{B}}$ such that $x_{B, i}^{*}=\bar{\omega} x_{A, i}$.

$$
\frac{\partial L_{A}}{\partial \omega_{B}}=-\int_{\bar{x}_{A}}^{1+\varepsilon_{A}}\left(x_{A, i}\right)^{2} f\left(x_{A, i}, \bar{\omega} x_{A, i}\right) \frac{\bar{\omega}}{\omega_{B}} d x_{A, i}<0
$$




$$
\begin{aligned}
\frac{\partial L_{B}}{\partial \omega_{A}}= & -\int_{\bar{x}_{B}}^{1} x_{B, i} f\left(\bar{x}_{A}, x_{B, i}\right) \frac{\bar{x}_{A}}{\omega_{A}} d x_{B, i}- \\
& -\left[\frac{\partial}{\partial \bar{x}_{A}} \int_{\bar{x}_{A}}^{1+\varepsilon_{A}}\left(\int_{x_{B, i}^{*}}^{1} x_{B, i} f\left(x_{A, i} x_{B, i}\right) d x_{B, i}\right) d x_{A, i}\right] \frac{\bar{x}_{A}}{\omega_{A}}- \\
& -\int_{\bar{x}_{A}}^{1+\varepsilon_{A}}\left(x_{A, i}\right)^{2} f\left(x_{A, i}, \bar{\omega} x_{A, i}\right) \frac{\bar{\omega}}{\omega_{B}} d x_{A, i}<0
\end{aligned}
$$

since the positive term in the second line of Equation A1.14 is outweighed by the other terms.

$$
\begin{aligned}
\frac{\partial L_{B}}{\partial \omega_{B}} & =\int_{\varepsilon_{A}}^{\bar{x}_{A}} f\left(x_{A, i}, \bar{x}_{B}\right) \frac{\left(\bar{x}_{B}\right)^{2}}{\omega_{B}} d x_{A, i}+ \\
& +\int_{\bar{x}_{A}}^{1+\varepsilon_{A}}\left(x_{A, i}\right)^{2} f\left(x_{A, i} \bar{\omega} x_{A, i}\right) \frac{\bar{\omega}^{2}}{\omega_{B}} d x_{A, i}>0
\end{aligned}
$$

These equations show that the supply of brawn (brain) labor increases as brawn (brain) wages increase and decreases if brain (brawn) wages increase. Next, I compute the change in equilibrium wages in response to an increase in the price of robots. Taking total differentials of Equations 3.2 and 3.3, I obtain that:

$$
\begin{gathered}
\frac{\partial \omega_{A}}{\partial p}=-\frac{\left(\frac{\beta}{\rho}-1\right) \rho R^{\rho-1} L_{B}}{\left(R^{\rho}+L_{A}^{\rho}\right)\left[\left(\frac{\beta}{\rho}-1\right) \frac{\rho L_{A}^{\rho-1} L_{B}}{R^{\rho}+L_{A}^{\rho}} \frac{\partial L_{A}}{\partial \omega_{A}}+(\rho-1) \frac{L_{B}}{L_{A}} \frac{\partial L_{A}}{\partial \omega_{A}}+(1-\beta) \frac{\partial L_{B}}{\partial \omega_{A}}-\frac{L_{B}}{\omega_{A}}\right]} \frac{\partial R}{\partial p}>0 \\
\frac{\partial \omega_{B}}{\partial p}=-\frac{\beta R^{\rho-1}}{\left(R^{\rho}+L_{A}^{\rho}\right)\left[\frac{\beta L_{A}^{\rho-1}}{R^{\rho}+L_{A}^{\rho}} \frac{\partial L_{A}}{\partial \omega_{B}}-\frac{\beta}{L_{B}} \frac{\partial L_{B}}{\partial \omega_{B}}-\frac{1}{\omega_{B}}\right]} \frac{\partial R}{\partial p}<0
\end{gathered}
$$

because of $0<\beta<\rho<1, \frac{\partial R}{\partial p}<0$ and Equations A1.12 to A1.15. Inserting Equations A1.12 to A1.17 in Equations A1.10 and A1.11 already shows that, as the price of robots falls, equilibrium brawn labor decreases and equilibrium brain labor increases:

$$
\begin{aligned}
\frac{\partial L_{A}}{\partial p}= & -\left[\frac{\partial}{\partial \bar{x}_{A}} \int_{\bar{x}_{A}}^{1+\varepsilon_{A}}\left(\int_{0}^{x_{B, i}^{*}} x_{A, i} f\left(x_{A, i}, x_{B, i}\right) d x_{B, i}\right) d x_{A, i}\right] \frac{\bar{x}_{A}}{\omega_{A}} \frac{\partial \omega_{A}}{\partial p}+ \\
& +\int_{\bar{x}_{A}}^{1+\varepsilon_{A}}\left(x_{A, i}\right)^{2} f\left(x_{A, i}, \bar{\omega} x_{A, i}\right) \frac{1}{\omega_{B}}\left[\frac{\partial \omega_{A}}{\partial p}-\bar{\omega} \frac{\partial \omega_{B}}{\partial p}\right] d x_{A, i}>0
\end{aligned}
$$




$$
\begin{aligned}
\frac{\partial L_{B}}{\partial p} & =\int_{\varepsilon_{A}}^{\bar{x}_{A}} f\left(x_{A, i}, \bar{x}_{B}\right) \frac{\left(\bar{x}_{B}\right)^{2}}{\omega_{B}} \frac{\partial \omega_{B}}{\partial p} d x_{A, i}- \\
& -\int_{\bar{x}_{B}}^{1} x_{B, i} f\left(\bar{x}_{A}, x_{B, i}\right) \frac{\bar{x}_{A}}{\omega_{A}} \frac{\partial \omega_{A}}{\partial p} d x_{B, i}- \\
& -\int_{\bar{x}_{A}}^{1+\varepsilon_{A}}\left(x_{A, i}\right)^{2} f\left(x_{A, i}, \bar{\omega} x_{A, i}\right) \frac{\bar{\omega}}{\omega_{B}}\left[\frac{\partial \omega_{A}}{\partial p}-\bar{\omega} \frac{\partial \omega_{B}}{\partial p}\right] d x_{A, i}- \\
& -\left[\frac{\partial}{\partial \bar{x}_{A}} \int_{\bar{x}_{A}}^{1+\varepsilon_{A}}\left(\int_{x_{B, i}^{*}}^{1} x_{B, i} f\left(x_{A, i}, x_{B, i}\right) d x_{B, i}\right) d x_{A, i}\right] \frac{\bar{x}_{A}}{\omega_{A}} \frac{\partial \omega_{A}}{\partial p}<0
\end{aligned}
$$

since the positive term in the fourth line of Equation A1.19 is outweighed by the other terms. This result follows from the fact that there is a more than offsetting increase in the demand for manual tasks in the form of robot capital (since it becomes relatively cheaper) which increases the productivity of brain labor (and therefore the respective wages), raising its equilibrium level.

Following the procedure outlined above, I can show that the share of workers who supply brawn labor decreases. These workers are either reallocating their labor supply towards brain labor, as the relative wage $\frac{\omega_{B}}{\omega_{A}}$ increases, or they opt for non-employment, since also $\frac{\omega_{N}}{\omega_{A}}$ increases.

$$
\begin{aligned}
\frac{\partial N_{A}}{\partial p}= & -\left[\frac{\partial}{\partial \bar{x}_{A}} \int_{\bar{x}_{A}}^{1+\varepsilon_{A}}\left(\int_{0}^{x_{B, i}^{*}} f\left(x_{A, i}, x_{B, i}\right) d x_{B, i}\right) d x_{A, i}\right] \frac{\bar{x}_{A}}{\omega_{A}} \frac{\partial \omega_{A}}{\partial p}+ \\
& +\int_{\bar{x}_{A}}^{1+\varepsilon_{A}} x_{A, i} f\left(x_{A, i}, \bar{\omega} x_{A, i}\right) \frac{1}{\omega_{B}}\left[\frac{\partial \omega_{A}}{\partial p}-\bar{\omega} \frac{\partial \omega_{B}}{\partial p}\right] d x_{A, i}>0
\end{aligned}
$$

The share of brain workers increases, since a fraction of workers previously employed in brawn labor reallocates towards brain task-intensive jobs (see previous equation) and some non-employed individuals enter the labor force offering brain labor, since $\frac{\omega_{N}}{\omega_{B}}$ decreases.

$$
\begin{aligned}
\frac{\partial N_{B}}{\partial p} & =\int_{\varepsilon_{A}}^{\bar{x}_{A}} f\left(x_{A, i}, \bar{x}_{B}\right) \frac{\bar{x}_{B}}{\omega_{B}} \frac{\partial \omega_{B}}{\partial p} d x_{A, i}- \\
& -\int_{\bar{x}_{B}}^{1} f\left(\bar{x}_{A}, x_{B, i}\right) \frac{\bar{x}_{A}}{\omega_{A}} \frac{\partial \omega_{A}}{\partial p} d x_{B, i}- \\
& -\int_{\bar{x}_{A}}^{1+\varepsilon_{A}} x_{A, i} f\left(x_{A, i}, \bar{\omega} x_{A, i}\right) \frac{1}{\omega_{B}}\left[\frac{\partial \omega_{A}}{\partial p}-\bar{\omega} \frac{\partial \omega_{B}}{\partial p}\right] d x_{A, i}- \\
& -\left[\frac{\partial}{\partial \bar{x}_{A}} \int_{\bar{x}_{A}}^{1+\varepsilon_{A}}\left(\int_{x_{B, i}^{*}}^{1} f\left(x_{A, i}, x_{B, i}\right) d x_{B, i}\right) d x_{A, i}\right] \frac{\bar{x}_{A}}{\omega_{A}} \frac{\partial \omega_{A}}{\partial p}<0
\end{aligned}
$$


since the positive term in the fourth line of Equation A1.21 is outweighed by the other terms. ${ }^{34}$ Altogether, robots could increase or decrease aggregate employment depending on whether the displacement effect or the productivity effect prevails:

$$
\begin{aligned}
\frac{\partial N_{N}}{\partial p}= & -\int_{0}^{\bar{x}_{B}} f\left(\bar{x}_{A}, x_{B, i}\right) \frac{\bar{x}_{A}}{\omega_{A}} \frac{\partial \omega_{A}}{\partial p} d x_{B, i}- \\
& -\int_{\varepsilon_{A}}^{\bar{x}_{A}} f\left(x_{A, i}, \bar{x}_{B}\right) \frac{\bar{x}_{B}}{\omega_{B}} \frac{\partial \omega_{B}}{\partial p} d x_{A, i} \lessgtr 0
\end{aligned}
$$

or simply:

$$
\frac{\partial N_{N}}{\partial p}=1-\frac{\partial N_{A}}{\partial p}-\frac{\partial N_{B}}{\partial p} \lessgtr 0
$$

Despite the ambiguous effect of robot adoption on employment, robots clearly reduce the gender employment gap:

$$
\frac{\partial E G^{(M, W)}}{\partial p}=-\int_{0}^{\varepsilon_{A}^{M}} f\left(x_{A, i}, \bar{x}_{B}\right) \frac{\bar{x}_{B}}{\omega_{B}} \frac{\partial \omega_{B}}{\partial p} d x_{A, i}>0
$$

Analogously, using Equation A1.9, I can show that the adoption of robots is widening the race and ethnicity employment gap:

$$
\frac{\partial E G^{(W H, N W)}}{\partial p}=-\int_{\varepsilon_{B}^{N W}}^{0} f\left(\bar{x}_{A}, x_{B, i}\right) \frac{\bar{x}_{A}}{\omega_{A}} \frac{\partial \omega_{A}}{\partial p} d x_{B, i}<0 .
$$

These results emerge from one of three scenarios. First, robots reduce male (non-white) employment more than female (white) employment. Second, robots increase male (non-white) employment less than female (white) employment. Third, robots reduce male (non-white) employment and increase female (white) employment. One could investigate which case occurs theoretically by assuming a closed form solution for the skill distribution, $f\left(x_{A, i}, x_{B, i}\right)$, as well as values for the exogenous parameters $\omega_{N}, \rho, \beta$ and $\varepsilon_{j}^{g}$ with $j \in\{A, B\}$ and $g \in\{(M, W),(W H, N W)\}$.

As stated in Propositions 3 and 4, Equations A1.24 and A1.25 show that an increase in the adoption of robots in the production of output $Y$ decreases the gender employment gap and increases the race and ethnicity employment gap.

These findings come along with a decrease (increase) in the gender (race and ethnicity) employment

${ }^{34}$ This result is visible from changes in the areas of the shapes in Figure 5 , where the share of brain workers, $N_{B}$, is formed by a rectangle and a trapezoid. The shift of $\bar{x}_{A}$ to the left decreases the rectangle (second term) and at the same time increases the trapezoid (fourth term), without affecting the area of $N_{B}$. This, however, is going to change with shifts in $x_{B, i}^{*}$ and $\bar{x}_{B}$. 
gap in brawn labor as robot capital increases:

$$
\begin{gathered}
\frac{\partial E G_{A}^{(M, W)}}{\partial p}=\int_{0}^{\varepsilon_{A}^{M}} x_{A, i} f\left(x_{A, i}, \bar{\omega} x_{A, i}\right) \frac{1}{\omega_{B}}\left[\frac{\partial \omega_{A}}{\partial p}-\bar{\omega} \frac{\partial \omega_{B}}{\partial p}\right] d x_{A, i}>0 \\
\frac{\partial E G_{A}^{(W H, N W)}}{\partial p}=-\int_{\varepsilon_{B}^{N W}}^{0} f\left(\bar{x}_{A}, x_{B, i}\right) \frac{\bar{x}_{A}}{\omega_{A}} \frac{\partial \omega_{A}}{\partial p} d x_{A, i}<0
\end{gathered}
$$

where $E G_{A}^{(M, W)}=N_{A}^{M}-N_{A}^{W}$. Conversely, the adoption of robots generates an ambiguous effect on the gender employment gap in brain labor:

$$
\begin{aligned}
\frac{\partial E G_{B}^{(M, W)}}{\partial p}= & -\int_{0}^{\varepsilon_{A}^{M}} f\left(x_{A, i}, \bar{x}_{B}\right) \frac{\bar{x}_{B}}{\omega_{B}} \frac{\partial \omega_{B}}{\partial p} d x_{A, i}- \\
& -\int_{0}^{\varepsilon_{A}^{M}} x_{A, i} f\left(x_{A, i}, \bar{\omega} x_{A, i}\right) \frac{1}{\omega_{B}}\left[\frac{\partial \omega_{A}}{\partial p}-\bar{\omega} \frac{\partial \omega_{B}}{\partial p}\right] d x_{A, i} \lessgtr 0
\end{aligned}
$$

where $E G_{B}^{(M, W)}=N_{B}^{M}-N_{B}^{W}$ and does not influence the race and ethnicity employment gap in brain labor (see Equation A1.7):

$$
\frac{\partial E G_{B}^{(W H, N W)}}{\partial p}=0
$$

\section{Example using a uniform skill distribution}

I provide an illustrative example of the impact of robots on the employment gaps using a uniform skill distribution, $f\left(x_{A, i}, x_{B, i}\right)=1$. The shares of workers (Equations 3.5 and 3.6 in the main text) and of non-employed individuals (Equation 3.7) simplify to:

$$
\begin{gathered}
N_{A}=\frac{1}{2} \bar{\omega}\left[\left(1+\varepsilon_{A}\right)^{2}-\left(\bar{x}_{A}\right)^{2}\right] \\
N_{B}=1-\bar{x}_{B}\left(\bar{x}_{A}-\varepsilon_{A}\right)-\frac{1}{2} \bar{\omega}\left[\left(1+\varepsilon_{A}\right)^{2}-\left(\bar{x}_{A}\right)^{2}\right] \\
N_{N}=\bar{x}_{B}\left(\bar{x}_{A}-\varepsilon_{A}\right)
\end{gathered}
$$

with $\varepsilon_{A}<\bar{x}_{A}$ and $\omega_{B}>\omega_{N}+\frac{1}{2} \omega_{A}$ to ensure that $N_{B}>0$ and $N_{N}>0$. Using Equation A1.32, we can again compute the gender employment gap (Equation 3.10 in the main text):

$$
E G^{(M, W)}=N_{N}^{W}-N_{N}^{M}=\varepsilon_{A}^{M} \bar{x}_{B}>0
$$


Analogously, the employment rates of whites and non-whites are equal to $1-\bar{x}_{A}\left(\bar{x}_{B}-\varepsilon_{B}\right)$ and the race and ethnicity employment gap is given by:

$$
E G^{(W H, N W)}=-\varepsilon_{B}^{N W} \bar{x}_{A}>0
$$

where $\varepsilon_{B}=0$ for whites and $\varepsilon_{B}<0$ for non-whites.

To calculate the effect of the adoption of robots on employment I need to define again all components of Equations A1.10 and A1.11. Let's start with the computation of the brawn and brain labor supply (Equations 3.8 and 3.9):

$$
\begin{gathered}
L_{A}=\frac{1}{3} \bar{\omega}\left[\left(1+\varepsilon_{A}\right)^{3}-\left(\bar{x}_{A}\right)^{3}\right] \\
L_{B}=\frac{1}{2}\left[1-\left(\bar{x}_{A}-\varepsilon_{A}\right)\left(\bar{x}_{B}\right)^{2}-\frac{1}{3} \bar{\omega}^{2}\left[\left(1+\varepsilon_{A}\right)^{3}-\left(\bar{x}_{A}\right)^{3}\right]\right]
\end{gathered}
$$

Next, I take first derivatives of the labor supplies with respect to wages (as in Equations A1.12 to A1.15):

$$
\begin{gathered}
\frac{\partial L_{A}}{\partial \omega_{A}}=\frac{1}{3 \omega_{B}}\left[\left(1+\varepsilon_{A}\right)^{3}+2\left(\bar{x}_{A}\right)^{3}\right]>0 \\
\frac{\partial L_{A}}{\partial \omega_{B}}=-\frac{1}{3} \frac{\bar{\omega}}{\omega_{B}}\left[\left(1+\varepsilon_{A}\right)^{3}-\left(\bar{x}_{A}\right)^{3}\right]<0 \\
\frac{\partial L_{B}}{\partial \omega_{A}}=\frac{1}{2}\left[\frac{\bar{x}_{A}\left(\bar{x}_{B}\right)^{2}}{\omega_{A}}-\frac{1}{3} \frac{\bar{\omega}}{\omega_{B}}\left[2\left(1+\varepsilon_{A}\right)^{3}+\left(\bar{x}_{A}\right)^{3}\right]\right]<0 \\
\frac{\partial L_{B}}{\partial \omega_{B}}=\left[\frac{\left(\bar{x}_{B}\right)^{2}}{\omega_{B}}\left(\bar{x}_{A}-\varepsilon_{A}\right)+\frac{1}{3} \frac{\bar{\omega}^{2}}{\omega_{B}}\left[\left(1+\varepsilon_{A}\right)^{3}-\left(\bar{x}_{A}\right)^{3}\right]\right]>0
\end{gathered}
$$

where Equations A1.38 and A1.40 hold since $\varepsilon_{A}<\bar{x}_{A}$ and Equation A1.39 holds since $\omega_{A}>\omega_{N}$. The partial derivatives of wages with respect to the price of robot capital are the same as in Equations A1.16 and A1.17, since they depend on the distribution of skills only through Equations A1.37 to A1.40.

With these equations, it is again possible to compute the impact of an exogenous decline in the price of robots on the equilibrium levels of labor and employment:

$$
\frac{\partial L_{A}}{\partial p}=\frac{\partial \omega_{A}}{\partial p}\left[\left(1+\varepsilon_{A}\right)^{3}+2\left(\bar{x}_{A}\right)^{3}\right] \frac{1}{3 \omega_{B}}-\frac{\partial \omega_{B}}{\partial p}\left[\left(1+\varepsilon_{A}\right)^{3}-\left(\bar{x}_{A}\right)^{3}\right] \frac{\bar{\omega}}{3 \omega_{B}}>0
$$




$$
\begin{gathered}
\frac{\partial L_{B}}{\partial p}=\frac{\partial \omega_{A}}{\partial p}\left[\left(\bar{x}_{A}\right)^{2} \bar{x}_{B}-\frac{1}{3} \bar{\omega}\left[2\left(1+\varepsilon_{A}\right)^{3}+\left(\bar{x}_{A}\right)^{3}\right]\right] \frac{1}{2 \omega_{B}}+ \\
+\frac{\partial \omega_{B}}{\partial p}\left[\bar{x}_{B}\left(\bar{x}_{A}-\varepsilon_{A}\right)+\frac{1}{3} \bar{\omega}^{2}\left[\left(1+\varepsilon_{A}\right)^{3}-\left(\bar{x}_{A}\right)^{3}\right]\right] \frac{1}{\omega_{B}}<0 \\
\frac{\partial N_{A}}{\partial p}=\frac{\partial \omega_{A}}{\partial p}\left[\left(1+\varepsilon_{A}\right)^{2}+\left(\bar{x}_{A}\right)^{2}\right] \frac{1}{2 \omega_{B}}-\frac{\partial \omega_{B}}{\partial p}\left[\left(1+\varepsilon_{A}\right)^{2}-\left(\bar{x}_{A}\right)^{2}\right] \frac{\bar{\omega}}{2 \omega_{B}}>0 \\
\frac{\partial N_{B}}{\partial p}=-\frac{\partial \omega_{A}}{\partial p}\left[\left(1+\varepsilon_{A}\right)^{2}-\left(\bar{x}_{A}\right)^{2}\right] \frac{1}{2 \omega_{B}}+ \\
+\frac{\partial \omega_{B}}{\partial p}\left[\left(1+\varepsilon_{A}\right)^{2}-\left(\bar{x}_{A}\right)^{2}+2 \frac{\bar{x}_{B}\left(\bar{x}_{A}-\varepsilon_{A}\right)}{\bar{\omega}}\right] \frac{\bar{\omega}}{2 \omega_{B}}<0 \\
\frac{\partial N_{N}}{\partial p}= \\
\frac{\partial \omega_{A}}{\partial p}\left[-\bar{x}_{A} \bar{x}_{B}\right] \frac{1}{\omega_{A}}+\frac{\partial \omega_{B}}{\partial p}\left[\left(-\bar{x}_{A}+\varepsilon_{A}\right) \bar{x}_{B}\right] \frac{1}{\omega_{B}} \lessgtr 0
\end{gathered}
$$

where the signs of the equations hold as long as $\omega_{N}<\omega_{A}$ and $\varepsilon_{A}<\bar{x}_{A}$. Again, an increase in the stock of robots unambiguously reduces the gender employment gap:

$$
\frac{\partial E G^{(M, W)}}{\partial p}=-\varepsilon_{A}^{M} \frac{\bar{x}_{B}}{\omega_{B}} \frac{\partial \omega_{B}}{\partial p}>0
$$

and increases the race and ethnicity employment gap:

$$
\frac{\partial E G^{(W H, N W)}}{\partial p}=\varepsilon_{B}^{N W} \frac{\bar{x}_{A}}{\omega_{A}} \frac{\partial \omega_{A}}{\partial p}<0 .
$$


Figure A1: Average wages in white-collar and blue-collar occupations

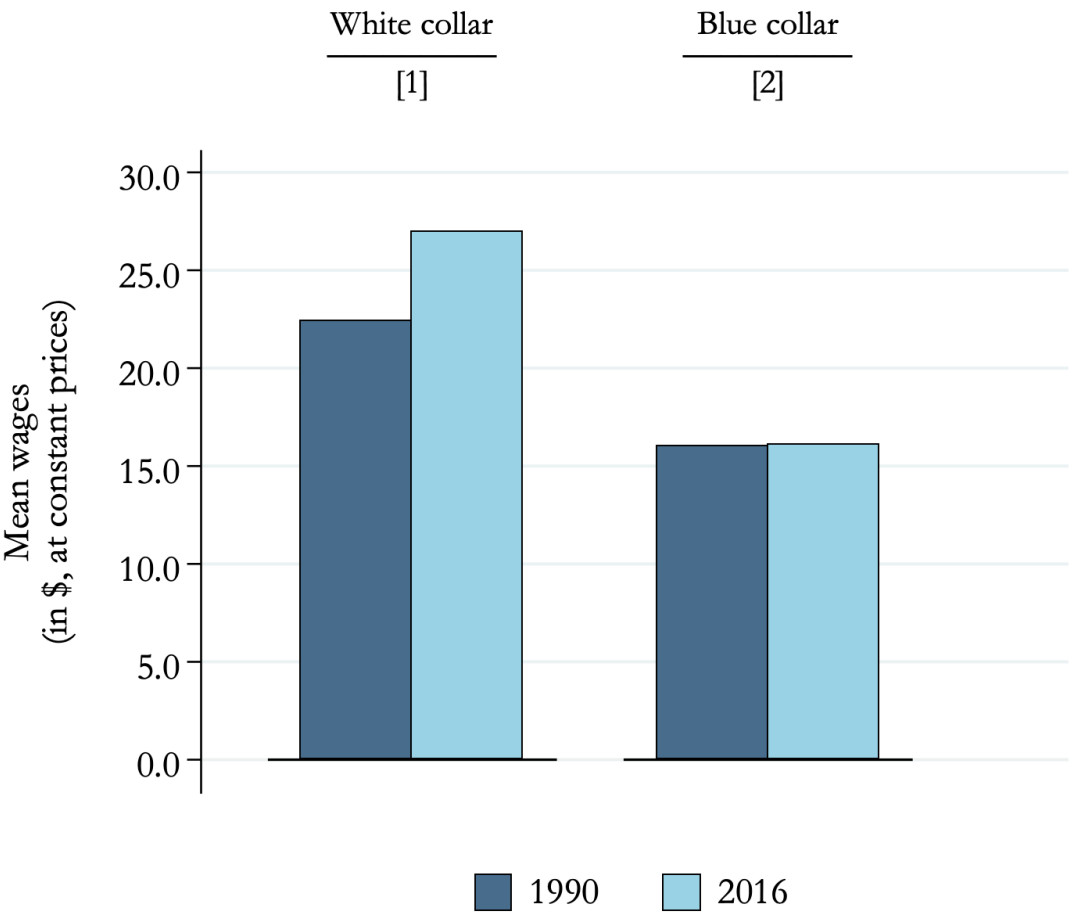

Note: This figure illustrates the average hourly wages in white-collar and blue-collar occupations in 2007 prices. Occupation groups are computed from a median split of the standardized measures of the brawn and brain task content of jobs. White-collar jobs include occupations that are brain task intensive and require only few brawn skills. Blue-collar jobs include occupations that are brawn task intensive and require only few brain skills. 
Figure A2: Robots and employment by race and ethnicity

Panel A: Employment by race and ethnicity

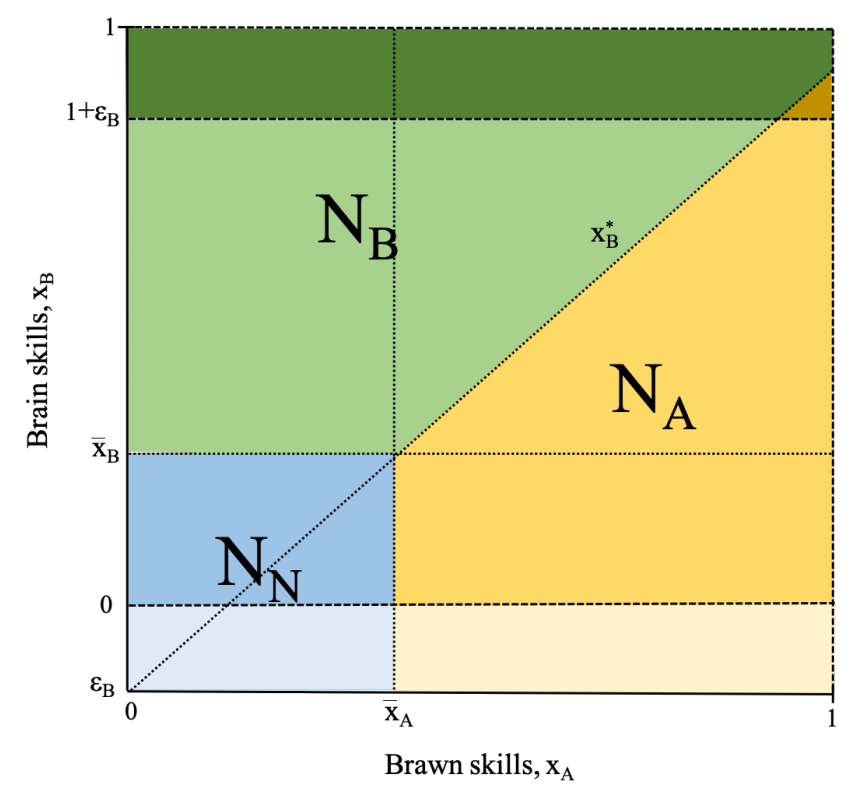

Panel B: Robots and employment

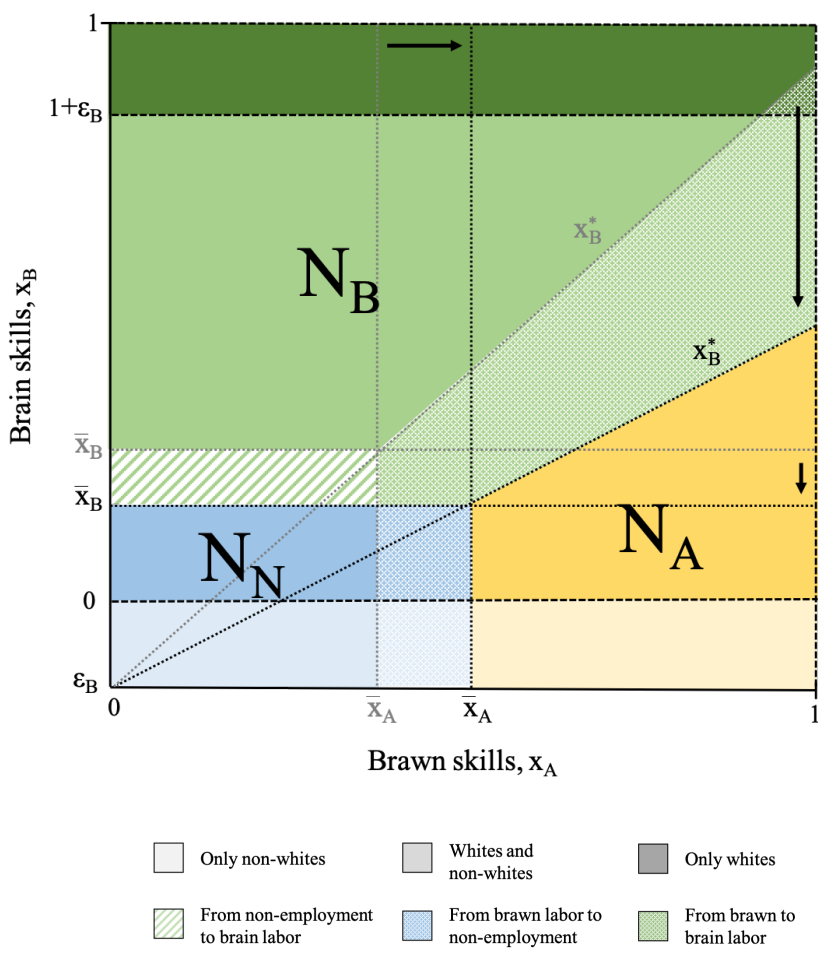

Note: This figure illustrates an economy's population density by employment status and gender in equilibrium, when solving for Equations 3.2, 3.3, 3.8 and 3.9. $N_{A}, N_{B}$ and $N_{N}$ represent the share of individuals that supply brawn labor, brain labor and no labor. $\varepsilon_{A}>0$ is the comparative advantage of men in brawn skills, and $\bar{x}_{A}=\frac{\omega_{N}}{\omega_{A}}, \bar{x}_{B}=\frac{\omega_{N}}{\omega_{B}}$ and $x_{B, i}^{*}=\frac{\omega_{A}}{\omega_{B}} x_{A, i}$. Panel $\mathrm{B}$ illustrates the impact of a decrease in the price of robot capital on relative wages and the equilibrium allocation of labor. 
Figure A3: Robots, elasticity of substitution and the gender employment gap

Wage of brawn labor, $\omega_{A}$

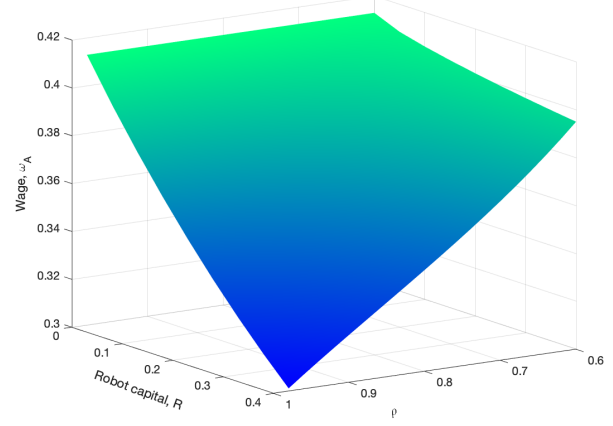

Brawn labor, $L_{A}$

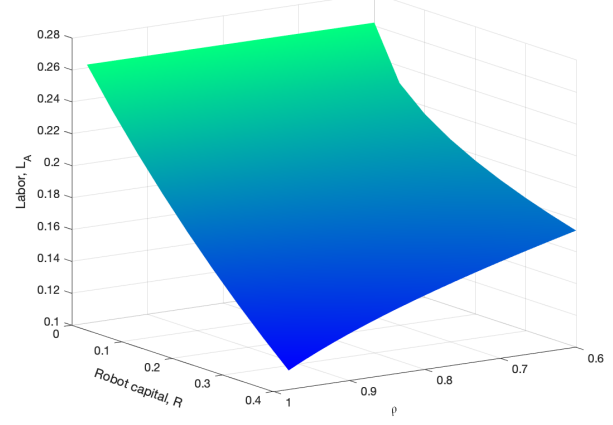

Employment

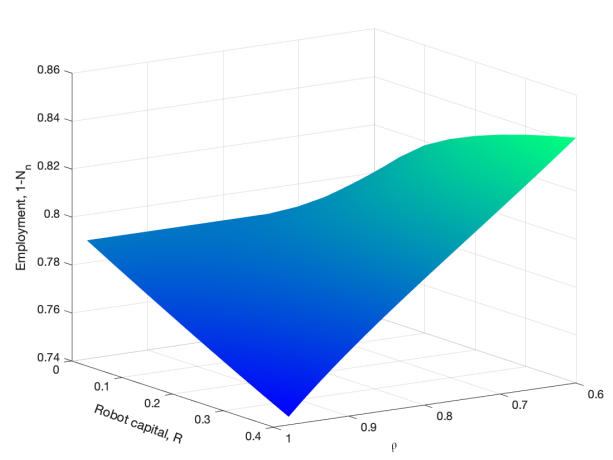

Wage of brain labor, $\omega_{B}$

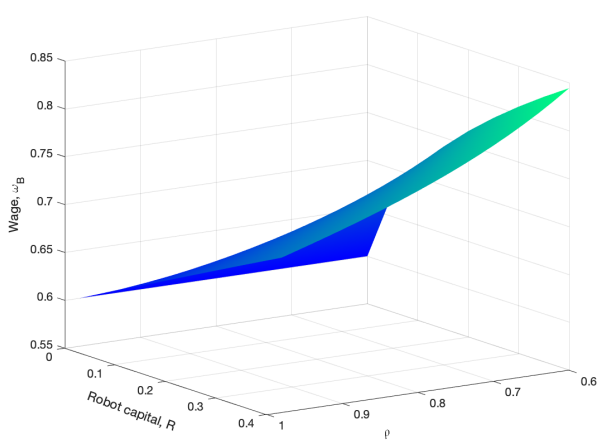

Brain labor, $L_{B}$

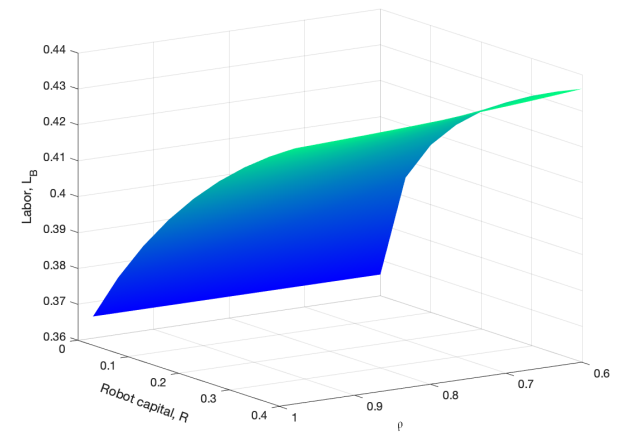

Employment gap, $E G^{(M, W)}$

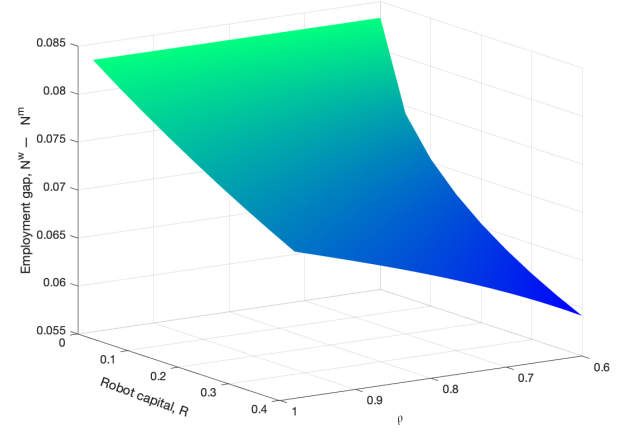

Note: This figure illustrates the impact of changes in $R$ (through changes in $p$ ) and $\rho$ on equilibrium wages, labor, employment rates and gaps by solving for Equations 3.2, 3.3, 3.8 and 3.9. The model is calibrated using a uniform skill distribution with the following parameters: $\beta=0.33$ (based on employment in blue-collar jobs in 1970), $\omega_{N}=0.25, \varepsilon_{A}^{M}=0.2$. 
Figure A4: Robots, elasticity of substitution and employment rates by gender

Brawn employment of women, $N_{A}^{W}$

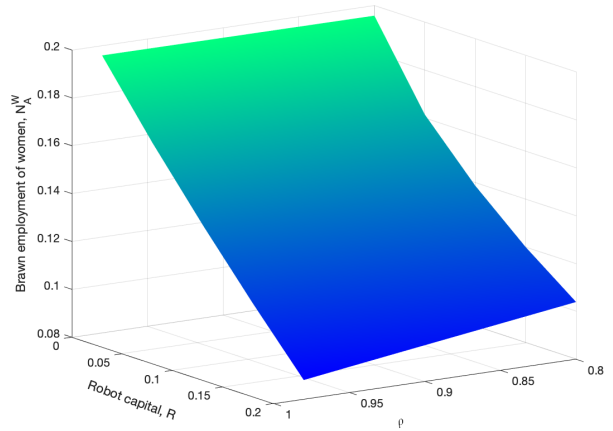

Brain employment of women, $N_{B}^{W}$

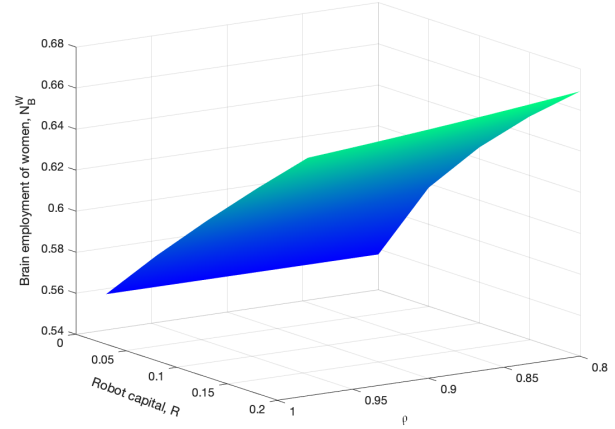

Employment gap, $E G_{A}^{(M, W)}$

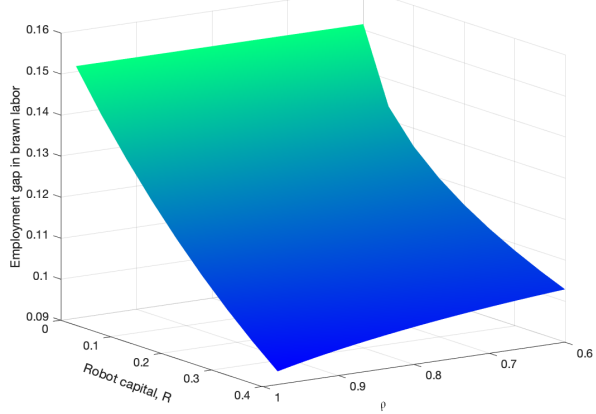

Employment gap, $E G_{B}^{(M, W)}$

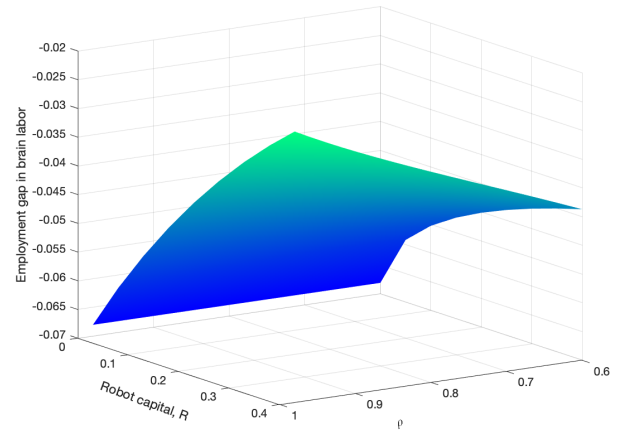

Note: This figure illustrates the impact of changes in $R$ (through changes in $p$ ) and $\rho$ on equilibrium gender-specific employment rates by solving for Equations 3.2, 3.3, 3.8 and 3.9. The model is calibrated using a uniform skill distribution with the following parameters: $\beta=0.33$ (based on employment in blue-collar jobs in 1970), $\omega_{N}=0.25, \varepsilon_{A}^{M}=0.2$. 
Figure A5: Robots, employment and intensity of manual factor inputs

Employment with $\rho=1$

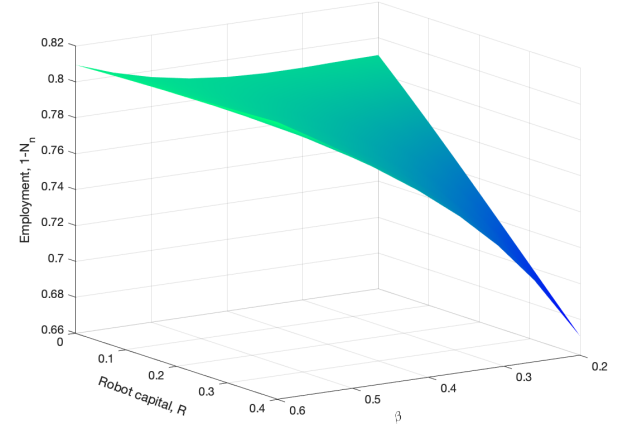

Employment with $\rho=0.6$

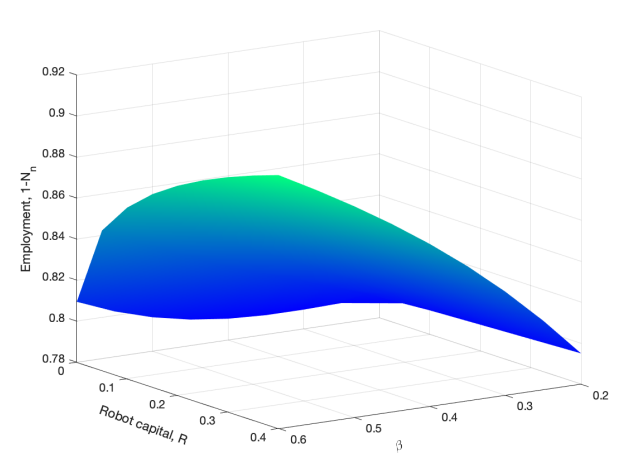

Employment gap with $\rho=1$

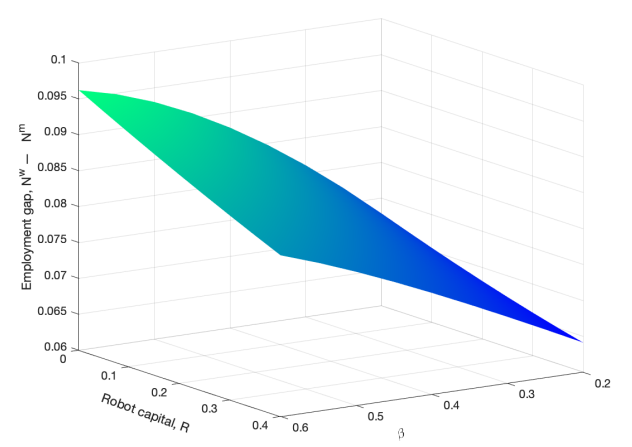

Employment gap with $\rho=0.6$

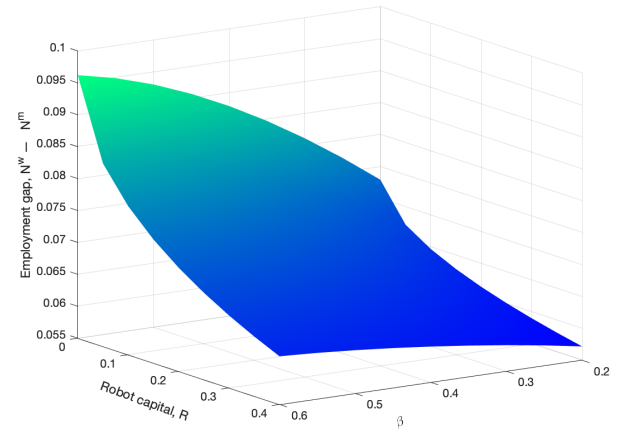

Note: This figure illustrates the impact of changes in $R$ (through changes in $p$ ), $\beta$ and $\rho$ on equilibrium employment rates and gaps by solving for Equations 3.2, 3.3, 3.8 and 3.9. The model is calibrated using a uniform skill distribution with the following parameters: $\omega_{N}=0.25, \varepsilon_{A}^{M}=0.2$. 


\section{A2 Additional data}

\section{A2.1 Import exposure}

China Following Autor et al. (2013), I use a shift-share approach to measure a labor market's exposure to imports from China. I interact CZs' industry employment shares in the manufacturing sector prior to the admission of China to the World Trade Organization in 2001 with the growth in product trade flows from China to the US:

$$
\text { US import exposure } e_{c,\left(t_{0}, t_{1}\right)}=\sum_{j \in J} \ell_{c, j}^{1990} \Delta I M_{j,\left(t_{0}, t_{1}\right)}^{U S}
$$

where $\Delta I M_{j,\left(t_{0}, t_{1}\right)}^{U S}$ is the change in US imports from China in thousand dollars per worker. Analogously to Equation 5.3, I exploit plausibly exogenous variation in the trade shock by instrumenting the shift-component of the measure with trade flows from China to other industrialized countries with a similar trade development as the US:

$$
\text { OT8 import exposure } e_{c,\left(t_{0}, t_{1}\right)}=\sum_{j \in J} \frac{1}{8} \sum_{i \in O T 8} \ell_{c, j}^{1990} \Delta I M_{j,\left(t_{0}, t_{1}\right)}^{i}
$$

where $i \in O T 8$ include Australia, Denmark, Finland, Germany, Japan, New Zealand, Spain, and Switzerland. I keep the baseline employment shares constant to avoid endogeneity and serial correlation concerns.

I collect product-level data at the six-digit Harmonized System (HS) on Chinese imports from the UN Comtrade Database which I match with industry employment shares from the 1991 County Business Pattern (CBP). The CBP classifies industry employment according to the Standard Classification System (SIC) until 1997 and according to the North American Industry Classification System (NAICS) afterwards. These systems are more detailed than the industrial classification system used in the IPUMS. I use crosswalks from Dorn's website to convert SIC and NAICS manufacturing industries and six-digit HS product-level trade data to 392 four-digit SIC industries. I construct the import penetration measure by matching local employment shares with converted product-level trade data on imports from China. For confidentiality reasons, county-industry observations with few cases are reported as ranges. In reconstructing these data, I follow Acemoglu et al. (2016).

Europe I build a measure of international product market competition from Europe using a shift-share approach, as outlined previously. The share component is unchanged and corresponds to $\ell_{c, j}^{1990}$ in Equation A2.1, while the shift-component does not account anymore for imports from China, but includes the change in average trade flows from Denmark, Finland, France, Italy, Spain, Sweden and the United Kingdom to the US. Since US imports could be subject to domestic shocks 
that affect also the local demand for labor (demand shocks), I instrument imports to the US with trade flows from Europe to Canada, an industrialized country with a comparable trade engagement with European countries as the US (see Figure A15), but whose import intensity is less affected by US domestic shocks than the US itself.

\section{A2.2 Non-robot technology shocks}

I account for technology shocks other than industrial robots using Bartik-style measures of the adoption of personal computers and IT capital intensity at the CZ level in 1990. I follow Acemoglu and Restrepo (2020) and construct a measure of baseline computer adoption by interacting the share of employees using a computer in each industry from the 1993 Current Population Survey with CZ baseline employment shares. ${ }^{35}$ Analogously, I construct a measure of IT capital intensity by interacting the 1992 share of IT investments in each industry (available for 4-digit SIC87 manufacturing industries from the American Survey of Manufacturing) with the baseline CZ employment shares.

\section{A2.3 Demographic, occupation and industry controls}

I construct measures of a local labor market's demographics (share of women, Blacks, Hispanics, college-educated individuals, 25-34, 35-44 and 45-54 year old individuals and log-population) and the industrial (construction, education and research, manufacturing, mining, services, and utilities) and occupational (routine, offshorability, skill intensive, white-collar, blue-collar and low skills) composition of employment from the 1990 Census to account for systematic differences across CZs which could influence both the adoption of robots and local labor market outcomes. The measures of routine task intensity and offshorability are build as in Autor and Dorn (2013). Furthermore, I control for the initial composition of employment of women and racial and ethnic minorities in industry (high robot-intensive manufacturing, low-robot intensive manufacturing and non-manufacturing) and occupation (skill intensive, white-collar, blue-collar and low skills) groups. I compute these measures as the number of women (or racial and ethnic minorities) employed in industry or occupation $j$ divided by total employment in $j$.

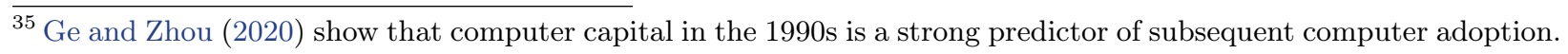


Table A1: Descriptive statistics: Covariates

\begin{tabular}{|c|c|c|c|c|c|}
\hline & \multirow[b]{2}{*}{ All } & \multicolumn{4}{|c|}{$\begin{array}{c}\text { US robot exposure } \\
1993-2014\end{array}$} \\
\hline & & Q1 & Q2 & Q3 & $\mathrm{Q} 4$ \\
\hline & {$[1]$} & {$[2]$} & {$[3]$} & {$[4]$} & {$[5]$} \\
\hline \multicolumn{6}{|l|}{ Pre-trends } \\
\hline Race and ethnicity employment gap & 5.48 & 4.30 & 3.82 & 4.80 & 7.34 \\
\hline Gender employment gap & -24.9 & -24.3 & -24.7 & -23.1 & -26.2 \\
\hline \multicolumn{6}{|l|}{ Non-robot technologies } \\
\hline US import exposure & 4.88 & 2.29 & 4.44 & 5.82 & 7.01 \\
\hline OT8 import exposure & 3.61 & 1.70 & 3.34 & 4.34 & 5.06 \\
\hline \multicolumn{6}{|l|}{ Imports } \\
\hline Computer & 44.8 & 44.5 & 44.8 & 44.2 & 45.3 \\
\hline IT capital & 2.02 & 1.40 & 1.92 & 2.32 & 2.15 \\
\hline \multicolumn{6}{|l|}{ Demographics } \\
\hline Black & 10.9 & 9.33 & 12.1 & 9.82 & 11.5 \\
\hline Hispanic & 7.94 & 15.8 & 7.92 & 10.2 & 3.62 \\
\hline Women & 51.1 & 50.9 & 51.3 & 50.7 & 51.4 \\
\hline Less educated & 77.1 & 76.6 & 75.4 & 77.7 & 78.0 \\
\hline Log population & 13.3 & 12.8 & 13.4 & 13.4 & 13.4 \\
\hline $25-34$ years & 33.9 & 34.1 & 34.2 & 34.5 & 33.2 \\
\hline $35-44$ years & 29.4 & 29.4 & 29.7 & 29.5 & 29.3 \\
\hline $45-54$ years & 20.0 & 19.7 & 19.8 & 19.9 & 20.3 \\
\hline \multicolumn{6}{|l|}{ Industries } \\
\hline Construction & 6.24 & 7.72 & 6.17 & 6.24 & 5.73 \\
\hline Manufacturing & 24.4 & 14.8 & 21.3 & 27.3 & 28.3 \\
\hline Mining & 0.99 & 1.45 & 1.05 & 0.96 & 0.81 \\
\hline Research and education & 1.91 & 1.89 & 1.98 & 1.76 & 1.96 \\
\hline Services & 63.0 & 69.4 & 65.9 & 60.1 & 60.5 \\
\hline Utilities & 1.49 & 1.59 & 1.46 & 1.40 & 1.52 \\
\hline \multicolumn{6}{|l|}{ Occupations } \\
\hline Skill-intensive & 16.1 & 17.0 & 16.2 & 15.5 & 16.2 \\
\hline White-collar & 41.4 & 42.1 & 42.6 & 40.2 & 41.0 \\
\hline Blue-collar & 28.3 & 26.1 & 27.1 & 30.1 & 29.0 \\
\hline Routine & 35.0 & 33.6 & 35.1 & 35.1 & 35.4 \\
\hline Offshorable & 37.2 & 37.2 & 38.0 & 37.4 & 36.6 \\
\hline \multicolumn{6}{|l|}{ Employment composition } \\
\hline Women in high robot-intensive industries & 30.8 & 31.9 & 32.3 & 32.2 & 28.7 \\
\hline Women in low robot-intensive industries & 35.3 & 35.1 & 36.8 & 36.8 & 33.6 \\
\hline Non-whites in high robot-intensive industries & 23.8 & 30.7 & 24.9 & 29.3 & 17.3 \\
\hline Non-whites in low robot-intensive industries & 22.7 & 30.0 & 25.4 & 28.1 & 15.3 \\
\hline Women in skill-intensive occupations & 47.3 & 47.5 & 47.3 & 46.2 & 47.8 \\
\hline Women in white-collar occupations & 50.8 & 51.4 & 51.0 & 50.0 & 50.8 \\
\hline Women in blue-collar occupations & 35.3 & 34.0 & 36.0 & 36.1 & 35.0 \\
\hline Non-whites in skill-intensive occupations & 17.9 & 24.1 & 19.1 & 20.9 & 13.0 \\
\hline Non-whites in white-collar occupations & 13.3 & 19.1 & 13.6 & 15.6 & 9.64 \\
\hline Non-whites in blue-collar occupations & 29.2 & 38.1 & 31.2 & 35.2 & 21.0 \\
\hline Observations & 722 & 181 & 180 & 181 & 180 \\
\hline
\end{tabular}

Note: This table illustrates averages of the covariates used in the main analysis. Column 1 reports averages over all $722 \mathrm{CZs}$ in the sample. Columns 2 to 5 split the sample into four quartiles, accounting for a labor market's exposure to robots between 1993 and 2014. Pre-trends account for changes in the employment gaps between 1970 and 1990. Non-robot technologies include the share of workers using a personal computer and the share of IT investments. Imports includes measures of a local labor market's exposure to Chinese imports in thousand dollars per worker between 1993 and 2014. Demographics, industries and occupations include measures of the population composition in 1990. The remaining variables report the employment composition by demographic group within industries and occupations. 


\section{A3 Additional figures and tables}

Figure A6: Racial and ethnic minorities at the commuting zone level in 1990

Panel A: Share of non-whites

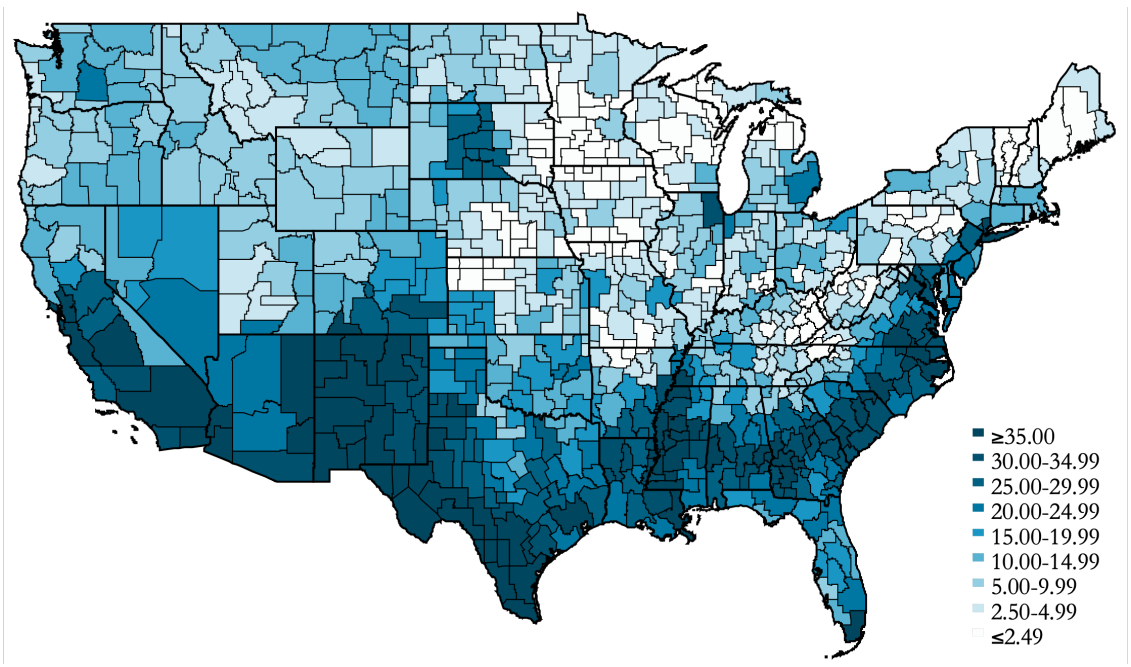

Panel B: Commuting zones with a large population of non-whites

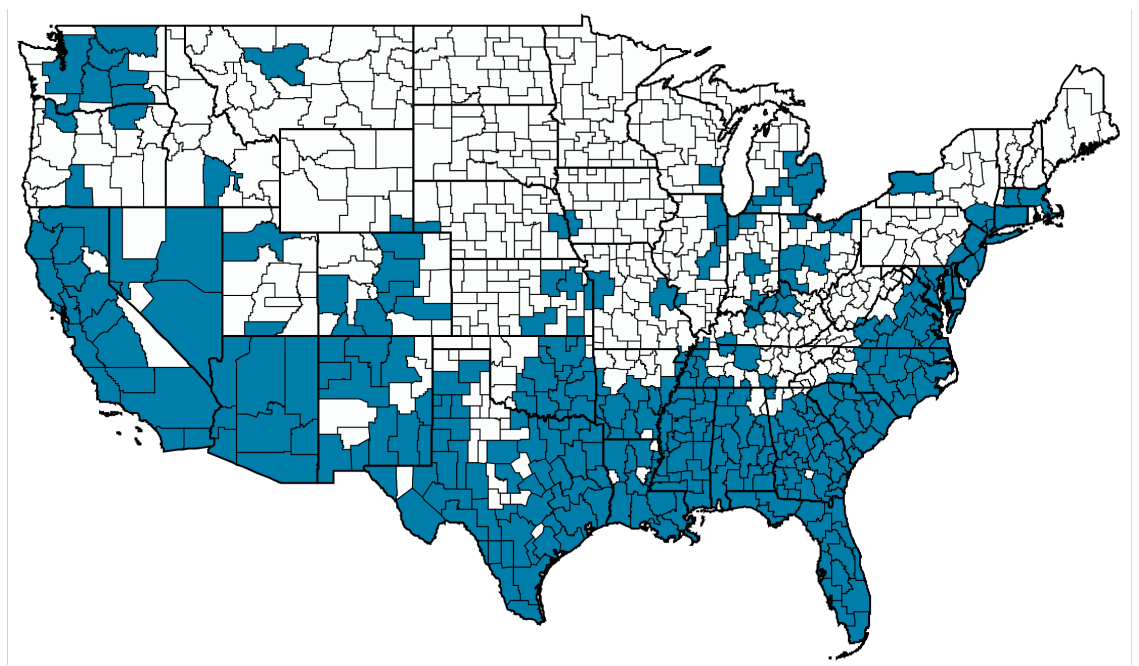

Note: This figure illustrates the geographic distribution of racial and ethnic minorities in the US in 1990. Panel A shows the CZ share of non-whites (multiplied by 100) in 1990. Panel B highlights the CZs with the total population of non-whites and a share of non-whites both above the US local labor market median. 
Figure A7: Employment gaps at the commuting zone level

Panel A: Employment gaps in 1990

Race and ethnicity

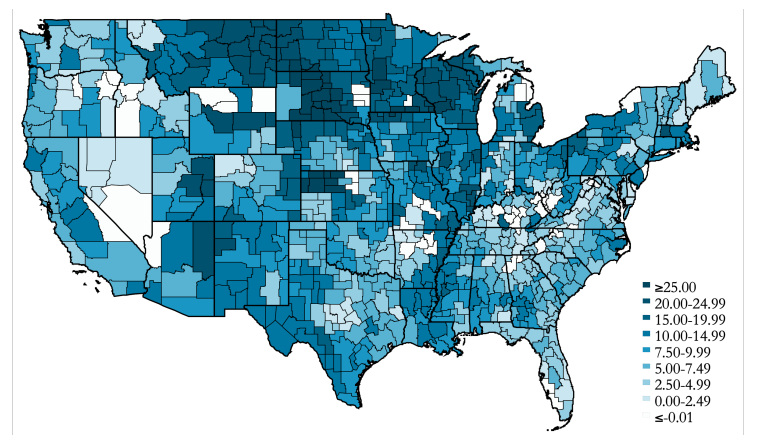

Gender

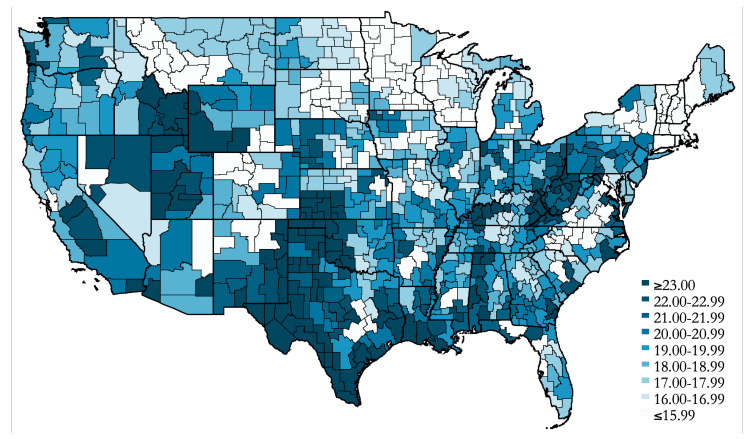

Panel B: Change in employment gaps between 1990 and 2014
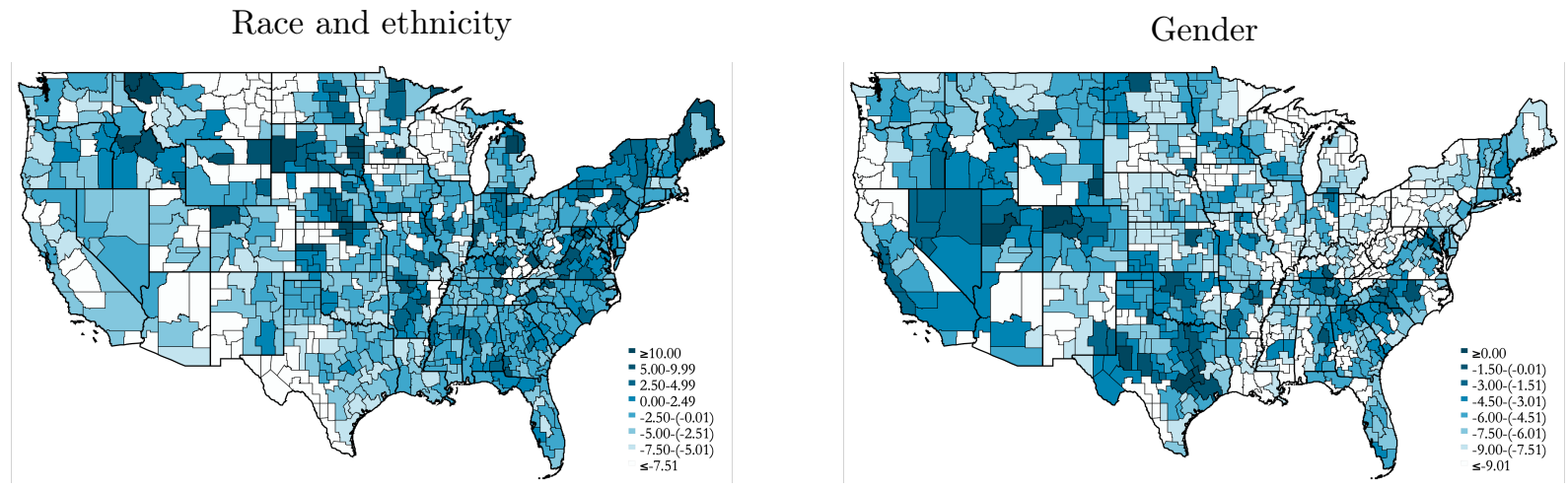

Note: This figure illustrates the geographic distribution of the race and ethnicity employment gap and the gender employment gap in 1990 and their changes between 1990 and 2014 at the CZ level (all multiplied by 100). 
Figure A8: Robot adoption in the US and Europe at industry level

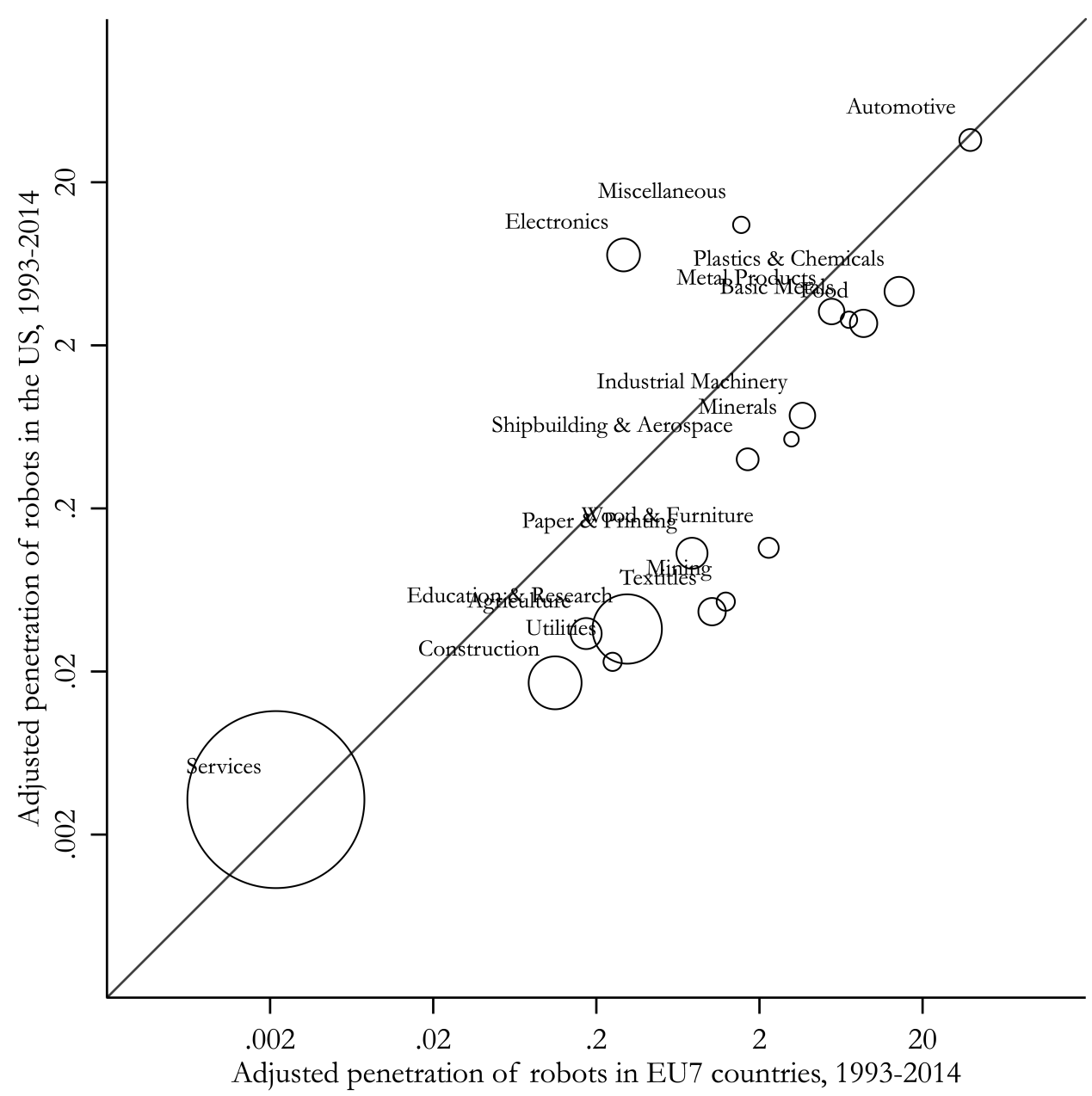

Note: This figure illustrates the unweighted correlation between the change in the stock of robots (adjusted by industry growth) in the US and in seven European countries by IFR industries between 1993 and 2014. The size of the circles represent the baseline US employment in the industry. The solid line corresponds to the $45^{\circ}$ line. This is a modified version of Figure 2 in Acemoglu and Restrepo (2020). 
Figure A9: Robots and blue-collar occupations

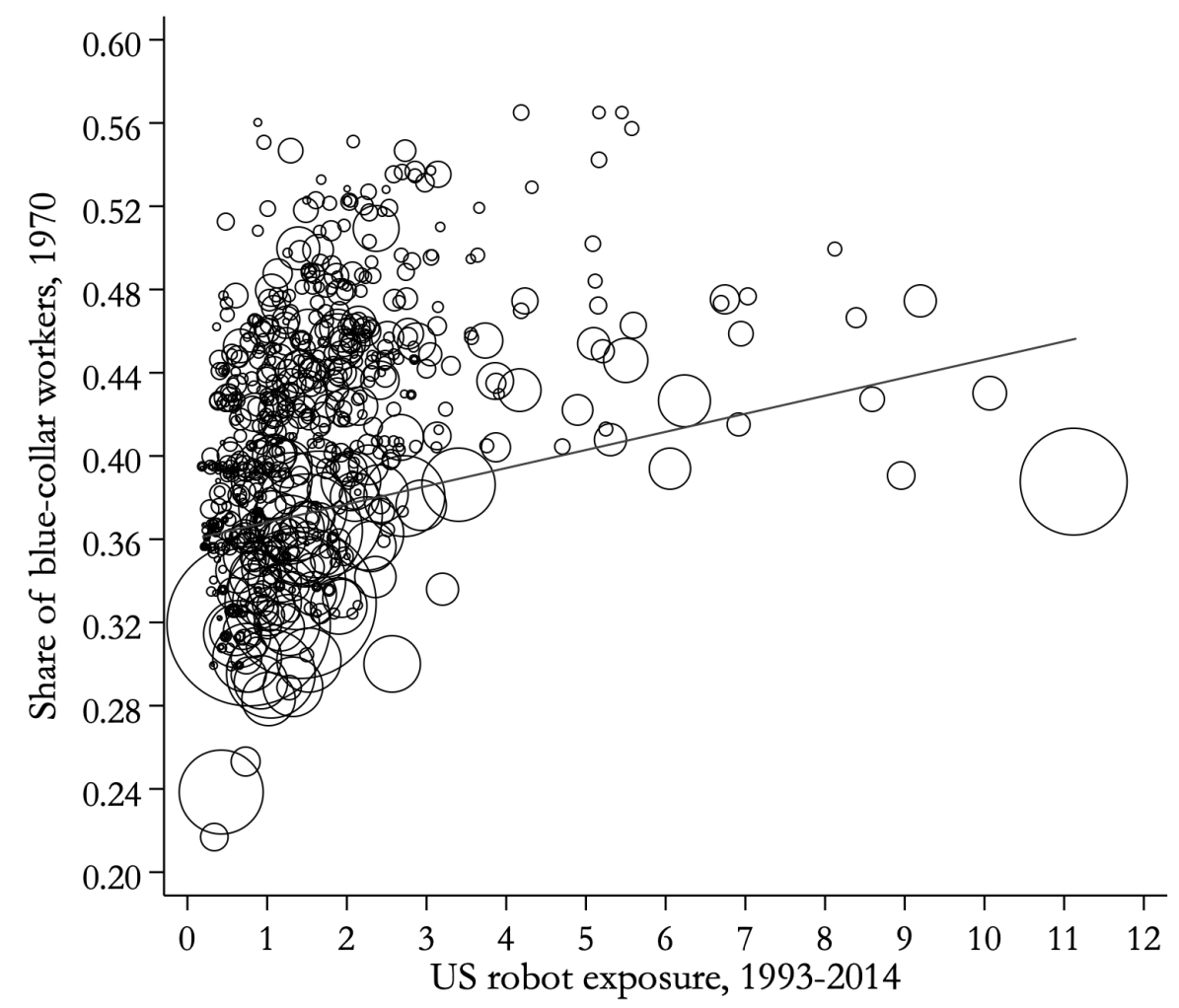

Note: This figure illustrates the correlation between US robot exposure and the share of blue-collar workers at the CZ level. Blue-collar occupations are computed from a median split of the standardized measures of the brawn and brain task content of jobs and include occupations that are brawn task intensive but require only few brain skills. The circle's size represent the relative size of a local labor market's population in 1970. 
Figure A10: Robots, employment gaps and the share of blue-collar workers

Panel A: Race and ethnicity

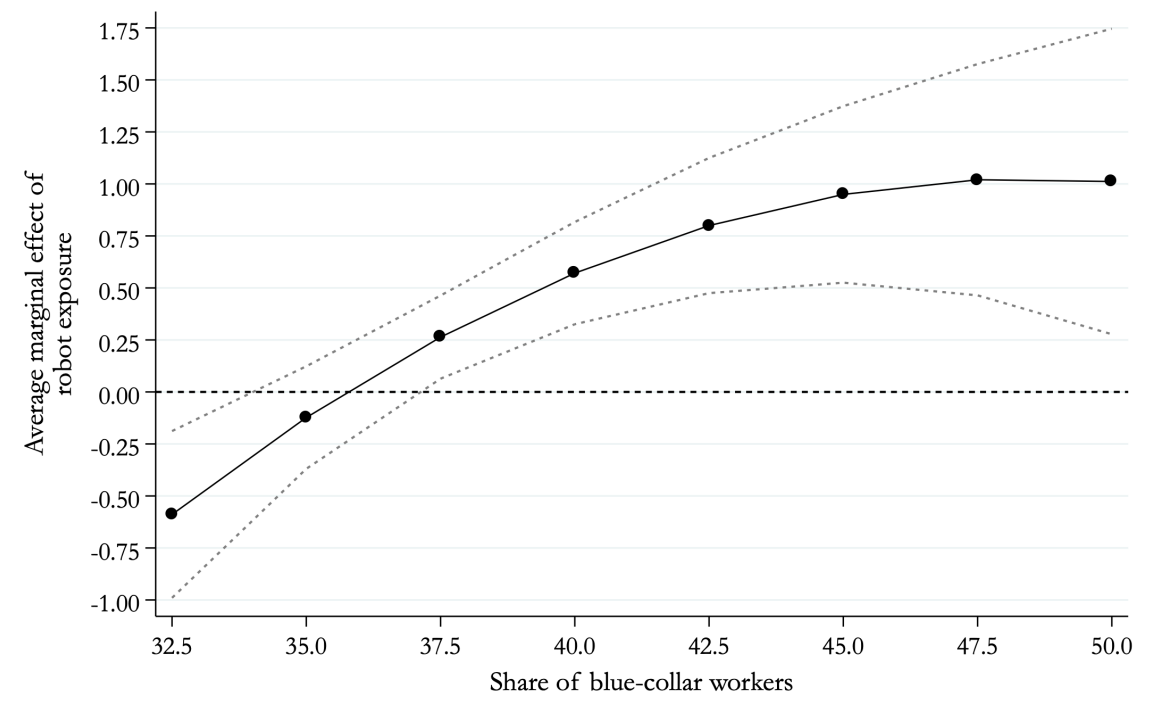

Panel B: Gender

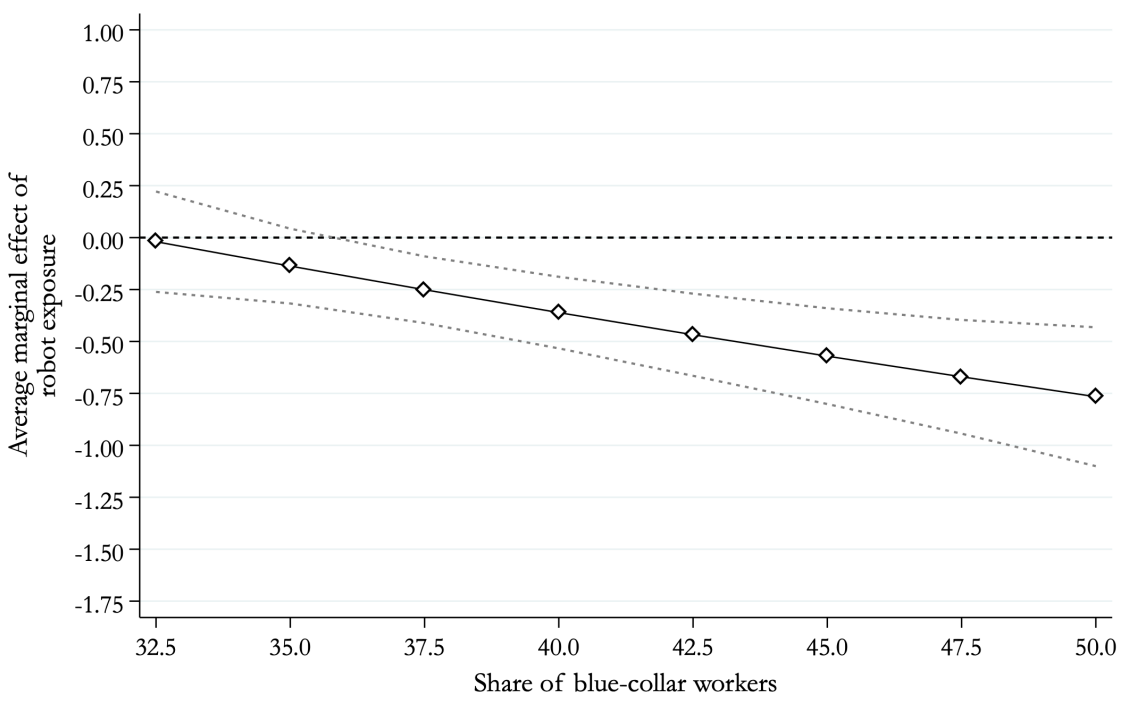

Note: This figure illustrates reduced form estimates of the average marginal effect of robot exposure with respect to the share of blue-collar workers in 1970 on the change in the employment gap by race and ethnicity and by gender. Changes are expressed in percentage points of the population subgroup and are multiplied by 100. Independent variables are standardized to have mean zero and standard deviation of one. There are three time periods and $722 \mathrm{CZs}$. Standard errors are robust against heteroskedasticity and allow for clustering at the state level. Confidence intervals are at the $95 \%$ level. Regressions include covariates of my preferred specification and are weighted by CZ population in 1990. 
Figure A11: Education and job task content in 1990

Workers in skill-intensive jobs

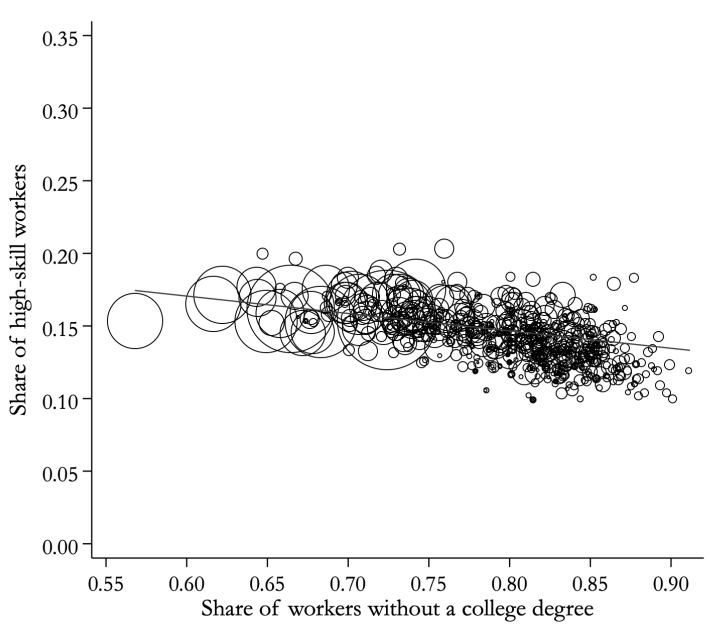

Blue-collar workers

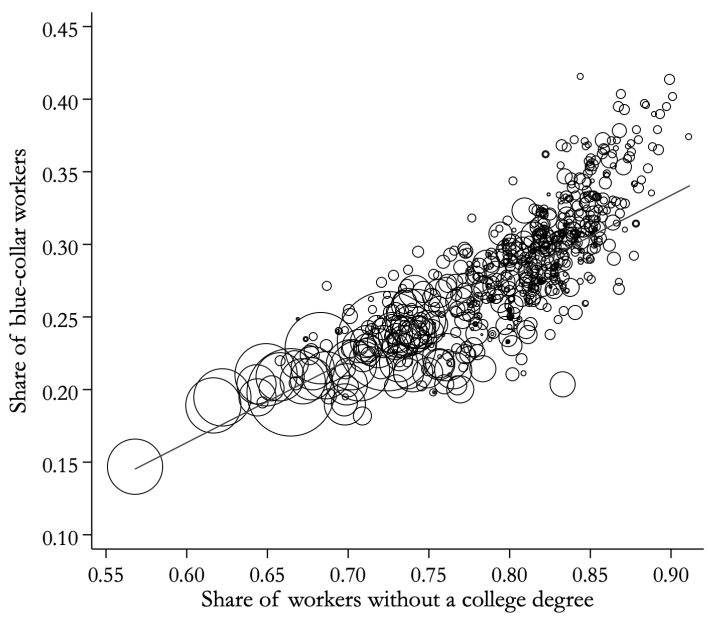

White-collar workers

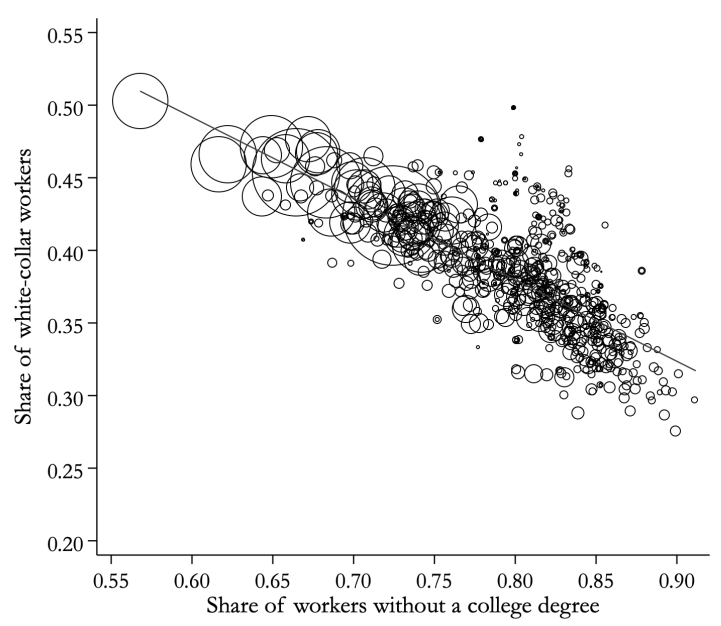

Low-skill workers

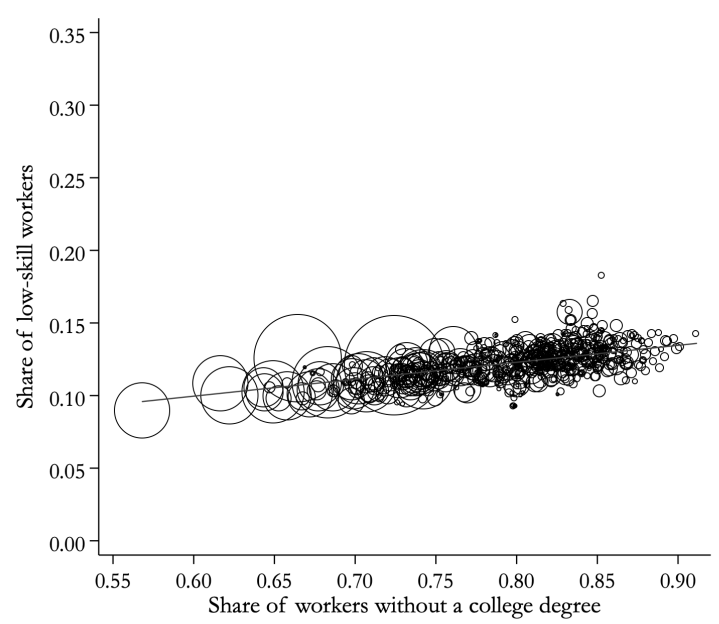

Note: This figure illustrates the relationship between the share of workers without a college degree and the share of workers employed in skill-intensive, blue-collar, white-collar and low-skill jobs at the CZ level in 1990. Occupation groups are computed from a median split of the standardized measures of the brawn and brain task content of jobs. Skill-intensive jobs include occupations that are both brawn and brain task intensive. White-collar jobs include occupations that are brain task intensive and require only few brawn skills. Blue-collar jobs include occupations that are brawn task intensive and require only few brain skills. Low-skill jobs include occupations that do not require particular brawn or brain skills. Values are weighted for the CZ population in 1990. 
Figure A12: Robots and employment rates: Education

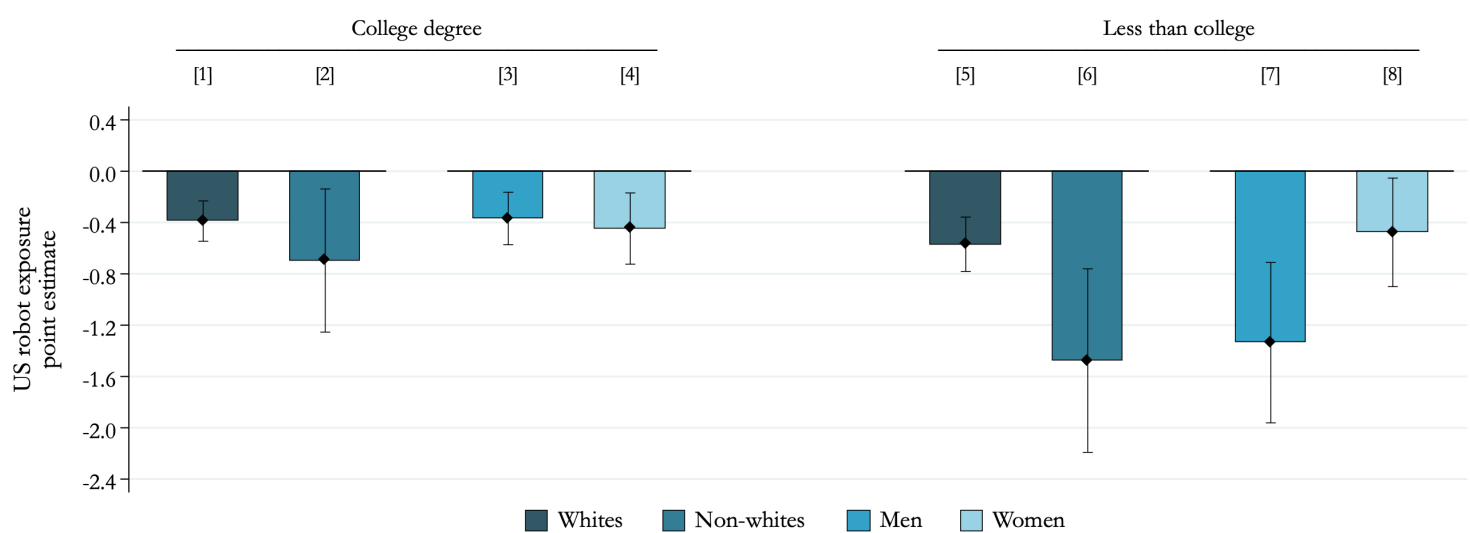

Note: This figure illustrates the IV point estimates of the effect of US robot exposure on the change in employment by race and ethnicity and by gender by education at the $\mathrm{CZ}$ level. Changes are expressed in percentage points of the population subgroup and are multiplied by 100. Independent variables are standardized to have mean zero and standard deviation of one. There are three time periods and $722 \mathrm{CZs}$. Standard errors are robust against heteroskedasticity and allow for clustering at the state level. Confidence intervals are at the $95 \%$ level. Regressions include covariates of my preferred specification and are weighted by CZ population in 1990 . 
Figure A13: Robots and employment rates: Occupations and industries

Panel A: Occupations

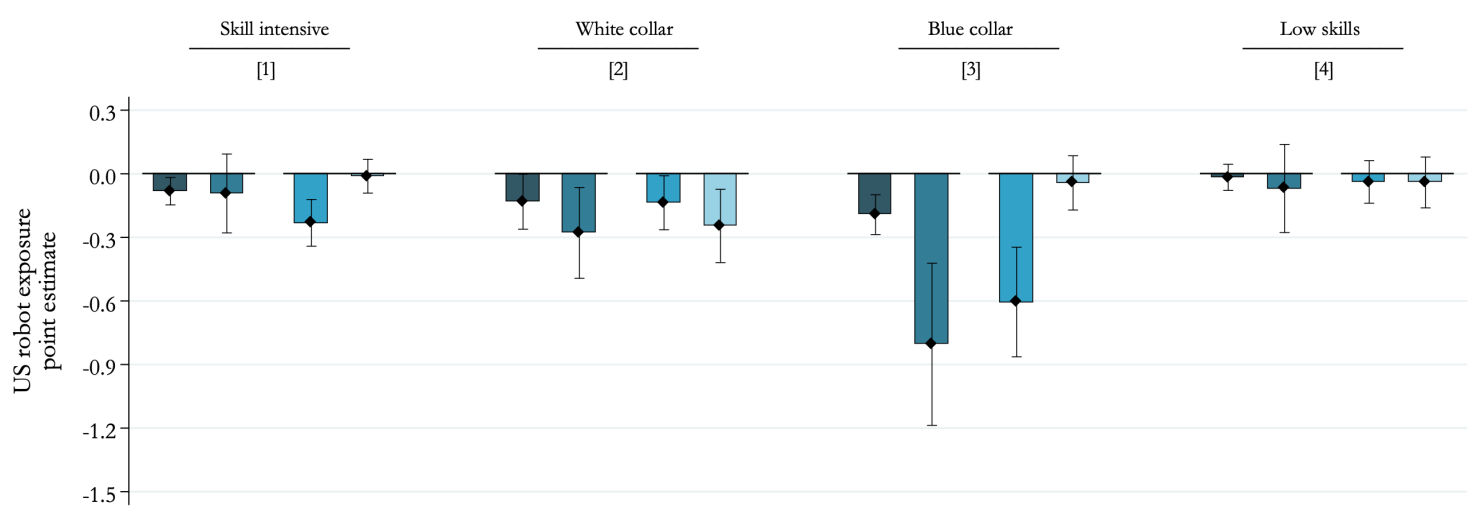

Panel B: Industries

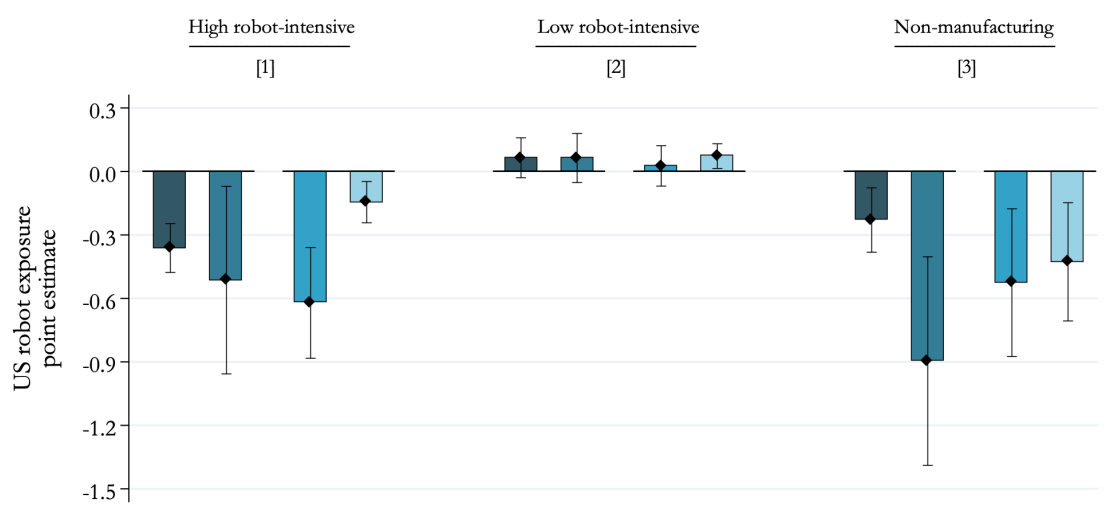

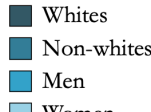

$\square$ Men

$\square$ Women

Note: This figure illustrates the IV point estimates of the effect of US robot exposure on the change in employment by race and ethnicity and by gender by industry and occupation group at the CZ level. Occupation groups are computed from a median split of the standardized measures of the brawn and brain task content of jobs. Skill-intensive jobs include occupations that are both brawn and brain task intensive. White-collar jobs include occupations that are brain task intensive and require only few brawn skills. Bluecollar jobs include occupations that are brawn task intensive and require only few brain skills. Low-skill jobs include occupations that do not require particular brawn or brain skills. Industry groups are created according to the relative adoption of industrial robots of industries. High robot-intensive manufacturing industries include the industries with the heaviest adoption of industrial robots. Low robot-intensive manufacturing industries include the remaining manufacturing industries, while non-manufacturing industries include all industries outside of the manufacturing sector. Changes are expressed in percentage points of the population subgroup and are multiplied by 100. Independent variables are standardized to have mean zero and standard deviation of one. There are three time periods and 722 CZs. Standard errors are robust against heteroskedasticity and allow for clustering at the state level. Confidence intervals are at the $95 \%$ level. Regressions include covariates of my preferred specification and are weighted by CZ population in 1990 
Figure A14: European robot exposure and imports to the US

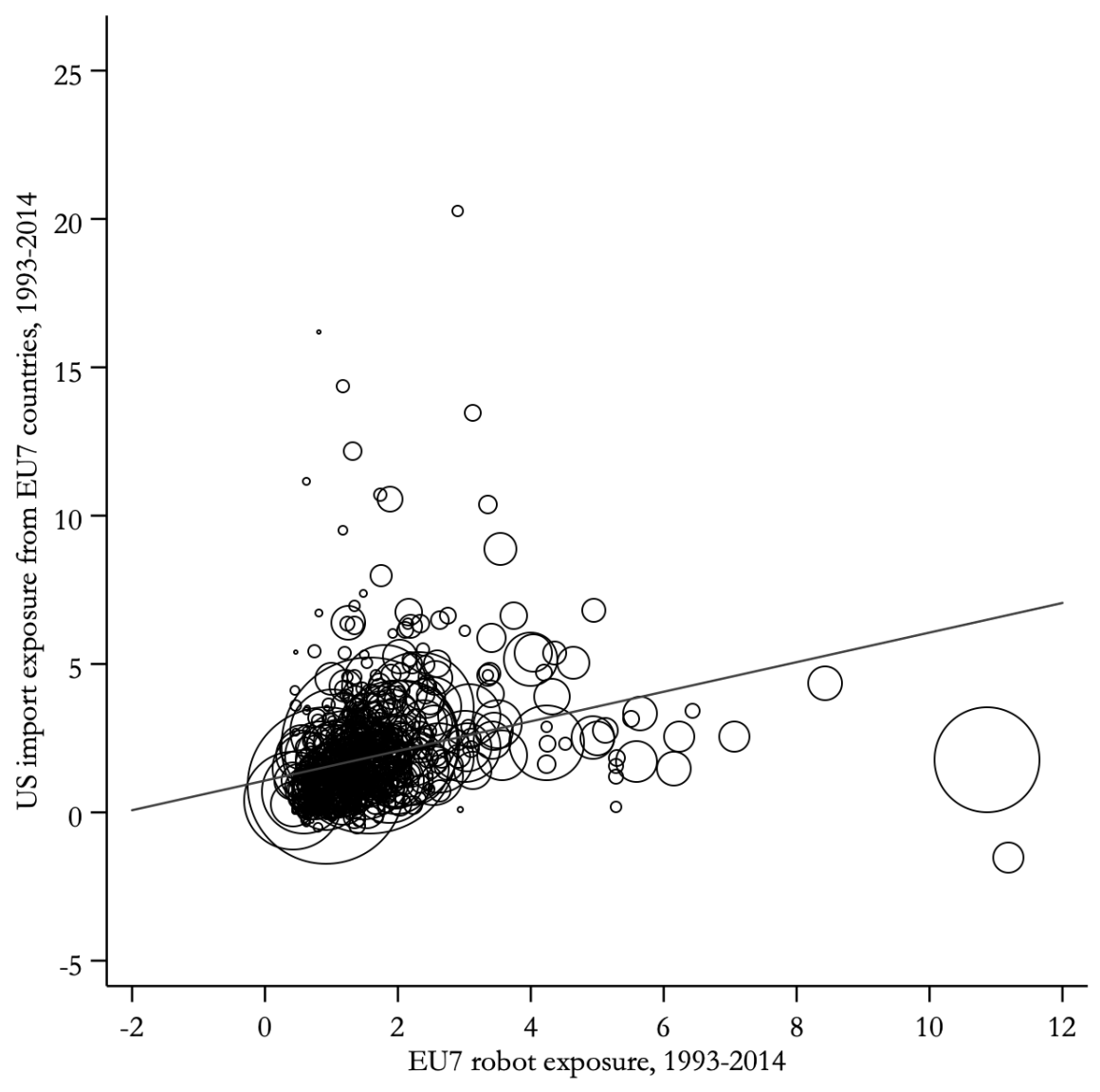

Note: This figure presents the unweighted correlation between robot exposure in European countries, as presented in Equation 5.3, and a shift-share measure of imports from these countries to the US. The size of the circles represent a labor market's size in terms of population in 1990. The solid line represents a prediction for US import exposure from European countries from a linear regression on robot exposure in Europe. Source: Lerch (2020). 
Figure A15: Trade flows from Europe to the US and Canada by industry

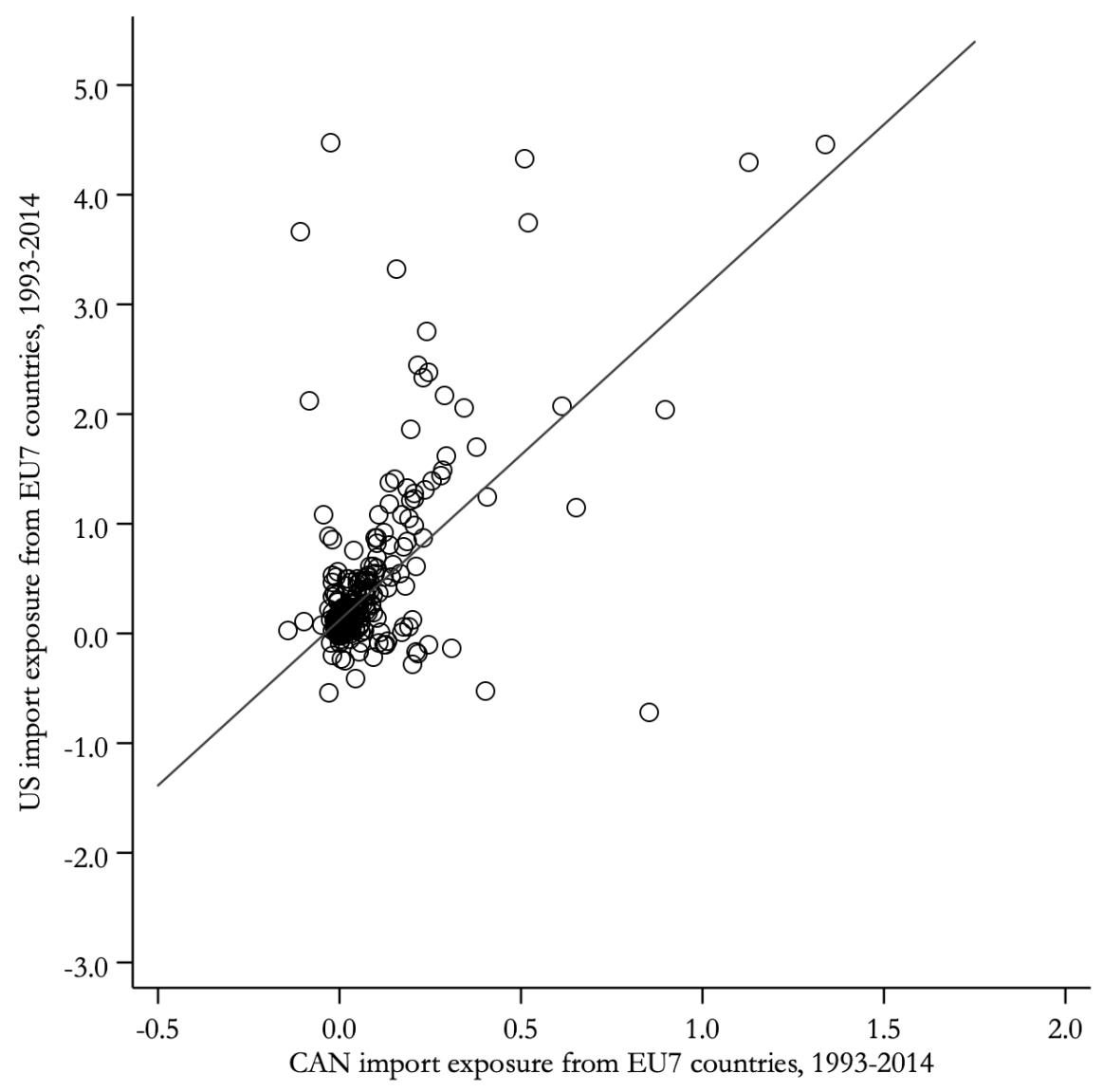

Note: This figure presents the unweighted correlation between imports from seven European countries (Denmark, Finland, France, Italy, Spain, Sweden and the United Kingdom) to the US and Canada. Imports are represented by SIC industry of the manufacturing sector (392) in billions of US dollars in 2017 prices. For visibility reasons, I omitt outlying industries with imports that exceed five billion US dollars in the US or three billion US dollars in Canada. These industries are ice cream and frozen desserts (2024), food preparations, nec (2099), hardwood dimension and flooring mills (2426), millwork (2431), pharmaceutical preparations (2834), petroleum refining (2911), women's handbags and purses (3171), primary nonferrous metals, nec (3339), electronic connectors (3678), motor vehicles and car bodies (3711), motor vehicle parts and accessories (3714), aircraft (3721), aircraft engines and engine parts (3724). The solid line represents a prediction for US import exposure from European countries from a linear regression on Canadian import exposure from European countries based on all 392 SIC industries of the manufacturing sector. Source: Lerch (2020). 
Table A2: Occupations with the largest and smallest shares of non-whites and women

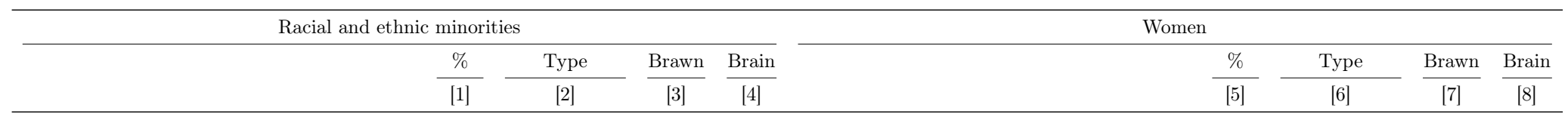

Panel A: Top 15 occupations

Panel A: Top 15 occupations

Private household cleaners and servants

Parking lot attelans

Parking lot attendants

Housekeepers, maids, butl

Blevator operator

Materials movers

Garbage and recyclable material collectors

Textile sewing machine operators

Laundry workers

Waiter's assistant

Taxi cab drivers and chauffeurs

Farm workers

Tailors

Graders and sorters in manufacturing

Vehicle washers and equipment cleaners

$\begin{array}{ll}62.03 & \text { Low skill } \\ 59.38 & \text { Low skill } \\ 53.58 & \text { Low skill } \\ 50.34 & \text { Blue collar } \\ 47.50 & \text { Low skill } \\ 47.10 & \text { Low skill } \\ 45.56 & \text { Low skill } \\ 45.53 & \text { Blue collar } \\ 45.19 & \text { Low skill } \\ 45.05 & \text { Low skill } \\ 44.74 & \text { Skill intensive } \\ 44.21 & \text { Blue collar } \\ 44.04 & \text { Blue collar } \\ 43.40 & \text { Blue collar } \\ 42.96 & \text { Low skill }\end{array}$

Panel B: Bottom 15 occupations
Tool and die markers and die setters

Psychology instructors

Lawyers

Other health and therapy

Other health

Veterinarians

Writers and authors

Writers and

Podiatrists

Foresters and conservation scientists

Dental hygenists

Geologists

History instructors

Sales engineer

Airplane pilots and navigators

Farmers (owners and tenants)

$\begin{array}{cc} & \\ 32 & \\ 1 & 13 \\ 42 & \\ 63 & 24 \\ 36 & 28 \\ 41 & \\ 23 & \\ 83 & \\ 49 & \\ 1 & \\ 87 & 13 \\ 50 & 55 \\ 92 & 18 \\ 50 & \\ 21 & \end{array}$

Secretaries

Dental hygenists

Receptionists

Typists

Private household cleaners and servants

Teacher's aides

Home economics instructors

Registered nurses

Licensed practical nurses

Dressmakers and seamstresses

Bank tellers

Health record tech specialists

98.33 White collar

$\begin{array}{ll}98.21 & \text { White collar } \\ 97.52 & \text { White collar }\end{array}$

$96.96 \quad$ Low skill

$96.58 \quad$ Low skil

$95.38 \quad$ Low skill

$94.80 \quad$ Low skill

94.62 White collar

94.52 White collar $\quad 38-100$

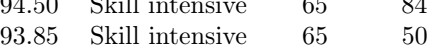

$\begin{array}{lll}93.54 & \text { Skill intensive } \quad 98 & 65\end{array}$

Panel B: Bottom 15 occupations

$\begin{array}{lcc}7.71 & \text { Skill intensive } & 86 \\ 7.61 & \text { White collar } & 1 \\ 7.53 & \text { White collar } & 2 \\ 7.22 & \text { Skill intensive } & 87 \\ 7.17 & \text { Skill intensive } & 97 \\ 7.04 & \text { Skill intensive } & 9 \\ 6.79 & \text { White collar } & 10 \\ 6.65 & \text { White collar } & 36 \\ 6.52 & \text { Low skill } & 46 \\ 6.00 & \text { White collar } & 20 \\ 5.44 & \text { Skill intensive } & 63 \\ 4.74 & \text { White collar } & 1 \\ 4.62 & \text { White collar } & 39 \\ 4.60 & \text { Skill intensive } & 97 \\ 2.88 & \text { White collar } & 22\end{array}$

$\begin{array}{clcc}53 & \text { Automobile mechanics } & 1.87 & \text { Skill intensive } \\ 100 & \text { Structural metal workers } & 1.82 & \text { Blue collar } \\ 96 & \text { Excavating and loading machine operators } & 1.82 & \text { Blue collar } \\ 94 & \text { Materials movers } & 1.71 & \text { Low skill } \\ 75 & \text { Operating engineers of construction equipm. } & 1.70 & \text { Blue collar } \\ 69 & \text { Carpenters } & 1.64 & \text { Blue collar } \\ 83 & \text { Mason, tilers, and carpet installers } & 1.59 & \text { Blue collar } \\ 88 & \text { Roofers and slaters } & 1.44 & \text { Blue collar } \\ 47 & \text { Electric power installers and repairers } & 1.44 & \text { Skill intensive } \\ 53 & \text { Plumbers, pipe fitters, and steamfitters } & 1.38 & \text { Blue collar } \\ 95 & \text { Railroad brake, coupler, and switch operators } & 1.36 & \text { Blue collar } \\ 100 & \text { Concrete and cement workers } & 1.35 & \text { Blue collar } \\ 94 & \text { Heating, air cond., and refrig. mechanics } & 1.22 & \text { Blue collar } \\ 66 & \text { Paving, surfacing, tamping equipm. operators } & 1.07 & \text { Blue collar } \\ 58 & \text { Heavy equipm. and farm equipm. mechanics } & 0.86 & \text { Blue collar }\end{array}$

Note: This table presents a set of occupations with the corresponding share of non-white and female workers, the percentile of the standardized brawn and brain task content in the distribution of occupations and the respective occupation group. Occupation groups are computed from a median split of the standardized measures of the brawn and brain task content of jobs. Skill-intensive jobs include occupations that are both brawn and brain task intensive. White-collar jobs include occupations that are brain task intensive and require only few brawn skills. Blue-collar jobs include occupations that are brawn task intensive and require only few brain skills. Low-skill jobs include occupations that do not require particular brawn or brain skills. Panel A shows the 15 occupations with the highest share of non-whites and women. Panel B shows the 15 occupations with the highest share of whites and men. 
Table A3: First-stage estimates

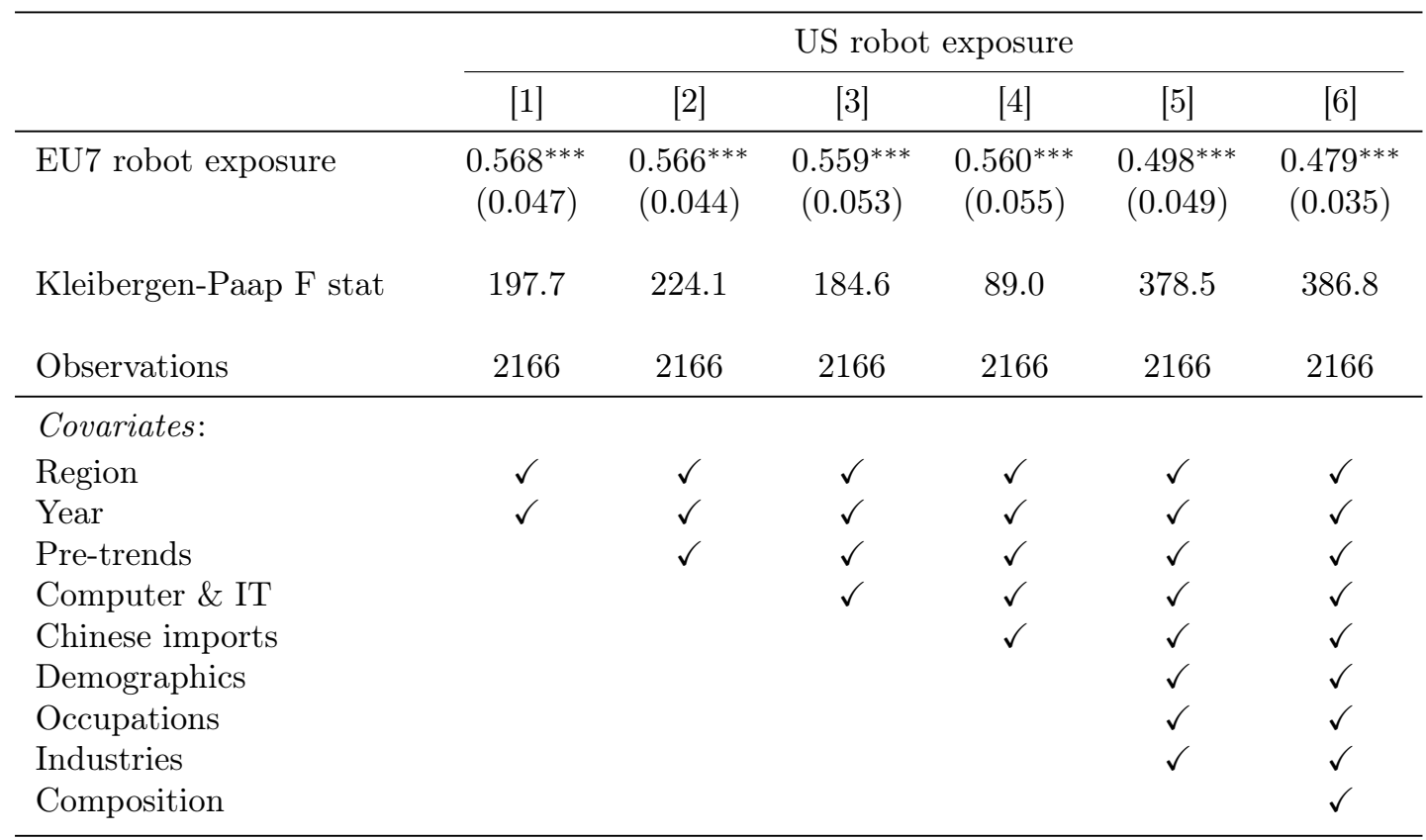

Note: This table presents first-stage estimates of the effect of EU7 robot exposure on US robot exposure at the CZ level. Variables are standardized to have mean zero and standard deviation of one. There are three time periods and 722 CZs. Column 1 includes only state fixed effects and time-varying division fixed effects. Column 2 includes also pre-trends in the change of the employment gaps between 1970 and 1990. Column 3 controls for the adoption of personal computers and IT capital intensity. Column 4 includes the exposure to Chinese imports. Column 5 includes also demographic (share of individuals aged between 25 and 34 years, 35 and 44 years, 45 and 54 years, the share of Blacks, Hispanics, women and individuals with less than a college degree and logarithmic population), industry (share of employment in the contruction, manufacturing, mining, research, service and utilities sector) and occupation (share of employment in routine, offshorable, skill-intensive, white-collar, blue-collar and low-skill occupations) characteristics of CZs in 1990. Column 6 controls also for the initial composition of employment by race, ethnicity and gender within occupation and industry groups. Standard errors are robust against heteroskedasticity and allow for clustering at the state level. Regressions are weighted by CZ population in 1990 . Coefficients with ${ }^{* * *},{ }^{* *}$ and ${ }^{*}$ are significant at the $1 \%, 5 \%$ and $10 \%$ confidence level. 
Table A4: Robots and the race and ethnicity employment gap

\begin{tabular}{|c|c|c|c|c|c|c|}
\hline & \multicolumn{6}{|c|}{ Panel A: White-Black } \\
\hline & {$[1]$} & {$[2]$} & {$[3]$} & {$[4]$} & {$[5]$} & {$[6]$} \\
\hline US robot exposure & $\begin{array}{l}0.725^{* *} \\
(0.352)\end{array}$ & $\begin{array}{l}0.788^{* *} \\
(0.351)\end{array}$ & $\begin{array}{c}0.802^{* *} \\
(0.371)\end{array}$ & $\begin{array}{c}0.808^{* *} \\
(0.370)\end{array}$ & $\begin{array}{l}1.056^{* *} \\
(0.402)\end{array}$ & $\begin{array}{c}1.091^{* * *} \\
(0.397)\end{array}$ \\
\hline \multirow[t]{3}{*}{ Observations } & 2127 & 2127 & 2127 & 2127 & 2127 & 2127 \\
\hline & \multicolumn{6}{|c|}{ Panel B: White-Hispanic } \\
\hline & {$[1]$} & {$[2]$} & {$[3]$} & {$[4]$} & {$[5]$} & {$[6]$} \\
\hline US robot exposure & $\begin{array}{c}1.084^{* * *} \\
(0.278)\end{array}$ & $\begin{array}{c}1.120^{* * *} \\
(0.276)\end{array}$ & $\begin{array}{c}1.121^{* * *} \\
(0.278)\end{array}$ & $\begin{array}{c}1.121^{* * *} \\
(0.279)\end{array}$ & $\begin{array}{c}1.347^{* * *} \\
(0.341)\end{array}$ & $\begin{array}{c}1.387^{* * *} \\
(0.354)\end{array}$ \\
\hline \multirow[t]{3}{*}{ Observations } & 2166 & 2166 & 2166 & 2166 & 2166 & 2166 \\
\hline & \multicolumn{6}{|c|}{ Panel C: White-other race } \\
\hline & {$[1]$} & {$[2]$} & {$[3]$} & {$[4]$} & {$[5]$} & {$[6]$} \\
\hline US robot exposure & $\begin{array}{c}0.290 \\
(0.202)\end{array}$ & $\begin{array}{c}0.319 \\
(0.208)\end{array}$ & $\begin{array}{c}0.303 \\
(0.207)\end{array}$ & $\begin{array}{c}0.308 \\
(0.207)\end{array}$ & $\begin{array}{c}0.368 \\
(0.273)\end{array}$ & $\begin{array}{c}0.385 \\
(0.278)\end{array}$ \\
\hline Observations & 2166 & 2166 & 2166 & 2166 & 2166 & 2166 \\
\hline \multicolumn{7}{|l|}{ Covariates: } \\
\hline Region & $\checkmark$ & $\checkmark$ & $\checkmark$ & $\checkmark$ & $\checkmark$ & $\checkmark$ \\
\hline Year & $\checkmark$ & $\checkmark$ & $\checkmark$ & $\checkmark$ & $\checkmark$ & $\checkmark$ \\
\hline Pre-trends & & $\checkmark$ & $\checkmark$ & $\checkmark$ & $\checkmark$ & $\checkmark$ \\
\hline Computer \& IT & & & $\checkmark$ & $\checkmark$ & $\checkmark$ & $\checkmark$ \\
\hline Chinese imports & & & & $\checkmark$ & $\checkmark$ & $\checkmark$ \\
\hline Demographics & & & & & $\checkmark$ & $\checkmark$ \\
\hline Occupations & & & & & $\checkmark$ & $\checkmark$ \\
\hline Industries & & & & & $\checkmark$ & $\checkmark$ \\
\hline Composition & & & & & & $\checkmark$ \\
\hline
\end{tabular}

Note: This table presents IV estimates of the effect of US robot exposure on the change in the race and ethnicity employment gap at the CZ level differentiating between Blacks, Hispanics and other non-White races. Panel A reports the results on the employment gap of Whites and Blacks, Panel B on Whites and Hispanics and Panel C on Whites and other races, such as Asians, American Indian and Alaska natives. Changes are expressed in percentage points of the working-age population subgroup and are multiplied by 100. Independent variables are standardized to have mean zero and standard deviation of one. There are three time periods and $722 \mathrm{CZs}$. Column 1 includes only state fixed effects and time-varying division fixed effects. Column 2 includes also pre-trends in the change of the employment gaps between 1970 and 1990. Column 3 controls for the adoption of personal computers and IT capital intensity. Column 4 includes the exposure to Chinese imports. Column 5 includes also demographic (share of individuals aged between 25 and 34 years, 35 and 44 years, 45 and 54 years, the share of Blacks, Hispanics, women and individuals with less than a college degree and logarithmic population), industry (share of employment in the contruction, manufacturing, mining, research, service and utilities sector) and occupation (share of employment in routine, offshorable, skill-intensive, white-collar, blue-collar and low-skill occupations) characteristics of CZs in 1990. Column 6 controls also for the initial composition of employment by race, ethnicity and gender within occupation and industry groups. Standard errors are robust against heteroskedasticity and allow for clustering at the state level. Regressions are weighted by CZ population in 1990. Coefficients with ${ }^{* *},{ }^{* *}$ and ${ }^{*}$ are significant at the $1 \%, 5 \%$ and $10 \%$ confidence level. 
Table A5: Chinese imports and employment gaps

\begin{tabular}{|c|c|c|c|c|c|}
\hline & \multicolumn{5}{|c|}{ Panel A: Race and ethnicity } \\
\hline & {$[1]$} & {$[2]$} & {$[3]$} & {$[4]$} & {$[5]$} \\
\hline US import exposure & $\begin{array}{c}0.148 \\
(0.097)\end{array}$ & $\begin{array}{c}0.156 \\
(0.100)\end{array}$ & $\begin{array}{c}0.038 \\
(0.119)\end{array}$ & $\begin{array}{l}-0.003 \\
(0.153)\end{array}$ & $\begin{array}{c}-0.014 \\
(0.160)\end{array}$ \\
\hline \multirow[t]{3}{*}{ Observations } & 2166 & 2166 & 2166 & 2166 & 2166 \\
\hline & \multicolumn{5}{|c|}{ Panel B: Gender } \\
\hline & {$[1]$} & {$[2]$} & {$[3]$} & {$[4]$} & {$[5]$} \\
\hline US import exposure & $\begin{array}{c}-0.072 \\
(0.064)\end{array}$ & $\begin{array}{c}-0.072 \\
(0.057)\end{array}$ & $\begin{array}{l}-0.023 \\
(0.069)\end{array}$ & $\begin{array}{c}-0.049 \\
(0.079)\end{array}$ & $\begin{array}{l}-0.073 \\
(0.080)\end{array}$ \\
\hline Observations & 2166 & 2166 & 2166 & 2166 & 2166 \\
\hline \multicolumn{6}{|l|}{ Covariates: } \\
\hline Region & $\checkmark$ & $\checkmark$ & $\checkmark$ & $\checkmark$ & $\checkmark$ \\
\hline Year & $\checkmark$ & $\checkmark$ & $\checkmark$ & $\checkmark$ & $\checkmark$ \\
\hline Pre-trends & & $\checkmark$ & $\checkmark$ & $\checkmark$ & $\checkmark$ \\
\hline Computer \& IT & & & $\checkmark$ & $\checkmark$ & $\checkmark$ \\
\hline Robots & & & $\checkmark$ & $\checkmark$ & $\checkmark$ \\
\hline Demographics & & & & $\checkmark$ & $\checkmark$ \\
\hline Occupations & & & & $\checkmark$ & $\checkmark$ \\
\hline Industries & & & & $\checkmark$ & $\checkmark$ \\
\hline Composition & & & & & $\checkmark$ \\
\hline
\end{tabular}

Note: This table presents IV estimates of the effect of US import exposure on the change in the race and ethnicity employment gap and the gender employment at the $\mathrm{CZ}$ level. Changes are expressed in percentage points of the working-age population subgroup and are multiplied by 100. Independent variables are standardized to have mean zero and standard deviation of one. There are three time periods and $722 \mathrm{CZs}$. Column 1 includes only state fixed effects and time-varying division fixed effects. Column 2 includes also pre-trends in the change of the employment gaps between 1970 and 1990. Column 3 controls also for the adoption of personal computers, IT capital intensity and US robot exposure. Column 4 includes also for demographic (share of individuals aged between 25 and 34 years, 35 and 44 years, 45 and 54 years, the share of Blacks, Hispanics, women and individuals with less than a college degree and logarithmic population), industry (share of employment in the contruction, manufacturing, mining, research, service and utilities sector) and occupation (share of employment in routine, offshorable, skill-intensive, white-collar, blue-collar and low-skill occupations) characteristics of CZs in 1990. Column 5 controls also for the initial composition of employment by race, ethnicity and gender within occupation and industry groups. Standard errors are robust against heteroskedasticity and allow for clustering at the state level. Regressions are weighted by CZ population in 1990. Coefficients with ${ }^{* * *},{ }^{* *}$ and ${ }^{*}$ are significant at the $1 \%, 5 \%$ and $10 \%$ confidence level. 
Table A6: US robot exposure across and within local labor markets

\begin{tabular}{lcc}
\hline & Mean & Std. Dev. \\
\cline { 2 - 3 } & {$[1]$} & {$[2]$} \\
\hline Panel A: Robots per thousand workers & \\
Overall & 0.526 & 0.491 \\
Between & & 0.452 \\
Within & & 0.192 \\
Panel B: Standardized & \\
Overall & & \\
Between & 0.000 & 1.000 \\
Within & & 0.921 \\
\hline
\end{tabular}

Note: This table presents unweighted averages and the between and within CZ standard deviation of US robot exposure. Panel A reports the mean and standard deviations in robots per thousand workers. Panel B reports standardized measures with mean zero and overall standard deviation of one. 
Table A7: Robots, employment gaps and employment rate without state fixed effects

\begin{tabular}{|c|c|c|c|}
\hline & \multicolumn{3}{|c|}{ Panel A: Race and ethnicity } \\
\hline & \multirow{2}{*}{$\begin{array}{c}\text { Employment } \\
\text { gap }\end{array}$} & \multicolumn{2}{|c|}{ Employment rate } \\
\hline & & Whites & Non-whites \\
\hline & {$[1]$} & {$[2]$} & {$[3]$} \\
\hline US robot exposure & $\begin{array}{c}0.523^{\text {*** }} \\
(0.158)\end{array}$ & $\begin{array}{c}0.379^{* * *} \\
(0.055)\end{array}$ & $\begin{array}{c}-0.903^{* * *} \\
(0.172)\end{array}$ \\
\hline \multirow[t]{5}{*}{ Observations } & 2166 & 2166 & 2166 \\
\hline & \multicolumn{3}{|c|}{ Panel B: Gender } \\
\hline & Employment & \multicolumn{2}{|c|}{ Employment rate } \\
\hline & gap & Men & Women \\
\hline & {$[1]$} & {$[2]$} & {$[3]$} \\
\hline US robot exposure & $\begin{array}{c}-0.372^{* * *} \\
(0.104)\end{array}$ & $\begin{array}{c}-0.758^{* * *} \\
(0.127)\end{array}$ & $\begin{array}{c}-0.386^{* * *} \\
(0.105)\end{array}$ \\
\hline Observations & 2166 & 2166 & 2166 \\
\hline Covariates: & $\checkmark$ & $\checkmark$ & $\checkmark$ \\
\hline
\end{tabular}

Note: This table presents IV estimates of the effect of US robot exposure on the change in employment gaps and employment rates at the CZ level. Panel A reports the results by race and ethnicity, while Panel B reports the results by gender. Column 1 illustrates results about the employment gaps, and Columns 2 and 3 on the employment rates by demographic group. Changes are expressed in percentage points of the working-age population subgroup and are multiplied by 100. Independent variables are standardized to have mean zero and standard deviation of one. There are three time periods and 722 CZs. All columns include state fixed effects and time-varying division fixed effects and control for the adoption of personal computers, IT capital intensity, the exposure to Chinese imports, as well as for demographic (share of individuals aged between 25 and 34 years, 35 and 44 years, 45 and 54 years, the share of Blacks, Hispanics, women and individuals with less than a college degree and logarithmic population), industry (share of employment in the contruction, manufacturing, mining, research, service and utilities sector) and occupation (share of employment in routine, offshorable, skill-intensive, white-collar, blue-collar and low-skill occupations) characteristics of CZs in 1990 and the initial composition of employment by race, ethnicity and gender within occupation and industry groups in 1990. Standard errors are robust against heteroskedasticity and allow for clustering at the state level. Regressions are weighted by CZ population in 1990 . Coefficients with ${ }^{* * *},{ }^{* *}$ and ${ }^{*}$ are significant at the $1 \%, 5 \%$ and $10 \%$ confidence level. 
Table A8: Robots and the race and ethnicity employment gap by birthplace

\begin{tabular}{|c|c|c|c|c|c|c|}
\hline & \multicolumn{6}{|c|}{ Panel A: Native whites and non-whites } \\
\hline & [1] & {$[2]$} & {$[3]$} & {$[4]$} & {$[5]$} & {$[6]$} \\
\hline US robot exposure & $\begin{array}{c}0.485^{* *} \\
(0.218)\end{array}$ & $\begin{array}{c}0.505^{* *} \\
(0.217)\end{array}$ & $\begin{array}{c}0.505^{* *} \\
(0.218)\end{array}$ & $\begin{array}{c}0.507^{* *} \\
(0.218)\end{array}$ & $\begin{array}{c}0.640^{* * *} \\
(0.236)\end{array}$ & $\begin{array}{c}0.644^{* *} \\
(0.243)\end{array}$ \\
\hline \multirow[t]{3}{*}{ Observations } & 2166 & 2166 & 2166 & 2166 & 2166 & 2166 \\
\hline & \multicolumn{6}{|c|}{ Panel B: Native whites and non-white immigrants } \\
\hline & [1] & {$[2]$} & {$[3]$} & {$[4]$} & {$[5]$} & {$[6]$} \\
\hline US robot exposure & $\begin{array}{c}0.513^{* *} \\
(0.226)\end{array}$ & $\begin{array}{l}0.541^{* *} \\
(0.231)\end{array}$ & $\begin{array}{l}0.521^{* *} \\
(0.229)\end{array}$ & $\begin{array}{c}0.525^{* *} \\
(0.230)\end{array}$ & $\begin{array}{l}0.552^{*} \\
(0.295)\end{array}$ & $\begin{array}{l}0.556^{*} \\
(0.299)\end{array}$ \\
\hline \multirow[t]{3}{*}{ Observations } & 2166 & 2166 & 2166 & 2166 & 2166 & 2166 \\
\hline & \multicolumn{6}{|c|}{ Panel C: White immigrants and native non-whites } \\
\hline & [1] & {$[2]$} & {$[3]$} & {$[4]$} & {$[5]$} & [6] \\
\hline US robot exposure & $\begin{array}{c}0.533^{*} \\
(0.283)\end{array}$ & $\begin{array}{l}0.550^{*} \\
(0.283)\end{array}$ & $\begin{array}{c}0.548^{*} \\
(0.289)\end{array}$ & $\begin{array}{c}0.547^{*} \\
(0.288)\end{array}$ & $\begin{array}{c}0.817^{* *} \\
(0.330)\end{array}$ & $\begin{array}{c}0.855^{* *} \\
(0.354)\end{array}$ \\
\hline \multirow[t]{3}{*}{ Observations } & 2166 & 2166 & 2166 & 2166 & 2166 & 2166 \\
\hline & \multicolumn{6}{|c|}{ Panel D: White and non-white immigrants } \\
\hline & [1] & {$[2]$} & {$[3]$} & {$[4]$} & {$[5]$} & {$[6]$} \\
\hline US robot exposure & $\begin{array}{c}0.561 \\
(0.340)\end{array}$ & $\begin{array}{l}0.586^{*} \\
(0.342)\end{array}$ & $\begin{array}{c}0.564 \\
(0.345)\end{array}$ & $\begin{array}{c}0.564 \\
(0.344)\end{array}$ & $\begin{array}{l}0.729^{*} \\
(0.395)\end{array}$ & $\begin{array}{c}0.767^{*} \\
(0.411)\end{array}$ \\
\hline Observations & 2166 & 2166 & 2166 & 2166 & 2166 & 2166 \\
\hline \multicolumn{7}{|l|}{ Covariates: } \\
\hline Region & $\checkmark$ & $\checkmark$ & $\checkmark$ & $\checkmark$ & $\checkmark$ & $\checkmark$ \\
\hline Year & $\checkmark$ & $\checkmark$ & $\checkmark$ & $\checkmark$ & $\checkmark$ & $\checkmark$ \\
\hline Pre-trends & & $\checkmark$ & $\checkmark$ & $\checkmark$ & $\checkmark$ & $\checkmark$ \\
\hline Computer \& IT & & & $\checkmark$ & $\checkmark$ & $\checkmark$ & $\checkmark$ \\
\hline Chinese imports & & & & $\checkmark$ & $\checkmark$ & $\checkmark$ \\
\hline Demographics & & & & & $\checkmark$ & $\checkmark$ \\
\hline Occupations & & & & & $\checkmark$ & $\checkmark$ \\
\hline Industries & & & & & $\checkmark$ & $\checkmark$ \\
\hline Composition & & & & & & $\checkmark$ \\
\hline
\end{tabular}

Note: This table presents IV estimates of the effect of US robot exposure on the change in the race and ethnicity employment gap at the CZ level differentiating between natives and immigrants. Panel A reports the results on the employment gap among native whites and native non-whites. Panel B reports the results on the employment gap among native whites and non-white immigrants. Panel $\mathrm{C}$ reports the results on the employment gap among white immigrant and native non-whites. Panel D reports the results on the employment gap among white and non-white immigrants. Changes are expressed in percentage points of the working-age population subgroup and are multiplied by 100. Independent variables are standardized to have mean zero and standard deviation of one. There are three time periods and $722 \mathrm{CZs}$. Column 1 includes only state fixed effects and time-varying division fixed effects. Column 2 includes also pre-trends in the change of the employment gaps between 1970 and 1990. Column 3 controls for the adoption of personal computers and IT capital intensity. Column 4 includes the exposure to Chinese imports. Column 5 includes also demographic (share of individuals aged between 25 and 34 years, 35 and 44 years, 45 and 54 years, the share of Blacks, Hispanics, women and individuals with less than a college degree and logarithmic population), industry (share of employment in the contruction, manufacturing, mining, research, service and utilities sector) and occupation (share of employment in routine, offshorable, skill-intensive, white-collar, blue-collar and low-skill occupations) characteristics of CZs in 1990. Column 6 controls also for the initial composition of employment by race, ethnicity and gender within occupation and industry groups. Standard errors are robust against heteroskedasticity and allow for clustering at the state level. Regressions are weighted by CZ population in 1990 . Coefficients with ${ }^{* * *},{ }^{* *}$ and ${ }^{*}$ are significant at the $1 \%, 5 \%$ and $10 \%$ confidence level. 
Table A9: Robots and labor force participation gaps

\begin{tabular}{|c|c|c|c|c|c|c|}
\hline & \multicolumn{6}{|c|}{ Panel A: Race and ethnicity } \\
\hline & [1] & {$[2]$} & {$[3]$} & {$[4]$} & {$[5]$} & {$[6]$} \\
\hline US robot exposure & $\begin{array}{c}0.490^{* * *} \\
(0.173)\end{array}$ & $\begin{array}{c}0.514^{* * *} \\
(0.172)\end{array}$ & $\begin{array}{c}0.509^{* * *} \\
(0.174)\end{array}$ & $\begin{array}{c}0.510^{* * *} \\
(0.175)\end{array}$ & $\begin{array}{c}0.593^{* * *} \\
(0.209)\end{array}$ & $\begin{array}{c}0.617^{* * *} \\
(0.220)\end{array}$ \\
\hline \multirow[t]{3}{*}{ Observations } & 2166 & 2166 & 2166 & 2166 & 2166 & 2166 \\
\hline & \multicolumn{6}{|c|}{ Panel B: Gender } \\
\hline & [1] & [2] & {$[3]$} & {$[4]$} & {$[5]$} & {$[6]$} \\
\hline US robot exposure & $\begin{array}{c}-0.414^{* * *} \\
(0.114)\end{array}$ & $\begin{array}{c}-0.419^{* * *} \\
(0.112)\end{array}$ & $\begin{array}{c}-0.438^{* * *} \\
(0.114)\end{array}$ & $\begin{array}{c}-0.440^{* * *} \\
(0.113)\end{array}$ & $\begin{array}{c}-0.501^{* * *} \\
(0.126)\end{array}$ & $\begin{array}{c}-0.508^{* * *} \\
(0.131)\end{array}$ \\
\hline Observations & 2166 & 2166 & 2166 & 2166 & 2166 & 2166 \\
\hline \multicolumn{7}{|l|}{ Covariates: } \\
\hline Region & $\checkmark$ & $\checkmark$ & $\checkmark$ & $\checkmark$ & $\checkmark$ & $\checkmark$ \\
\hline Year & $\checkmark$ & $\checkmark$ & $\checkmark$ & $\checkmark$ & $\checkmark$ & $\checkmark$ \\
\hline Pre-trends & & $\checkmark$ & $\checkmark$ & $\checkmark$ & $\checkmark$ & $\checkmark$ \\
\hline Computer \& IT & & & $\checkmark$ & $\checkmark$ & $\checkmark$ & $\checkmark$ \\
\hline Chinese imports & & & & $\checkmark$ & $\checkmark$ & $\checkmark$ \\
\hline Demographics & & & & & $\checkmark$ & $\checkmark$ \\
\hline Occupations & & & & & $\checkmark$ & $\checkmark$ \\
\hline Industries & & & & & $\checkmark$ & $\checkmark$ \\
\hline Composition & & & & & & $\checkmark$ \\
\hline
\end{tabular}

Note: This table presents IV estimates of the effect of US robot exposure on the race and ethnicity labor force participation gap and the gender labor force participation gap at the CZ level. Changes are expressed in percentage points of the workingage population subgroup and are multiplied by 100. Independent variables are standardized to have mean zero and standard deviation of one. There are three time periods and $722 \mathrm{CZs}$. Column 1 includes only state fixed effects and time-varying division fixed effects. Column 2 includes also pre-trends in the change of the employment gaps between 1970 and 1990 . Column 3 controls for the adoption of personal computers and IT capital intensity. Column 4 includes the exposure to Chinese imports. Column 5 includes also demographic (share of individuals aged between 25 and 34 years, 35 and 44 years, 45 and 54 years, the share of Blacks, Hispanics, women and individuals with less than a college degree and logarithmic population), industry (share of employment in the contruction, manufacturing, mining, research, service and utilities sector) and occupation (share of employment in routine, offshorable, skill-intensive, white-collar, blue-collar and low-skill occupations) characteristics of CZs in 1990. Column 6 controls also for the initial composition of employment by race, ethnicity and gender within occupation and industry groups. Standard errors are robust against heteroskedasticity and allow for clustering at the state level. Regressions are weighted by $\mathrm{CZ}$ population in 1990 . Coefficients with ${ }^{* * *},{ }^{* *}$ and ${ }^{*}$ are significant at the $1 \%, 5 \%$ and $10 \%$ confidence level. 
Table A10: Robots and race and ethnicity employment gaps in non-manufacturing industries

\begin{tabular}{|c|c|c|c|c|c|c|}
\hline & $\begin{array}{l}\text { Agricul- } \\
\text { ture }\end{array}$ & $\begin{array}{l}\text { Construc- } \\
\text { tion }\end{array}$ & Mining & $\begin{array}{l}\text { Research } \\
\text { and } \\
\text { Education }\end{array}$ & Services & Utilities \\
\hline & {$[1]$} & {$[2]$} & {$[3]$} & {$[4]$} & {$[5]$} & {$[6]$} \\
\hline US robot exposure & $\begin{array}{l}0.069^{*} \\
(0.039)\end{array}$ & $\begin{array}{c}-0.003 \\
(0.051)\end{array}$ & $\begin{array}{c}-0.016 \\
(0.011)\end{array}$ & $\begin{array}{c}-0.037 \\
(0.024)\end{array}$ & $\begin{array}{c}0.607^{* * *} \\
(0.192)\end{array}$ & $\begin{array}{l}0.029^{*} \\
(0.016)\end{array}$ \\
\hline Observations & 2166 & 2166 & 2166 & 2166 & 2166 & 2166 \\
\hline Covariates: & $\checkmark$ & $\checkmark$ & $\checkmark$ & $\checkmark$ & $\checkmark$ & $\checkmark$ \\
\hline
\end{tabular}

Note: This table presents IV estimates of the effect of US robot exposure on the change in the employment gap by race and ethnicity for IFR non-manufacturing sectors (see Table 1) at the CZ level. Changes are expressed in percentage points of the working-age population subgroup and are multiplied by 100. Independent variables are standardized to have mean zero and standard deviation of one. There are three time periods and 722 CZs. All columns include state fixed effects and timevarying division fixed effects and control for the adoption of personal computers, IT capital intensity, the exposure to Chinese imports, as well as for demographic (share of individuals aged between 25 and 34 years, 35 and 44 years, 45 and 54 years, the share of Blacks, Hispanics, women and individuals with less than a college degree and logarithmic population), industry (share of employment in the contruction, manufacturing, mining, research, service and utilities sector) and occupation (share of employment in routine, offshorable, skill-intensive, white-collar, blue-collar and low-skill occupations) characteristics of CZs in 1990 and the initial composition of employment by race, ethnicity and gender within occupation and industry groups in 1990. Standard errors are robust against heteroskedasticity and allow for clustering at the state level. Regressions are weighted by CZ population in 1990 . Coefficients with ${ }^{* * *},{ }^{* *}$ and ${ }^{*}$ are significant at the $1 \%, 5 \%$ and $10 \%$ confidence level. 
Table A11: Industry employment gaps and robots

\begin{tabular}{|c|c|c|}
\hline & $\begin{array}{l}\text { Race and } \\
\text { ethnicity }\end{array}$ & Gender \\
\hline & [1] & {$[2]$} \\
\hline Robots in high robot-intensive industries & $\begin{array}{c}0.394^{* * *} \\
(0.117)\end{array}$ & $\begin{array}{c}-0.297^{* * *} \\
(0.082)\end{array}$ \\
\hline Robots in low robot-intensive industries & $\begin{array}{c}0.385^{* *} \\
(0.149)\end{array}$ & $\begin{array}{l}-0.031 \\
(0.070)\end{array}$ \\
\hline Robots in non-manufacturing industries & $\begin{array}{c}0.044 \\
(0.174)\end{array}$ & $\begin{array}{c}-0.298^{* * *} \\
(0.080)\end{array}$ \\
\hline Observations & 2166 & 2166 \\
\hline Covariates: & $\checkmark$ & $\checkmark$ \\
\hline
\end{tabular}

Note: This table presents reduced form estimates of the effect of EU7 robot exposure by industry on the change in the employment gaps by race and ethnicity and gender at the CZ level. Industry groups are created according to the relative adoption of industrial robots of industries. High robot-intensive manufacturing industries include the industries with the heaviest adoption of industrial robots. Low robot-intensive manufacturing industries include the remaining manufacturing industries, while non-manufacturing industries include all industries outside of the manufacturing sector. Changes are expressed in percentage points of the working-age population subgroup and are multiplied by 100 . Independent variables are standardized to have mean zero and standard deviation of one. There are three time periods and $722 \mathrm{CZs}$. All columns include state fixed effects and time-varying division fixed effects and control for the adoption of personal computers, IT capital intensity, the exposure to Chinese imports, as well as for demographic (share of individuals aged between 25 and 34 years, 35 and 44 years, 45 and 54 years, the share of Blacks, Hispanics, women and individuals with less than a college degree and logarithmic population), industry (share of employment in the contruction, manufacturing, mining, research, service and utilities sector) and occupation (share of employment in routine, offshorable, skill-intensive, white-collar, blue-collar and low-skill occupations) characteristics of CZs in 1990 and the initial composition of employment by race, ethnicity and gender within occupation and industry groups in 1990. Standard errors are robust against heteroskedasticity and allow for clustering at the state level. Regressions are weighted by $\mathrm{CZ}$ population in 1990 . Coefficients with ${ }^{* * *},{ }^{* *}$ and ${ }^{*}$ are significant at the $1 \%, 5 \%$ and $10 \%$ confidence level. 
Table A12: Robots and industry employment by race and ethnicity as a share of total population

\begin{tabular}{|c|c|c|c|c|c|c|}
\hline & \multicolumn{2}{|c|}{ High robot-intensive } & \multicolumn{2}{|c|}{ Low robot-intensive } & \multicolumn{2}{|c|}{ Non-manufacturing } \\
\hline & White & Non-white & White & Non-white & White & Non-white \\
\hline & [1] & {$[2]$} & {$[3]$} & {$[4]$} & {$[5]$} & {$[6]$} \\
\hline US robot exposure & $\begin{array}{c}-0.285^{* * *} \\
(0.062)\end{array}$ & $\begin{array}{c}-0.116^{* * *} \\
(0.032)\end{array}$ & $\begin{array}{c}0.057 \\
(0.040)\end{array}$ & $\begin{array}{c}0.006 \\
(0.017)\end{array}$ & $\begin{array}{c}-0.250^{* * *} \\
(0.086)\end{array}$ & $\begin{array}{c}-0.210^{*} \\
(0.115)\end{array}$ \\
\hline Observations & 2166 & 2166 & 2166 & 2166 & 2166 & 2166 \\
\hline Covariates: & $\checkmark$ & $\checkmark$ & $\checkmark$ & $\checkmark$ & $\checkmark$ & $\checkmark$ \\
\hline
\end{tabular}

Note: This table presents IV estimates of the effect of US robot exposure on the change in the employment rates of whites and non-whites by industry groups at the $\mathrm{CZ}$ level. Industry groups are created according to the relative adoption of industrial robots of industries. High robot-intensive manufacturing industries include the industries with the heaviest adoption of industrial robots. Low robot-intensive manufacturing industries include the remaining manufacturing industries, while non-manufacturing industries include all industries outside of the manufacturing sector. Changes are expressed in percentage points of the total (white and non-white) working-age population and are multiplied by 100 . Independent variables are standardized to have mean zero and standard deviation of one. There are three time periods and $722 \mathrm{CZs}$. All columns include state fixed effects and time-varying division fixed effects and control for the adoption of personal computers, IT capital intensity, the exposure to Chinese imports, as well as for demographic (share of individuals aged between 25 and 34 years, 35 and 44 years, 45 and 54 years, the share of Blacks, Hispanics, women and individuals with less than a college degree and logarithmic population), industry (share of employment in the contruction, manufacturing, mining, research, service and utilities sector) and occupation (share of employment in routine, offshorable, skill-intensive, white-collar, blue-collar and low-skill occupations) characteristics of CZs in 1990 and the initial composition of employment by race, ethnicity and gender within occupation and industry groups in 1990. Standard errors are robust against heteroskedasticity and allow for clustering at the state level. Regressions are weighted by $\mathrm{CZ}$ population in 1990 . Coefficients with ${ }^{* * *},{ }^{* *}$ and ${ }^{*}$ are significant at the $1 \%, 5 \%$ and $10 \%$ confidence level. 
Table A13: Descriptive statistics: Employment gaps by occupation and industry

\begin{tabular}{|c|c|c|c|c|c|c|c|c|}
\hline & \multicolumn{8}{|c|}{ Panel A: Occupation } \\
\hline & \multicolumn{2}{|c|}{ Skill intensive } & \multicolumn{2}{|c|}{ White collar } & \multicolumn{2}{|c|}{ Blue collar } & \multicolumn{2}{|c|}{ Low skills } \\
\hline & 1990 & $\overline{\Delta_{14-90}}$ & 1990 & $\overline{\Delta_{14-90}}$ & 1990 & $\overline{\Delta_{14-90}}$ & 1990 & $\Delta_{14-90}$ \\
\hline & $\overline{[1]}$ & {$[2]$} & {$[3]$} & {$[4]$} & {$[5]$} & {$[6]$} & {$[7]$} & {$[8]$} \\
\hline Race and ethnicity & 2.71 & -0.99 & 15.0 & -1.40 & -5.40 & 0.23 & -4.90 & -0.98 \\
\hline Gender & 3.47 & -4.20 & 0.53 & -1.40 & 11.8 & -0.00 & -0.84 & 0.19 \\
\hline \multirow[t]{5}{*}{ Observations } & 722 & 722 & 722 & 722 & 722 & 722 & 722 & 722 \\
\hline & \multicolumn{8}{|c|}{ Panel B: Industry } \\
\hline & & \multicolumn{2}{|c|}{$\begin{array}{l}\text { High robot-intensive } \\
\text { manufacturing }\end{array}$} & \multicolumn{2}{|c|}{$\begin{array}{l}\text { Low robot-intensive } \\
\text { manufacturing }\end{array}$} & \multicolumn{2}{|c|}{$\begin{array}{c}\text { Non- } \\
\text { manufacturing }\end{array}$} & \\
\hline & & 1990 & $\overline{\Delta_{14-90}}$ & 1990 & $\overline{\Delta_{14-90}}$ & 1990 & $\overline{\Delta_{14-90}}$ & \\
\hline & & {$[1]$} & {$[2]$} & {$[3]$} & [4] & {$[5]$} & {$[6]$} & \\
\hline Race and ethnicity & & -0.94 & 0.13 & 0.15 & 0.30 & 8.67 & -3.10 & \\
\hline Gender & & 5.70 & -1.50 & 4.40 & -1.10 & 8.03 & -4.20 & \\
\hline Observations & & 722 & 722 & 722 & 722 & 722 & 722 & \\
\hline
\end{tabular}

Note: This table presents the average employment gaps by race and ethnicity and by gender in 1990 as well as changes between 1990 and 2014 across industry and occupation groups weighted by CZ population in 1990. Occupation groups are computed from a median split of the standardized measures of the brawn and brain task content of jobs. Skill-intensive jobs include occupations that are both brawn and brain task intensive. White-collar jobs include occupations that are brain task intensive and require only few brawn skills. Blue-collar jobs include occupations that are brawn task intensive and require only few brain skills. Low-skill jobs include occupations that do not require particular brawn or brain skills. Industry groups are created according to the relative adoption of industrial robots of industries. High robot-intensive manufacturing industries include the industries with the heaviest adoption of industrial robots. Low robot-intensive manufacturing industries include the remaining manufacturing industries, while non-manufacturing industries include all industries outside of the manufacturing sector. 
Table A14: Robustness check: Product market competition from Europe

\begin{tabular}{|c|c|c|c|c|}
\hline & \multicolumn{2}{|c|}{ Race and ethnicity } & \multicolumn{2}{|c|}{ Gender } \\
\hline & All & $\begin{array}{l}\text { Less than } \\
\text { college }\end{array}$ & All & $\begin{array}{c}\text { Less than } \\
\text { college }\end{array}$ \\
\hline & {$[1]$} & {$[2]$} & {$[3]$} & {$[4]$} \\
\hline \multicolumn{5}{|c|}{ Panel A: Import competition in the US } \\
\hline US robot exposure & $\begin{array}{c}0.750^{* * *} \\
(0.257)\end{array}$ & $\begin{array}{c}0.866^{* * *} \\
(0.281)\end{array}$ & $\begin{array}{c}-0.597^{* * *} \\
(0.155)\end{array}$ & $\begin{array}{c}-0.850^{* * *} \\
(0.175)\end{array}$ \\
\hline US imports from EU7 & $\begin{array}{c}0.189^{*} \\
(0.104)\end{array}$ & $\begin{array}{c}0.234^{* *} \\
(0.105)\end{array}$ & $\begin{array}{l}-0.067 \\
(0.069)\end{array}$ & $\begin{array}{c}-0.083 \\
(0.078)\end{array}$ \\
\hline Observations & 2166 & 2166 & 2166 & 2166 \\
\hline \multicolumn{5}{|c|}{ Panel B: Import competition in Canada } \\
\hline US robot exposure & $\begin{array}{c}0.818^{* * *} \\
(0.270)\end{array}$ & $\begin{array}{c}0.949^{* * *} \\
(0.294)\end{array}$ & $\begin{array}{c}-0.621^{* * *} \\
(0.162)\end{array}$ & $\begin{array}{c}-0.880^{* * *} \\
(0.187)\end{array}$ \\
\hline CAN imports from EU7 & $\begin{array}{l}-0.079 \\
(0.122)\end{array}$ & $\begin{array}{c}-0.072 \\
(0.146)\end{array}$ & $\begin{array}{c}0.042 \\
(0.064)\end{array}$ & $\begin{array}{c}0.088 \\
(0.082)\end{array}$ \\
\hline Observations & 2166 & 2166 & 2166 & 2166 \\
\hline \multicolumn{5}{|c|}{ Panel C: Include only countries with least trade with the US } \\
\hline US robot exposure & $\begin{array}{l}0.572^{*} \\
(0.313)\end{array}$ & $\begin{array}{l}0.620^{*} \\
(0.341)\end{array}$ & $\begin{array}{c}-0.307^{* *} \\
(0.127)\end{array}$ & $\begin{array}{c}-0.443^{* * *} \\
(0.160)\end{array}$ \\
\hline Observations & 2166 & 2166 & 2166 & 2166 \\
\hline Covariates: & $\checkmark$ & $\checkmark$ & $\checkmark$ & $\checkmark$ \\
\hline
\end{tabular}

Note: This table presents IV estimates of the effect of US robot exposure on the change in the employment gaps at the CZ level. Changes are expressed in percentage points of the working-age population subgroup and are multiplied by 100 . Independent variables are standardized to have mean zero and standard deviation of one. There are three time periods and 722 CZs. Panel A includes a shift-share measure of US imports from the seven European countries included in the instrument. Panel B includes a shift-share measure of Canadian imports from the seven European countries included in the instrument. Panel C reports IV estimates using an instrument that includes only the four European countries with the lowest trade engagement with the US (Denmark, Finland, Spain and Sweden). Columns 1 and 3 report results for all individuals, while Columns 2 and 4 report results for individuals with less than a college degree. All columns include state fixed effects and time-varying division fixed effects and control for the adoption of personal computers, IT capital intensity, the exposure to Chinese imports, as well as for demographic (share of individuals aged between 25 and 34 years, 35 and 44 years, 45 and 54 years, the share of Blacks, Hispanics, women and individuals with less than a college degree and logarithmic population), industry (share of employment in the contruction, manufacturing, mining, research, service and utilities sector) and occupation (share of employment in routine, offshorable, skill-intensive, white-collar, blue-collar and low-skill occupations) characteristics of CZs in 1990 and the initial composition of employment by race, ethnicity and gender within occupation and industry groups in 1990. Standard errors are robust against heteroskedasticity and allow for clustering at the state level. Regressions are weighted by CZ population in 1990. Coefficients with ${ }^{* * *},{ }^{* *}$ and ${ }^{*}$ are significant at the $1 \%, 5 \%$ and $10 \%$ confidence level. 
Table A15: Robustness check: Placebo test

\begin{tabular}{|c|c|c|c|c|}
\hline & \multicolumn{2}{|c|}{ Race and ethnicity } & \multicolumn{2}{|c|}{ Gender } \\
\hline & All & $\begin{array}{c}\text { Less than } \\
\text { college }\end{array}$ & All & $\begin{array}{c}\text { Less than } \\
\text { college }\end{array}$ \\
\hline & [1] & {$[2]$} & {$[3]$} & {$[4]$} \\
\hline US robot exposure & $\begin{array}{c}-0.010 \\
(0.137)\end{array}$ & $\begin{array}{c}0.074 \\
(0.204)\end{array}$ & $\begin{array}{c}0.175 \\
(0.190)\end{array}$ & $\begin{array}{c}0.303 \\
(0.191)\end{array}$ \\
\hline Observations & 1444 & 1444 & 1444 & 1444 \\
\hline Covariates: & $\checkmark$ & $\checkmark$ & $\checkmark$ & $\checkmark$ \\
\hline
\end{tabular}

Note: This table presents IV estimates of the effect of US robot exposure on the employment gaps prior to 1990 at the CZ level. Changes are expressed in percentage points of the working-age population subgroup and are multiplied by 100 . Independent variables are standardized to have mean zero and standard deviation of one. There are two time periods (1970-80 and 1980-90 for the employment gaps and 1990-2000 and 2000-07 for robot exposure) and 722 CZs. Columns 1 and 3 report results for all individuals, while Columns 2 and 4 report results for individuals with less than a college degree. All columns include state fixed effects and time-varying division fixed effects and control for the adoption of personal computers, IT capital intensity, the exposure to Chinese imports, as well as for demographic (share of individuals aged between 25 and 34 years, 35 and 44 years, 45 and 54 years, the share of Blacks, Hispanics, women and individuals with less than a college degree and logarithmic population), industry (share of employment in the contruction, manufacturing, mining, research, service and utilities sector) and occupation (share of employment in routine, offshorable, skill-intensive, white-collar, blue-collar and low-skill occupations) characteristics of CZs in 1970 and the initial composition of employment by race, ethnicity and gender within occupation and industry groups in 1970. Standard errors are robust against heteroskedasticity and allow for clustering at the state level. Regressions are weighted by $\mathrm{CZ}$ population in 1990 . Coefficients with ${ }^{* * *},{ }^{* *}$ and ${ }^{*}$ are significant at the $1 \%, 5 \%$ and $10 \%$ confidence level. 
Table A16: Robustness check: Weights

\begin{tabular}{|c|c|c|c|c|c|c|}
\hline & \multicolumn{6}{|c|}{ Panel A: Race and ethnicity } \\
\hline & All & $\begin{array}{l}\text { Less than } \\
\text { college }\end{array}$ & All & $\begin{array}{l}\text { Less than } \\
\text { college }\end{array}$ & All & $\begin{array}{c}\text { Less than } \\
\text { college }\end{array}$ \\
\hline & {$[1]$} & {$[2]$} & {$[3]$} & {$[4]$} & {$[5]$} & {$[6]$} \\
\hline US robot exposure & $\begin{array}{c}1.214^{* * *} \\
(0.349)\end{array}$ & $\begin{array}{c}1.391^{* * *} \\
(0.398)\end{array}$ & $\begin{array}{l}-0.035 \\
(0.390)\end{array}$ & $\begin{array}{c}0.119 \\
(0.486)\end{array}$ & $\begin{array}{c}0.834^{* *} \\
(0.315)\end{array}$ & $\begin{array}{l}1.039^{* *} \\
(0.406)\end{array}$ \\
\hline \multirow[t]{4}{*}{ Observations } & 2166 & 2166 & 2166 & 2166 & 825 & 825 \\
\hline & \multicolumn{6}{|c|}{ Panel B: Gender } \\
\hline & All & $\begin{array}{c}\text { Less than } \\
\text { college }\end{array}$ & All & $\begin{array}{l}\text { Less than } \\
\text { college }\end{array}$ & All & $\begin{array}{c}\text { Less than } \\
\text { college }\end{array}$ \\
\hline & {$[1]$} & {$[2]$} & {$[3]$} & {$[4]$} & {$[5]$} & {$[6]$} \\
\hline US robot exposure & $\begin{array}{c}0.886^{* * *} \\
(0.199)\end{array}$ & $\begin{array}{c}-1.244^{* * *} \\
(0.255)\end{array}$ & $\begin{array}{c}-0.860^{* *} \\
(0.320)\end{array}$ & $\begin{array}{c}-1.139^{* * *} \\
(0.396)\end{array}$ & $\begin{array}{c}-0.576^{* *} \\
(0.249)\end{array}$ & $\begin{array}{c}-0.684^{* *} \\
(0.291)\end{array}$ \\
\hline Observations & 2166 & 2166 & 2166 & 2166 & 825 & 825 \\
\hline \multicolumn{7}{|l|}{ Covariates: } \\
\hline Division & $\checkmark$ & $\checkmark$ & $\checkmark$ & $\checkmark$ & $\checkmark$ & $\checkmark$ \\
\hline Year & $\checkmark$ & $\checkmark$ & $\checkmark$ & $\checkmark$ & $\checkmark$ & $\checkmark$ \\
\hline Computer \& IT & $\checkmark$ & $\checkmark$ & $\checkmark$ & $\checkmark$ & $\checkmark$ & $\checkmark$ \\
\hline Chinese imports & $\checkmark$ & $\checkmark$ & $\checkmark$ & $\checkmark$ & $\checkmark$ & $\checkmark$ \\
\hline Demographics & $\checkmark$ & $\checkmark$ & $\checkmark$ & $\checkmark$ & $\checkmark$ & $\checkmark$ \\
\hline Occupations & $\checkmark$ & $\checkmark$ & $\checkmark$ & $\checkmark$ & $\checkmark$ & $\checkmark$ \\
\hline Industries & $\checkmark$ & $\checkmark$ & $\checkmark$ & $\checkmark$ & $\checkmark$ & $\checkmark$ \\
\hline Non-white population weights & $\checkmark$ & & & $\checkmark$ & & \\
\hline Unweighted & & $\checkmark$ & $\checkmark$ & & $\checkmark$ & $\checkmark$ \\
\hline Non-white CZs & & & $\checkmark$ & & & $\checkmark$ \\
\hline
\end{tabular}

Note: This table presents IV estimates of the effect of US robot exposure on the change in the employment gaps at the CZ level using different regression weights. Changes are expressed in percentage points of the working-age population subgroup and are multiplied by 100. Independent variables are standardized to have mean zero and standard deviation of one. There are three time periods and $722 \mathrm{CZs}$ in the first four columns and $275 \mathrm{CZs}$ in the last two columns, which restrict the sample to CZs with a population of non-whites and a share of non-whites above the respective local labor market median in 1990 . Odd columns report results for all individuals, while even columns report results for individuals with less than a college degree. All columns include state fixed effects and time-varying division fixed effects and control for the adoption of personal computers, IT capital intensity, the exposure to Chinese imports, as well as for demographic (share of individuals aged between 25 and 34 years, 35 and 44 years, 45 and 54 years, the share of Blacks, Hispanics, women and individuals with less than a college degree and logarithmic population), industry (share of employment in the contruction, manufacturing, mining, research, service and utilities sector) and occupation (share of employment in routine, offshorable, skill-intensive, white-collar, blue-collar and lowskill occupations) characteristics of CZs in 1990 and the initial composition of employment by race, ethnicity and gender within occupation and industry groups in 1990. Standard errors are robust against heteroskedasticity and allow for clustering at the state level. Regressions in the first two columns are weighted by CZ non-white population of non-whites in 1990 . Regressions in the remaining columns are unweighted. Coefficients with ${ }^{* * *},{ }^{* *}$ and ${ }^{*}$ are significant at the $1 \%, 5 \%$ and $10 \%$ confidence level. 
Table A17: Robustness check: Alternative construction of the instrument

\begin{tabular}{|c|c|c|c|c|}
\hline & \multicolumn{2}{|c|}{ Race and ethnicity } & \multicolumn{2}{|c|}{ Gender } \\
\hline & All & $\begin{array}{l}\text { Less than } \\
\text { college }\end{array}$ & All & $\begin{array}{l}\text { Less than } \\
\text { college }\end{array}$ \\
\hline & [1] & {$[2]$} & {$[3]$} & [4] \\
\hline \multicolumn{5}{|c|}{ Panel A: EU7 countries and Germany } \\
\hline US robot exposure & $\begin{array}{c}0.704^{* * *} \\
(0.236)\end{array}$ & $\begin{array}{c}0.804^{* * *} \\
(0.255)\end{array}$ & $\begin{array}{c}-0.542^{* * *} \\
(0.142)\end{array}$ & $\begin{array}{c}-0.765^{* * *} \\
(0.166)\end{array}$ \\
\hline Observations & 2166 & 2166 & 2166 & 2166 \\
\hline \multicolumn{5}{|c|}{ Panel B: EU5 countries (Acemoglu and Restrepo, 2020) } \\
\hline US robot exposure & $\begin{array}{c}0.901^{* * *} \\
(0.304)\end{array}$ & $\begin{array}{c}1.027^{* * *} \\
(0.333)\end{array}$ & $\begin{array}{c}-0.605^{* * *} \\
(0.158)\end{array}$ & $\begin{array}{c}-0.850^{* * *} \\
(0.195)\end{array}$ \\
\hline Observations & 2166 & 2166 & 2166 & 2166 \\
\hline \multicolumn{5}{|c|}{ Panel C: EU7 countries with $\ell_{j, c}^{1990}$} \\
\hline US robot exposure & $\begin{array}{c}0.917^{* * *} \\
(0.274)\end{array}$ & $\begin{array}{c}0.986^{* * *} \\
(0.306)\end{array}$ & $\begin{array}{c}-0.570^{* * *} \\
(0.154)\end{array}$ & $\begin{array}{c}-0.765^{* * *} \\
(0.194)\end{array}$ \\
\hline Observations & 2166 & 2166 & 2166 & 2166 \\
\hline \multicolumn{5}{|c|}{ Panel D: EU7 countries without $g_{j,\left(t_{0}, t_{1}\right)} \frac{R_{j, t_{0}}}{L_{j, 1990}}$} \\
\hline US robot exposure & $\begin{array}{c}0.629^{* * *} \\
(0.227)\end{array}$ & $\begin{array}{c}0.763^{* * *} \\
(0.249)\end{array}$ & $\begin{array}{c}-0.484^{* * *} \\
(0.154)\end{array}$ & $\begin{array}{c}-0.722^{* * *} \\
(0.171)\end{array}$ \\
\hline Observations & 2166 & 2166 & 2166 & 2166 \\
\hline Covariates: & $\checkmark$ & $\checkmark$ & $\checkmark$ & $\checkmark$ \\
\hline
\end{tabular}

Note: This table presents IV estimates of the effect of US robot exposure on the change in the employment gaps at the CZ level using different instrument measures. Changes are expressed in percentage points of the working-age population subgroup and are multiplied by 100. Independent variables are standardized to have mean zero and standard deviation of one. There are three time periods and $722 \mathrm{CZs}$. Panel A reports estimates using an instrument which includes seven European countries and Germany. Panel B reports estimates using an instrument that includes only five European countries. I exclude Spain and the United Kingdom as in the measure of Acemoglu and Restrepo (2020). Panel C reports estimates using an instrument with seven European countries, but US employment shares of 1990 instead of 1970. Panel D reports estimates using an endogenous variable and an instrument of robot density without the adjustment term of industry growth. Columns 1 and 3 report results for all individuals, while Columns 2 and 4 report results for individuals with less than a college degree. All columns include state fixed effects and time-varying division fixed effects and control for the adoption of personal computers, IT capital intensity, the exposure to Chinese imports, as well as for demographic (share of individuals aged between 25 and 34 years, 35 and 44 years, 45 and 54 years, the share of Blacks, Hispanics, women and individuals with less than a college degree and logarithmic population), industry (share of employment in the contruction, manufacturing, mining, research, service and utilities sector) and occupation (share of employment in routine, offshorable, skill-intensive, white-collar, blue-collar and low-skill occupations) characteristics of CZs in 1990 and the initial composition of employment by race, ethnicity and gender within occupation and industry groups in 1990. Standard errors are robust against heteroskedasticity and allow for clustering at the state level. Regressions are weighted by $\mathrm{CZ}$ population in 1990 . Coefficients with ${ }^{* * *},{ }^{* *}$ and ${ }^{*}$ are significant at the $1 \%, 5 \%$ and $10 \%$ confidence level. 
Table A18: Robustness check: Exclude CZs with highest robot exposure

\begin{tabular}{|c|c|c|c|c|}
\hline & \multicolumn{2}{|c|}{ Race and ethnicity } & \multicolumn{2}{|c|}{ Gender } \\
\hline & All & $\begin{array}{l}\text { Less than } \\
\text { college }\end{array}$ & All & $\begin{array}{l}\text { Less than } \\
\text { college }\end{array}$ \\
\hline & [1] & {$[2]$} & {$[3]$} & [4] \\
\hline \multicolumn{5}{|c|}{ Panel A: Exclusion of Detroit area } \\
\hline US robot exposure & $\begin{array}{l}1.040^{* *} \\
(0.422)\end{array}$ & $\begin{array}{c}1.273^{* * *} \\
(0.465)\end{array}$ & $\begin{array}{c}-0.488^{*} \\
(0.276)\end{array}$ & $\begin{array}{l}-0.694^{*} \\
(0.350)\end{array}$ \\
\hline Observations & 2163 & 2163 & 2163 & 2163 \\
\hline \multicolumn{5}{|c|}{ Panel B: Exclusion of CZs with highest US robot exposure } \\
\hline US robot exposure & $\begin{array}{c}0.988 \\
(0.619)\end{array}$ & $\begin{array}{l}1.367^{*} \\
(0.701)\end{array}$ & $\begin{array}{l}-0.505 \\
(0.375)\end{array}$ & $\begin{array}{l}-0.814^{*} \\
(0.448)\end{array}$ \\
\hline Observations & 2142 & 2142 & 2142 & 2142 \\
\hline Covariates: & $\checkmark$ & $\checkmark$ & $\checkmark$ & $\checkmark$ \\
\hline
\end{tabular}

Note: This table presents IV estimates of the effect of US robot exposure on the change in the employment gaps at the CZ level excluding the set of CZs with the largest robot exposure. Changes are expressed in percentage points of the workingage population subgroup and are multiplied by 100. Independent variables are standardized to have mean zero and standard deviation of one. There are three time periods and $722 \mathrm{CZs}$. Panel A reports estimates excluding Detroit from the sample. Panel B reports estimates excluding the CZs in the top 1 percentile of US robot exposure between 1993 and 2014 . Columns 1 and 3 report results for all individuals, while Columns 2 and 4 report results for individuals with less than a college degree. All columns include state fixed effects and time-varying division fixed effects and control for the adoption of personal computers, IT capital intensity, the exposure to Chinese imports, as well as for demographic (share of individuals aged between 25 and 34 years, 35 and 44 years, 45 and 54 years, the share of Blacks, Hispanics, women and individuals with less than a college degree and logarithmic population), industry (share of employment in the contruction, manufacturing, mining, research, service and utilities sector) and occupation (share of employment in routine, offshorable, skill-intensive, white-collar, blue-collar and low-skill occupations) characteristics of CZs in 1990 and the initial composition of employment by race, ethnicity and gender within occupation and industry groups in 1990. Standard errors are robust against heteroskedasticity and allow for clustering at the state level. Regressions are weighted by CZ population in 1990 . Coefficients with ${ }^{* * *},{ }^{* *}$ and ${ }^{*}$ are significant at the $1 \%$, $5 \%$ and $10 \%$ confidence level. 
Table A19: Robustness check: Unobserved heterogeneity

\begin{tabular}{|c|c|c|c|c|}
\hline & \multicolumn{2}{|c|}{ Race and ethnicity } & \multicolumn{2}{|c|}{ Gender } \\
\hline & All & $\begin{array}{c}\text { Less than } \\
\text { college }\end{array}$ & All & $\begin{array}{l}\text { Less than } \\
\text { college }\end{array}$ \\
\hline & {$[1]$} & {$[2]$} & {$[3]$} & {$[4]$} \\
\hline \multicolumn{5}{|c|}{ Panel A: Inclusion of beginning of subperiod covariates } \\
\hline US robot exposure & $\begin{array}{l}0.457^{* *} \\
(0.183)\end{array}$ & $\begin{array}{c}0.557^{* * *} \\
(0.195)\end{array}$ & $\begin{array}{c}-0.564^{* * *} \\
(0.113)\end{array}$ & $\begin{array}{c}-0.753^{* * *} \\
(0.149)\end{array}$ \\
\hline Observations & 2166 & 2166 & 2166 & 2166 \\
\hline \multicolumn{5}{|c|}{ Panel B: Inclusion of CZ fixed effects and beginning of subperiod covariates } \\
\hline US robot exposure & $\begin{array}{c}1.344^{* * *} \\
(0.154)\end{array}$ & $\begin{array}{c}1.499^{* * *} \\
(0.169)\end{array}$ & $\begin{array}{c}-0.855^{* * *} \\
(0.168)\end{array}$ & $\begin{array}{c}-1.058^{* * *} \\
(0.217)\end{array}$ \\
\hline Observations & 2166 & 2166 & 2166 & 2166 \\
\hline Covariates: & $\checkmark$ & $\checkmark$ & $\checkmark$ & $\checkmark$ \\
\hline
\end{tabular}

Note: This table presents IV estimates of the effect of US robot exposure on the change in the employment gaps at the CZ level using time-varying covariates (Panel A) and fully exploiting temporal variation in robot exposure within labor markets (Panel B). Changes are expressed in percentage points of the working-age population subgroup and are multiplied by 100 . Independent variables are standardized to have mean zero and standard deviation of one. There are three time periods and $722 \mathrm{CZs}$. Columns 1 and 3 report results for all individuals, while Columns 2 and 4 report results for individuals with less than a college degree. All columns include state fixed effects and time-varying division fixed effects and control for the adoption of personal computers, IT capital intensity, the exposure to Chinese imports, as well as for demographic (share of individuals aged between 25 and 34 years, 35 and 44 years, 45 and 54 years, the share of Blacks, Hispanics, women and individuals with less than a college degree and logarithmic population), industry (share of employment in the contruction, manufacturing, mining, research, service and utilities sector) and occupation (share of employment in routine, offshorable, skill-intensive, white-collar, blue-collar and low-skill occupations) characteristics of CZs at the beginning of each period and the initial composition of employment by race, ethnicity and gender within occupation and industry groups at the beginning of each period. Standard errors are robust against heteroskedasticity and allow for clustering at the state level. Regressions are weighted by CZ population in 1990. Coefficients with $^{* * *},{ }^{* *}$ and ${ }^{*}$ are significant at the $1 \%, 5 \%$ and $10 \%$ confidence level. 
Table A20: Exclusion of the Great Recession period (2007-14)

\begin{tabular}{|c|c|c|c|c|c|c|}
\hline & \multicolumn{6}{|c|}{ Panel A: Race and ethnicity } \\
\hline & [1] & {$[2]$} & {$[3]$} & {$[4]$} & {$[5]$} & [6] \\
\hline US robot exposure & $\begin{array}{l}0.553^{* *} \\
(0.230)\end{array}$ & $\begin{array}{c}0.613^{* *} \\
(0.230)\end{array}$ & $\begin{array}{l}0.600^{* *} \\
(0.231)\end{array}$ & $\begin{array}{c}0.599^{* *} \\
(0.230)\end{array}$ & $\begin{array}{c}0.720^{* * *} \\
(0.252)\end{array}$ & $\begin{array}{c}0.754^{* * *} \\
(0.276)\end{array}$ \\
\hline \multirow[t]{3}{*}{ Observations } & 1444 & 1444 & 1444 & 1444 & 1444 & 1444 \\
\hline & \multicolumn{6}{|c|}{ Panel B: Gender } \\
\hline & [1] & {$[2]$} & {$[3]$} & {$[4]$} & {$[5]$} & {$[6]$} \\
\hline US robot exposure & $\begin{array}{c}-0.457^{* * *} \\
(0.106)\end{array}$ & $\begin{array}{c}-0.468^{* * *} \\
(0.104)\end{array}$ & $\begin{array}{c}-0.553^{* * *} \\
(0.132)\end{array}$ & $\begin{array}{c}-0.553^{* * *} \\
(0.133)\end{array}$ & $\begin{array}{c}-0.582^{* * *} \\
(0.121)\end{array}$ & $\begin{array}{c}-0.548^{* * *} \\
(0.120)\end{array}$ \\
\hline Observations & 1444 & 1444 & 1444 & 1444 & 1444 & 1444 \\
\hline \multicolumn{7}{|l|}{ Covariates: } \\
\hline Region & $\checkmark$ & $\checkmark$ & $\checkmark$ & $\checkmark$ & $\checkmark$ & $\checkmark$ \\
\hline Year & $\checkmark$ & $\checkmark$ & $\checkmark$ & $\checkmark$ & $\checkmark$ & $\checkmark$ \\
\hline Pre-trends & & $\checkmark$ & $\checkmark$ & $\checkmark$ & $\checkmark$ & $\checkmark$ \\
\hline Computer \& IT & & & $\checkmark$ & $\checkmark$ & $\checkmark$ & $\checkmark$ \\
\hline Chinese imports & & & & $\checkmark$ & $\checkmark$ & $\checkmark$ \\
\hline Demographics & & & & & $\checkmark$ & $\checkmark$ \\
\hline Occupations & & & & & $\checkmark$ & $\checkmark$ \\
\hline Industries & & & & & $\checkmark$ & $\checkmark$ \\
\hline Composition & & & & & & $\checkmark$ \\
\hline
\end{tabular}

Note: This table presents IV estimates of the effect of US robot exposure on the change in the race and ethnicity employment gap and the gender employment gap at the CZ level, excluding the Great Recession period. Changes are expressed in percentage points of the working-age population subgroup and are multiplied by 100 . Independent variables are standardized to have mean zero and standard deviation of one. There are two time periods (1990-2000 and 2000-07) and 722 CZs. Column 1 includes only state fixed effects and time-varying division fixed effects. Column 2 includes also pre-trends in the change of the employment gaps between 1970 and 1990. Column 3 controls for the adoption of personal computers and IT capital intensity. Column 4 includes the exposure to Chinese imports. Column 5 includes also demographic (share of individuals aged between 25 and 34 years, 35 and 44 years, 45 and 54 years, the share of Blacks, Hispanics, women and individuals with less than a college degree and logarithmic population), industry (share of employment in the contruction, manufacturing, mining, research, service and utilities sector) and occupation (share of employment in routine, offshorable, skill-intensive, white-collar, blue-collar and low-skill occupations) characteristics of CZs in 1990. Column 6 controls also for the initial composition of employment by race, ethnicity and gender within occupation and industry groups. Standard errors are robust against heteroskedasticity and allow for clustering at the state level. Regressions are weighted by CZ population in 1990 . Coefficients with ${ }^{* * *},{ }^{* *}$ and ${ }^{*}$ are significant at the $1 \%, 5 \%$ and $10 \%$ confidence level. 


\section{IdEP Economic Papers}

The series IdEP Economic Papers, ideally continues the work of the "Quaderni della Facoltà" the publication of which began in 1998 and ended in 2013.

For a complete list of the Quaderni see: http://econpapers.repec.org/paper/lugwpaper/

IdEP Economic Papers also gathers the legacy of the CEPRA Working Papers, published from 2012 to 2013.

The full list at: http://econpapers.repec.org/paper/lugwcepra/

2014:

No. 01

F. Mazzonna, F. Peracchi, Unhealthy retirement? Evidence of occupation heterogeneity

No. 02

L. Di Giorgio, M. Filippini, G. Masiero, The relationship between costs and quality in nonprofit nursing homes

No. 03

F.C. Billari, V. Galasso, Fertility decisions and pension reforms : evidence from natural experiments in Italy

No. 04

M. Jametti, M. Joanis, Elections and de facto expenditure decentralization in Canada

No. 05

M. Jametti, Weathering the global financial crisis : is direct democracy of any help?

No. 06

U. Pagano, M. Vatiero, Costly institutions as substitutes : novelty and limits of the Coasian approach

No. 07

R. Parchet, Are local tax rates strategic complements or strategic substitutes?

No. 08

R. Ippoliti, M. Vatiero, An analysis of how 2002 judicial reorganization has impacted on the performance of the First Instance Courts (Preture) in Ticino

No. 09

F. Mazzonna, P. Salari, Short term effects of public smoking bans on health 
2015:

No. 01

S. Galletta, Direct democracy, partial decentralization and voter information : evidence from Swiss municipalities

No. 02

I. Sarman, Second homeowners' intention to move : an integrated ordered logit model with latent variable

No. 03

M.J. Roe, M. Vatiero, Corporate governance and its political economy

No. 04

M. Filippini, M. Koller, G. Masiero, Competitive tendering versus performance-based negotiation in Swiss public transport

No. 05

O. Giuntella, F. Mazzonna, If you don't snooze you lose health and gain weight : evidence from a regression discontinuity design

No. 06

M. Filippini, B. Hirl, G. Masiero, Rational habits in residential electricity demand

2016:

No. 01

S. Galletta, Law enforcement, municipal budgets and spillover effects: evidence from a quasiexperiment in Italy

No. 02

S. Galletta, A. Redonda, Corporate flat tax reforms and businesses'location choices. Evidence from Switzerland

No. 03

M. Filippini, W. Greene, G. Masiero, Persistent and transient productive inefficiency in a regulated industry: electricity distribution in New Zealand 
No. 04

M. Vatiero, On the (political) origin of "corporate governance" species

No. 05

E. Gentili, G. Masiero, F. Mazzonna, The role of culture in long-term care

No. 06

M. Vatiero, Learning from the Swiss corporate governance exception

No. 07

F. Cavalcanti, G. Daniele, S. Galletta, Popularity shocks and political selection : the effects of anti-corruption audits on candidates' quality

2017:

No. 01

P. Bello, Exchange rate fluctuations and border crossings : evidence from the Swiss-Italian border

No. 02

E. Gentili, F. Mazzonna, What drives the substitutability between native and foreign workers? Evidence about the role of language

No. 03

G. Daniele, S. Galletta, B. Geys, Abandon ship? Party brands and politicians' responses to a political scandal

2018:

No. 01

G. Masiero, F. Mazzonna, O. Verbeek, What drives the rise of antidepressant consumption? Evidence from Switzerland

No. 02

U. Pagano, M. Vatiero, Positional goods and legal orderings 
2019:

No. 01

G. Masiero, M. Santarossa, Earthquakes, grants and public expenditure : how municipalities respond to natural disasters

No. 02

G. Masiero, F. Mazzonna, S. Steinbach, O. Verbeek, The effect of local growth in antidepressant consumption on mental health outcomes

No. 03

T. Ly, Taxes, traffic jam and spillover in the metropolis

2020:

No. 01

P. Bello, The environmental cost and the accident externality of driving: evidence from the Swiss franc's appreciation

No. 02

P. Bello, Gender-based price discrimination in the annuity market: evidence from Chile

No. 03

B. Lerch, Robots and nomparticipation in the US: where have all the workers gone?

2021:

No. 01

N. Gatti, B. Retali

Fighting the spread of Covid-19: was the Swiss lockdown worth it?

No. 02

B. Lerch

From blue to steel-collar jobs: the decline in employment gaps? 